\title{
Substrate Discrimination by Cholapod Anion Receptors: Geometric Effects and the "Affinity-Selectivity Principle".
}

John P. Clare, ${ }^{\dagger}$ Alan J. Ayling, ${ }^{\dagger}$ Jean-Baptiste Joos, ${ }^{\dagger}$ Adam L. Sisson, ${ }^{\dagger}$ Germinal Magro, ${ }^{\dagger}$ M. Nieves PérezPayán, ${ }^{\ddagger}$ Timothy N. Lambert, ${ }^{\S}$ Rameshwer Shukla, ${ }^{\S}$ Bradley D. Smith ${ }^{\S *}$ and Anthony P. Davis ${ }^{\dagger *}$

${ }^{\dagger}$ School of Chemistry, University of Bristol, Cantock's Close, Bristol BS8 ITS, UK

${ }^{\ddagger}$ Department of Chemistry, Trinity College, Dublin 2, Ireland

${ }^{\S}$ Department of Chemistry and Biochemistry and Walther Cancer Research Center, University of Notre Dame, Notre Dame, Indiana 46556 (USA).

\section{Supporting Information}




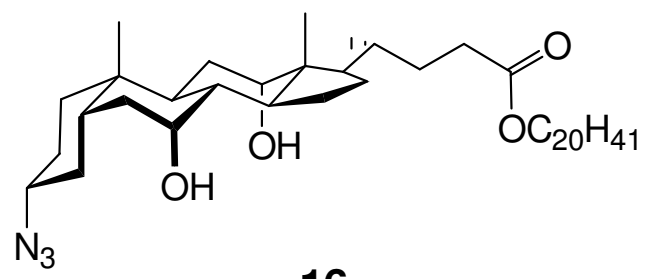

16
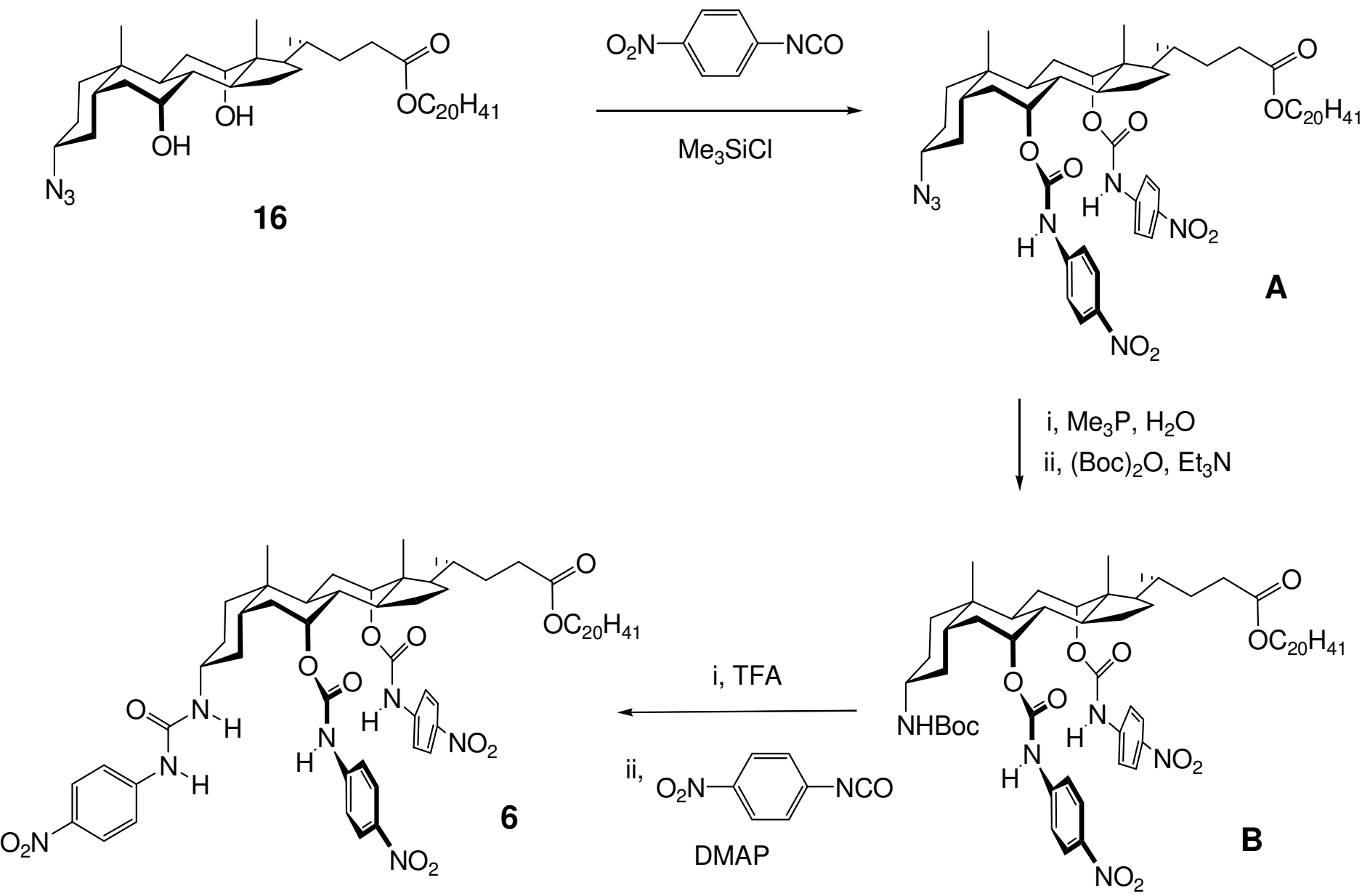

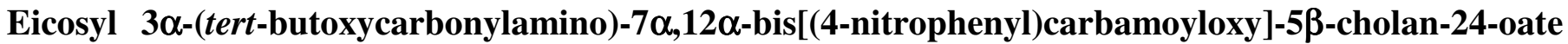

(B). Azido diol $\mathbf{1 6}^{1}$ (2.00 g, $\left.2.80 \mathrm{mmol}\right)$ was dissolved in dry DCM $(100 \mathrm{~mL})$ under argon. 4-Nitrophenyl isocyanate ( $4.6 \mathrm{~g}, 28 \mathrm{mmol}, 10$ equiv) was added and then followed by chlorotrimethylsilane $(0.58 \mathrm{~mL}$, $4.6 \mathrm{mmol}, 1.6$ equiv). The mixture was stirred at room temperature for 4 days. Water $(50 \mathrm{~mL})$ was added and the mixture was stirred for a further day. The resulting bright yellow suspension was allowed to settle and the organic phase was removed. The aqueous phase was then washed with DCM $(2 \times 100 \mathrm{~mL})$. The combined organic phases were dried over $\mathrm{MgSO}_{4}$. The solvent was removed under reduced pressure. Flash chromatography (hexane-EtOAc, 4:1) gave azide $\mathbf{A}$ as a pale yellow solid (1.89 g, $1.81 \mathrm{mmol}, 65 \%): \mathrm{R}_{f} 0.5$ 
(DCM); IR (thin film) 2093 (azide), 1734 (ester C=O), 1611 (carbamate C=O), $1543\left(\mathrm{NO}_{2}\right), 1329\left(\mathrm{NO}_{2}\right)$ $\mathrm{cm}^{-1} ;{ }^{1} \mathrm{H}$ NMR $\left(400.13 \mathrm{MHz}, \mathrm{CDCl}_{3}\right) \delta 0.81\left(\mathrm{~s}, 3 \mathrm{H}, 18-\mathrm{CH}_{3}\right), 0.88\left(\mathrm{~m}, 6 \mathrm{H}, 21-\mathrm{CH}_{3}\right.$; eicosyl $\left.\mathrm{CH}_{3}\right), 0.99(\mathrm{~s}$, $\left.3 \mathrm{H}, 19-\mathrm{CH}_{3}\right), 1.25\left(\mathrm{~m}, \sim 36 \mathrm{H}\right.$, eicosyl $\left.\mathrm{C}_{18} \mathrm{H}_{36}\right), 3.21(\mathrm{~m}, 1 \mathrm{H}, 3 \beta-\mathrm{H}), 3.98\left(\mathrm{t}, J=6.5 \mathrm{~Hz}, 2 \mathrm{H}\right.$, eicosyl $\left.\mathrm{OCH}_{2}\right)$,

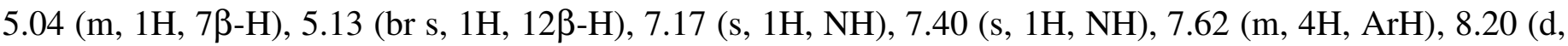
$J=9.0 \mathrm{~Hz}, 4 \mathrm{H}, \mathrm{ArH}) ;{ }^{13} \mathrm{C} \mathrm{NMR}\left(100.61 \mathrm{MHz}, \mathrm{CDCl}_{3}\right) \delta 12.24\left(\mathrm{CH}_{3}\right), 14.09\left(\mathrm{CH}_{3}\right), 17.58\left(\mathrm{CH}_{3}\right), 22.51$ $\left(\mathrm{CH}_{3}\right), 22.68\left(\mathrm{CH}_{2}\right), 22.97\left(\mathrm{CH}_{2}\right), 25.73\left(\mathrm{CH}_{2}\right), 25.91\left(\mathrm{CH}_{2}\right), 26.91\left(\mathrm{CH}_{2}\right), 27.21\left(\mathrm{CH}_{2}\right), 28.60\left(\mathrm{CH}_{2}\right), 28.99$ (CH), $29.22\left(\mathrm{CH}_{2}\right), 29.35\left(\mathrm{CH}_{2}\right), 29.50\left(\mathrm{CH}_{2}\right), 29.57\left(\mathrm{CH}_{2}\right), 29.70\left(\mathrm{CH}_{2}\right), 30.76\left(\mathrm{CH}_{2}\right), 31.18\left(\mathrm{CH}_{2}\right), 31.49$ $\left(\mathrm{CH}_{2}\right), 34.44\left(\mathrm{CH}_{2}\right), 34.55\left(\mathrm{CH}_{2}\right), 34.64(\mathrm{CH}), 34.83\left(\mathrm{CH}_{2}\right), 35.04\left(\mathrm{CH}_{2}\right), 37.90(\mathrm{CH}), 41.04(\mathrm{CH}), 43.54$ $(\mathrm{CH}), 45.45(\mathrm{CH}), 47.40(\mathrm{CH}), 61.10(\mathrm{CH}), 64.61$ (eicosyl $\left.\mathrm{OCH}_{2}\right), 72.84,117.83(\mathrm{CH}), 125.17(\mathrm{CH}), 142.98$, 144.13, 144.17, 152.11 (carbamate $\mathrm{C}=\mathrm{O}), 152.46$ (carbamate $\mathrm{C}=\mathrm{O}), 174.31(\mathrm{C}-24)$.

Azide A (1.52 g, $1.46 \mathrm{mmol})$ was dissolved in dry THF (30 mL). Trimethylphosphine (1.0 M solution in THF, $1.75 \mathrm{~mL}, 1.75 \mathrm{mmol}$ ) was added and the mixture stirred at room temperature under nitrogen for $3 \mathrm{~h}$. Water $(0.53 \mathrm{~mL}, 20$ equiv) was added and the mixture was stirred for a further $4 \mathrm{~h}$. The volatiles were removed in vacuo and the free amine was evaporated to dryness from toluene $(2 \times 10 \mathrm{~mL})$ then DCM $(2 \times 10$ $\mathrm{mL})$. The dried amine was redissolved in dry THF (15 mL). Di-tert-butyl dicarbonate (0.42 $\mathrm{g}, 1.90 \mathrm{mmol}$, 1.3 equiv) was added, followed by triethylamine $(0.51 \mathrm{~mL}, 3.65 \mathrm{mmol}, 2.5$ equiv $)$ and the mixture was stirred under nitrogen at $45{ }^{\circ} \mathrm{C}$ for $4 \mathrm{~d}$. The solvent was removed in vacuo and the product was purified by flash chromatography (hexane-EtOAc, 8:1 - 1:1), giving carbamate $\mathbf{B}$ as an off-white solid (1.45 g, $1.30 \mathrm{mmol}$, $68 \%) ; R_{\mathrm{f}} 0.4$ (hexane-EtOAc 2:1); IR (solid state) $1736(\mathrm{C}=\mathrm{O}), 1538\left(\mathrm{NO}_{2}\right), 1326\left(\mathrm{NO}_{2}\right) \mathrm{cm}^{-1} ;{ }^{1} \mathrm{H}$ NMR $\left(400.18 \mathrm{MHz}, \mathrm{CDCl}_{3} \delta 0.80\left(\mathrm{~s}, 3 \mathrm{H} 18-\mathrm{CH}_{3}\right), 0.86-0.89\left(\mathrm{~m}, 6 \mathrm{H}\right.\right.$, eicosyl $\left.\mathrm{CH}_{3}, 21-\mathrm{CH}_{3}\right), 0.98\left(\mathrm{~s}, 3 \mathrm{H} 19-\mathrm{CH}_{3}\right)$,

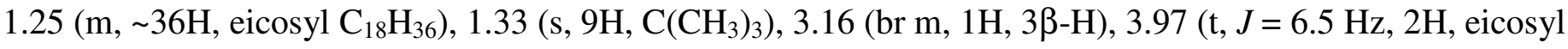

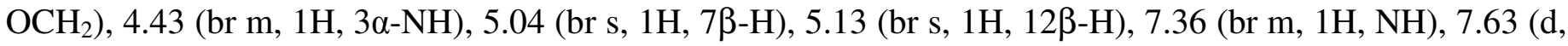
$J=9.0 \mathrm{~Hz}, 5 \mathrm{H}, \mathrm{ArH} x 4, \mathrm{NH}), 8.19(\mathrm{~m}, 4 \mathrm{H}, \mathrm{ArH}) ;{ }^{13} \mathrm{C} \mathrm{NMR}\left(100.61 \mathrm{MHz}, \mathrm{CDCl}_{3}\right) \delta 12.00(\mathrm{C}-18), 14.10$ (eicosyl $\left.\mathrm{CH}_{3}\right), 17.54(\mathrm{C}-21), 22.52(\mathrm{C}-19), 22.67\left(\mathrm{CH}_{2}\right), 23.46\left(\mathrm{CH}_{2}\right), 25.42\left(\mathrm{CH}_{2}\right), 25.86\left(\mathrm{CH}_{2}\right), 27.41\left(\mathrm{CH}_{2}\right)$, 28.06, 28.21 (CH), $28.55\left(\mathrm{CH}_{2}\right), 29.20\left(\mathrm{CH}_{2}\right), 29.34\left(\mathrm{CH}_{2}\right), 29.48\left(\mathrm{CH}_{2}\right), 29.56\left(\mathrm{CH}_{2}\right), 29.63\left(\mathrm{CH}_{2}\right), 29.68$ 
$\left(\mathrm{CH}_{2}\right), 30.73\left(\mathrm{CH}_{2}\right), 31.21\left(\mathrm{CH}_{2}\right), 31.90\left(\mathrm{CH}_{2}\right), 34.63(\mathrm{CH}), 34.77,35.64\left(\mathrm{CH}_{2}\right), 38.20(\mathrm{CH}), 41.31(\mathrm{CH})$, $42.68(\mathrm{CH}), 45.41,47.58(\mathrm{CH}), 50.91,64.49$ (eicosyl $\left.\mathrm{OCH}_{2}\right), 72.96(\mathrm{C}-7), 77.52(\mathrm{C}-12), 78.92,117.43$ $(\mathrm{ArCH}), 117.51(\mathrm{ArCH}), 124.88(\mathrm{ArCH}), 125.01(\mathrm{ArCH}), 141.81,141.85,145.45,145.54,152.26(\mathrm{C}=\mathrm{O})$, $152.57(\mathrm{C}=\mathrm{O}), 154.97(\mathrm{C}=\mathrm{O}), 174.18(\mathrm{C}-24)$; Anal. Calcd for $\mathrm{C}_{63} \mathrm{H}_{97} \mathrm{~N}_{5} \mathrm{O}_{12}: \mathrm{C}$ 67.77, $\mathrm{H}$ 8.76, N 6.27. Found C 67.79, H 9.24, N 5.99.

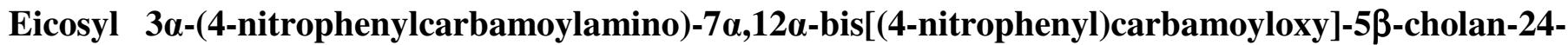

oate (6). To a solution of carbamate $\mathbf{B}(0.50 \mathrm{~g}, 0.45 \mathrm{mmol})$ in dry DCM $(2.0 \mathrm{~mL})$ at $0{ }^{\circ} \mathrm{C}$ was added trifluoroacetic acid $(0.5 \mathrm{~mL}, 0.74 \mathrm{~g}, 6.5 \mathrm{mmol}, 14.4$ equiv). The mixture was stirred under nitrogen for $2 \mathrm{~h}$ then allowed to warm to room temperature and stirred for a further $1 \mathrm{~h}$. The volatiles were removed under reduced pressure and the ammonium salt was evaporated to dryness from toluene $(2 \times 5 \mathrm{~mL})$, then chloroform $(2 \times 5 \mathrm{~mL})$. The salt was dissolved in dry DCM $(2 \mathrm{~mL})$, and 4-nitrophenyl isocyanate (96 mg, $0.59 \mathrm{mmol}, 1.3$ equiv) and DMAP (71 $\mathrm{mg}, 0.59 \mathrm{mmol}, 1.3$ equiv) were added. The mixture was stirred under nitrogen at room temperature for $16 \mathrm{~h}$, at which time TLC analysis showed the absence of amine. Flash chromatography (DCM-methanol, 99:1 -97:3) afforded the pure urea bis-carbamate 6 as a yellow solid (0.405 g, 0.34 mmol, $76 \%$ ): $\mathrm{R}_{f} 0.33$ (DCM-methanol, 95:5); IR (thin film) $1737(\mathrm{C}=\mathrm{O}), 1537\left(\mathrm{NO}_{2}\right), 1324$ $\left(\mathrm{NO}_{2}\right) \mathrm{cm}^{-1}$; HRMS (FAB) $\mathrm{m} / \mathrm{z}$ : calcd for $[\mathrm{M}+\mathrm{Na}]^{+} 1202.6729$, found 1202.6715; Anal. Calcd for $\mathrm{C}_{65} \mathrm{H}_{93} \mathrm{~N}_{7} \mathrm{O}_{13}: \mathrm{C}, 66.13 ; \mathrm{H}, 7.94 ; \mathrm{N}, 8.31$. Found: $\mathrm{C}, 65.92 ; \mathrm{H}, 8.42 ; \mathrm{N}, 8.27$. NMR spectra were obtained on a solution of $6(19 \mathrm{mg}, 16 \mu \mathrm{mol})$ in $\mathrm{CDCl}_{3}(600 \mu \mathrm{L})$ to which $\mathrm{Et}_{4} \mathrm{~N}^{+} \mathrm{Cl}^{-}(1.5 \mathrm{eq})$ had been added: ${ }^{1} \mathrm{H} \mathrm{NMR}$ $\left(400.13 \mathrm{MHz}, \mathrm{CDCl}_{3}\right) \delta=0.79\left(\mathrm{~s}, 3 \mathrm{H} 18-\mathrm{CH}_{3}\right), 0.88\left(\mathrm{t}, J=7.0 \mathrm{~Hz}, 3 \mathrm{H}\right.$, eicosyl $\left.\mathrm{CH}_{3}\right), 0.93\left(\mathrm{~s}, 3 \mathrm{H}, 19-\mathrm{CH}_{3}\right)$, $0.98\left(\mathrm{~d}, J=6.5 \mathrm{~Hz}, 3 \mathrm{H}, 21-\mathrm{CH}_{3}\right), 1.25\left(\mathrm{~m}, \sim 36 \mathrm{H}\right.$, eicosyl $\left.\mathrm{C}_{18} \mathrm{H}_{36}\right), 1.38\left(\mathrm{~m} ; \mathrm{Et}_{4} \mathrm{~N}^{+} \mathrm{CH}_{3}\right), 2.56(\mathrm{~m}, 1 \mathrm{H}), 2.64$

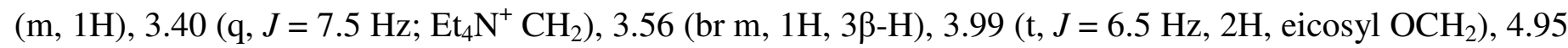
(s, 1H, 7ß-H), $5.28(\mathrm{~s}, 1 \mathrm{H}, 12 \beta-\mathrm{H}), 7.51(\mathrm{~d}, J=9.0 \mathrm{~Hz}, 1 \mathrm{H}, 3 \alpha-\mathrm{NH}), 7.62(\mathrm{~d}, J=9.0 \mathrm{~Hz}, 2 \mathrm{H}, \operatorname{ArH}), 8.01(\mathrm{~d}, J$ $=9.5 \mathrm{~Hz}, 2 \mathrm{H}, \mathrm{ArH}), 8.08(\mathrm{~d}, J=9.5 \mathrm{~Hz}, 2 \mathrm{H}, \mathrm{ArH}), 8.10(\mathrm{~m}, 4 \mathrm{H}, \mathrm{ArH}), 8.16(\mathrm{~d}, J=9.0 \mathrm{~Hz}, 2 \mathrm{H}, \operatorname{ArH}), 8.31(\mathrm{~s}$, $1 \mathrm{H}, \mathrm{NH}), 9.57(\mathrm{~s}, 1 \mathrm{H}, \mathrm{NH}), 10.20(\mathrm{~s}, 1 \mathrm{H}, \mathrm{NH}) ;{ }^{13} \mathrm{C} \mathrm{NMR}\left(100.61 \mathrm{MHz}, \mathrm{CDCl}_{3}\right) \delta 7.73\left(\mathrm{Et}_{4} \mathrm{~N}^{+} \mathrm{CH}_{3}\right), 12.39$ 
(C-18), 14.13 (eicosyl $\left.\mathrm{CH}_{3}\right), 17.79$ (C-21), 21.95 (C-19), $22.69\left(\mathrm{CH}_{2}\right), 25.92\left(\mathrm{CH}_{2}\right), 27.19\left(\mathrm{CH}_{2}\right), 28.04$ (CH), $28.64\left(\mathrm{CH}_{2}\right), 29.25\left(\mathrm{CH}_{2}\right), 29.36\left(\mathrm{CH}_{2}\right), 29.52\left(\mathrm{CH}_{2}\right), 29.59\left(\mathrm{CH}_{2}\right), 29.66\left(\mathrm{CH}_{2}\right), 29.71\left(\mathrm{CH}_{2}\right), 30.78$ $\left(\mathrm{CH}_{2}\right), 31.36\left(\mathrm{CH}_{2}\right), 31.93\left(\mathrm{CH}_{2}\right), 33.72,34.92(\mathrm{CH}), 35.50\left(\mathrm{CH}_{2}\right), 38.09(\mathrm{CH}), 40.77(\mathrm{CH}), 42.75(\mathrm{CH})$, 44.98, $47.18(\mathrm{CH}), 48.41(\mathrm{CH}), 52.81\left(\mathrm{t},{ }^{1} J_{\mathrm{C}, \mathrm{N}}=3.0 \mathrm{~Hz} ; \mathrm{Et}_{4} \mathrm{~N}^{+} \mathrm{CH}_{2}\right), 64.41\left(\right.$ eicosyl $\left.\mathrm{OCH}_{2}\right), 71.91(\mathrm{C}-7)$, $76.39(\mathrm{C}-12), 117.15(\mathrm{ArCH}), 117.98(\mathrm{ArCH}), 118.70(\mathrm{ArCH}), 124.62(\mathrm{ArCH}), 124.79(\mathrm{ArCH}), 125.04$ $(\mathrm{ArCH}), 141.80,141.89,146.41,146.65,147.30,153.14(\mathrm{C}=\mathrm{O}), 153.45(\mathrm{C}=\mathrm{O}), 154.88(\mathrm{C}=\mathrm{O}), 174.33(\mathrm{C}-$ 24). 
<smiles>Nc1ccc([N+](=O)[O-])cc1</smiles><smiles>O=C(Cl)c1cccc(C(=O)Cl)c1</smiles><smiles>CC(F)(C(=O)O)C(=O)OC(=O)c1cccc(C(=O)Nc2ccc([N+](=O)[O-])cc2)c1</smiles>

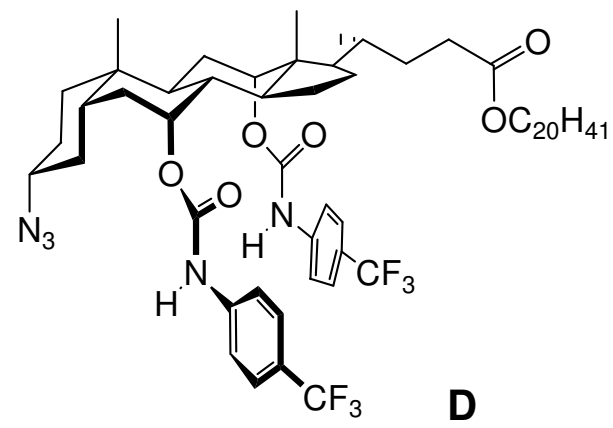

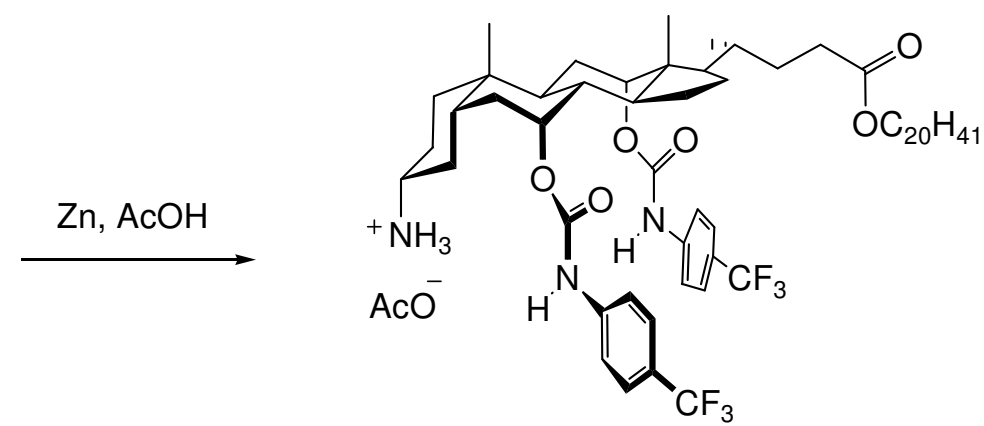

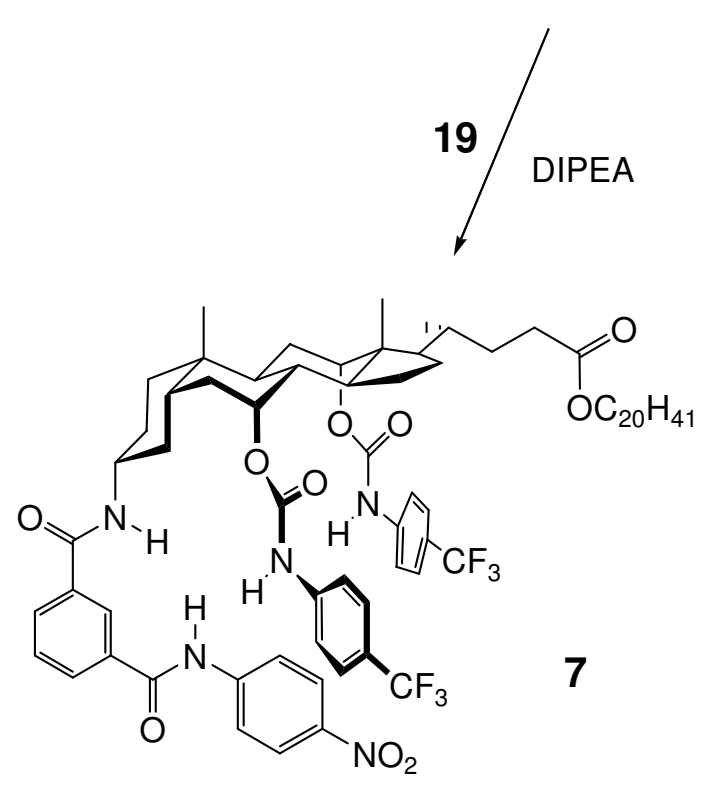

Pentafluorophenyl-3-[(4-nitrophenyl)carbamoyl] benzoate (19). A solution of 4-nitroaniline (1.50 g, $10.9 \mathrm{mmol})$ in dry THF $(55 \mathrm{~mL})$ was added to a solution of isophthaloyl dichloride $(4.85 \mathrm{~g}, 24 \mathrm{mmol}$, 2.2 equiv) under argon at room temperature. The temperature was raised to $40{ }^{\circ} \mathrm{C}$ and the mixture was stirred overnight. $\mathrm{NaOH}(1 \mathrm{M}, 75 \mathrm{~mL})$ was added and the mixture was stirred for $1 \mathrm{~min}$. The mixture was then acidified to $\mathrm{pH} 1$ by the addition of aliquots of $1 \mathrm{M} \mathrm{HCl}$. The resulting yellow precipitate was removed by filtration and dried in air. TLC analysis showed it to be a mixture of two compounds. ${ }^{1} \mathrm{H}$ NMR analysis 
showed these to be isophthalic acid $(57 \mathrm{~mol} \%)$ and the expected 3-[4-(nitrophenyl)carbamoyl]benzoic acid C (43 mol \%); R 0.16 (methanol-DCM, 1:9); ${ }^{1} \mathrm{H}$ NMR (400.13 MHz, [D 6 DMSO) $\delta 7.71(\mathrm{t}, J=7.5 \mathrm{~Hz}, 1 \mathrm{H}$, H-5), $8.10(\mathrm{~d}, J=9.0 \mathrm{~Hz}, 2 \mathrm{H}, N-\operatorname{ArH}), 8.19(\mathrm{~d}, J=8.0 \mathrm{~Hz}, 1 \mathrm{H}, \operatorname{ArH}), 8.23(\mathrm{~d}, J=7.5 \mathrm{~Hz}, 1 \mathrm{H}, \operatorname{ArH}), 8.30(\mathrm{~d}$, $J=9.0 \mathrm{~Hz}, 2 \mathrm{H}, \mathrm{N}-\mathrm{ArH}), 8.57(\mathrm{~s}, 1 \mathrm{H}, \mathrm{H}-2), 10.98(\mathrm{~s}, 1 \mathrm{H}, \mathrm{NH}), 13.31$ (br m, 1H, $\left.\mathrm{CO}_{2} \mathrm{H}\right)$. The mixture contained $10.6 \mathrm{mmol} \mathrm{CO} 2 \mathrm{H}$ groups according to NMR analysis. The mixture was dissolved in a solution of pentafluorophenol (2.15 g, $11.7 \mathrm{mmol}, 1.1$ equiv) in dry THF (50 mL) under argon. The solution was cooled to $0{ }^{\circ} \mathrm{C}$ and $\mathrm{DCC}\left(2.41 \mathrm{~g}, 11.7 \mathrm{mmol}, 1.1\right.$ equiv) was added. The solution was stirred at $0{ }^{\circ} \mathrm{C}$ for $1 \mathrm{~h}$ and then warmed to $40{ }^{\circ} \mathrm{C}$ and stirred for a further $1 \mathrm{~h}$. The solution was filtered through celite to remove the precipitated dicyclohexylurea and the solvent was removed under reduced pressure. Crystallization from chloroform/hexane gave the intended ester 19 as a pale yellow solid $(0.66 \mathrm{~g}, 1.5 \mathrm{mmol}, 14 \%$ from 4 nitroaniline): $\mathrm{R}_{f} 0.3$ (DCM); mp $173^{\circ} \mathrm{C}$; IR (thin film) 1764 (ester $\mathrm{C}=\mathrm{O}$ ), 1667 (amide $\left.\mathrm{C}=\mathrm{O}\right), 1519\left(\mathrm{NO}_{2}\right)$, $1332\left(\mathrm{NO}_{2}\right) \mathrm{cm}^{-1} ;{ }^{1} \mathrm{H}$ NMR $\left(400.13 \mathrm{MHz}, \mathrm{CDCl}_{3}\right) \delta 7.76(\mathrm{t}, J=8.0 \mathrm{~Hz}, 1 \mathrm{H}, \mathrm{H}-5), 7.88(\mathrm{~m}, 2 \mathrm{H}, N-\mathrm{ArH}), 8.15$ (br s, 1H, NH), $8.3\left(\mathrm{~m}, 3 \mathrm{H}, 2\right.$ x N-ArH, ArH), $8.43(\mathrm{~d}, J=7.5 \mathrm{~Hz}, 1 \mathrm{H}, \mathrm{ArH}), 8.66(\mathrm{~s}, 1 \mathrm{H}, \mathrm{H}-2)$; ${ }^{19} \mathrm{~F} \mathrm{NMR}$ $\left(376.50 \mathrm{MHz}, \mathrm{CDCl}_{3}\right) \delta-162.25(\mathrm{t}, J=20.5 \mathrm{~Hz}, 2 \mathrm{~F}$, meta $),-157.50(\mathrm{t}, J=22.0 \mathrm{~Hz}, 1 \mathrm{~F}$, para $),-152.89(\mathrm{~d}$, $J=19.0 \mathrm{~Hz}, 2 \mathrm{~F}$, ortho); ${ }^{13} \mathrm{C}$ NMR $\left(100.61 \mathrm{MHz}, \mathrm{CDCl}_{3}\right) \delta 119.77(N-\mathrm{ArCH}), 124.99$ (ester OC), $125.17(N-$ ArCH), 127.84, $128.82(\mathrm{CH}), 129.97(\mathrm{CH}), 133.64(\mathrm{CH}), 134.29(\mathrm{CH}), 135.05,138.02$ (meta CF, $\left.J_{\mathrm{C}, \mathrm{F}}=259 \mathrm{~Hz}\right), 139.84\left(\right.$ para $\left.\mathrm{CF}, J_{\mathrm{C}, \mathrm{F}}=255 \mathrm{~Hz}\right), 141.24$ (ortho $\left.\mathrm{CF}, J_{\mathrm{C}, \mathrm{F}}=253 \mathrm{~Hz}\right), 143.30,144.13,161.74$ (amide $\mathrm{C}=\mathrm{O}$ ), 164.28 (ester $\mathrm{C}=\mathrm{O}$ ); Anal. Calcd for $\mathrm{C}_{20} \mathrm{H}_{9} \mathrm{~F}_{5} \mathrm{~N}_{2} \mathrm{O}_{5}$ : C, 53.11; H, 2.01; N, 6.19. Found: C, $53.15 ; \mathrm{H}, 2.03 ; \mathrm{N}, 6.00$.

\section{Eicosyl-3 $\alpha$-[3-(4-nitrophenylcarbamoyl)benzamido]-7 $\alpha, 12 \alpha$-bis[(4-trifluoro-}

methylphenyl)carbamoyloxy]-5 $\boldsymbol{\beta}$-cholan-24-oate (7). Azido dicarbamate $\mathbf{D}^{1}$ (220 $\left.\mathrm{mg}, 0.20 \mathrm{mmol}\right)$ was dissolved in glacial acetic acid $(8 \mathrm{~mL})$. Zinc powder $(0.15 \mathrm{~g})$ was added and the mixture was stirred for $12 \mathrm{~h}$. The zinc was removed by vacuum filtration and washed with acetic acid $(10 \mathrm{~mL})$. The acetic acid was removed under reduced pressure and the residue was evaporated to dryness with toluene $(2 \times 5 \mathrm{~mL})$, and 
DCM $(2 \times 5 \mathrm{~mL})$, affording the acetate salt $\mathbf{E}$ as a slightly off-white solid. Flash chromatography (DCMmethanol, 95:5) gave $\mathbf{E}$ as an off-white solid (212 mg, 0.19 mmol, $95 \%$ ): $\mathrm{R}_{f} 0.61$ (DCM-methanol, 9:1); m.p. $128{ }^{\circ} \mathrm{C}$; IR (thin film) $1735(\mathrm{C}=\mathrm{O}), 1709(\mathrm{C}=\mathrm{O}) \mathrm{cm}^{-1} ;{ }^{1} \mathrm{H}$ NMR $\left(400.13 \mathrm{MHz}, \mathrm{CDCl}_{3}\right) \delta 0.76(\mathrm{~s}, 3 \mathrm{H}, 18-$ $\left.\mathrm{CH}_{3}\right), 0.77\left(\mathrm{~s}, 3 \mathrm{H}, 19-\mathrm{CH}_{3}\right), 0.88\left(\mathrm{t}, J=7.0 \mathrm{~Hz}, 3 \mathrm{H}\right.$, eicosyl $\left.\mathrm{CH}_{3}\right), 0.92\left(\mathrm{~d}, J=6.5 \mathrm{~Hz}, 3 \mathrm{H}, 21-\mathrm{CH}_{3}\right), 1.24(\mathrm{~m}$,

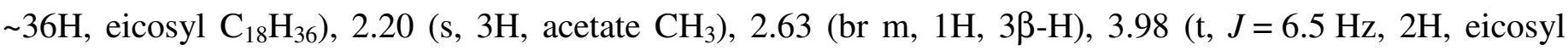

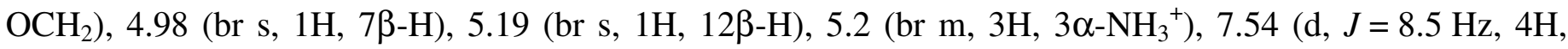
ArH), $7.66(\mathrm{~d}, J=8.0 \mathrm{~Hz}, 2 \mathrm{H}, \mathrm{ArH}), 7.72(\mathrm{~d}, J=8.5 \mathrm{~Hz}, 2 \mathrm{H}, \mathrm{ArH}), 8.76$ (br m, 1H, $7 \alpha-\mathrm{NH}), 9.28$ (br m, 1H, $12 \alpha-\mathrm{NH}) ;{ }^{13} \mathrm{C}$ NMR $\left(100.61 \mathrm{MHz}, \mathrm{CDCl}_{3}\right) \delta 12.47$ (C18), $14.08\left(\right.$ eicosyl $\left.\mathrm{CH}_{3}\right), 17.66(\mathrm{C}-21), 21.75(\mathrm{C}-19)$, $22.67\left(\mathrm{CH}_{2}\right), 22.80\left(\mathrm{CH}_{2}\right), 24.66\left(\mathrm{CH}_{3} \mathrm{CO}_{2}{ }^{-}\right), 25.89\left(\mathrm{CH}_{2}\right), 26.04\left(\mathrm{CH}_{2}\right), 26.13\left(\mathrm{CH}_{2}\right), 27.15\left(\mathrm{CH}_{2}\right), 28.59$ $\left(\mathrm{CH}_{2}\right), 28.94(\mathrm{CH}), 29.21\left(\mathrm{CH}_{2}\right), 29.34\left(\mathrm{CH}_{2}\right), 29.48\left(\mathrm{CH}_{2}\right), 29.55\left(\mathrm{CH}_{2}\right), 29.62\left(\mathrm{CH}_{2}\right), 29.68\left(\mathrm{CH}_{2}\right), 30.77$ $\left(\mathrm{CH}_{2}\right), 31.32\left(\mathrm{CH}_{2}\right), 31.44\left(\mathrm{CH}_{2}\right), 31.91\left(\mathrm{CH}_{2}\right), 33.51,33.60\left(\mathrm{CH}_{2}\right), 34.46\left(\mathrm{CH}_{2}\right), 34.85(\mathrm{CH}), 37.69(\mathrm{CH})$, $39.91(\mathrm{CH}), 44.07(\mathrm{CH}), 45.37,47.44(\mathrm{CH}), 51.33(\mathrm{CH}), 64.53$ (eicosyl $\left.\mathrm{OCH}_{2}\right), 70.90(\mathrm{CH}), 76.28(\mathrm{CH})$, $117.94(\mathrm{ArCH}), 118.06(\mathrm{ArCH}), 126.15(\mathrm{ArCH}), 126.19(\mathrm{ArCH}), 142.26,142.61,152.84(\mathrm{NCHO}), 153.18$ (NCHO), $174.27(\mathrm{C}-24), 179.92\left(\mathrm{CH}_{3} \mathrm{CO}_{2}{ }^{-}\right)$.

Steroidal ammonium salt E (105 mg, $0.0943 \mathrm{mmol})$ and pentafluorophenyl ester 19 (56 mg, $0.123 \mathrm{mmol}$, 1.3 equiv) were dissolved in dry DCM (18 mL). Diisopropylethylamine ( $84 \mu \mathrm{L}, 5$ equiv) was added and the solution was stirred under argon for 3 days at $20^{\circ} \mathrm{C}$. The solvent was removed under reduced pressure and the product was purified by flash chromatography (DCM-methanol, 48:1), giving 7 as a pale yellow solid (93 mg, $0.07 \mathrm{mmol}, 74 \%$ ): R 0.7 (DCM-methanol, 10:1); IR (thin film) $1737(\mathrm{C}=\mathrm{O}), 1710(\mathrm{C}=\mathrm{O}), 1537$ $\left(\mathrm{NO}_{2}\right), 1327\left(\mathrm{NO}_{2}\right) \mathrm{cm}^{-1} ;{ }^{1} \mathrm{H} \mathrm{NMR}\left(400.13 \mathrm{MHz}, \mathrm{CDCl}_{3}\right) \delta 0.81\left(\mathrm{~s}, 3 \mathrm{H}, 18-\mathrm{CH}_{3}\right), 0.88(\mathrm{t}, J=7.0 \mathrm{~Hz}, 3 \mathrm{H}$, eicosyl $\left.\mathrm{CH}_{3}\right), 0.90\left(\mathrm{~d}, J=6.5 \mathrm{~Hz}, 3 \mathrm{H}, 21-\mathrm{CH}_{3}\right), 0.99\left(\mathrm{~s}, 3 \mathrm{H}, 19-\mathrm{CH}_{3}\right), 1.25\left(\mathrm{~m}, \sim 36 \mathrm{H}\right.$, eicosyl $\left.\mathrm{C}_{18} \mathrm{H}_{36}\right), 3.60$

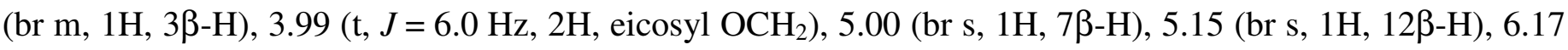
(br m, 1H, NH), 7.33 (br s, 1H, NH), $7.4-7.6(\mathrm{~m}, 9 \mathrm{H}, 8$ x carbamate ArH, 3-ArH-5), $7.78-7.83$ (m, 3H, 3$N$-ArH, 3-ArH), 7.91 (d, $J=7.5 \mathrm{~Hz}, 1 \mathrm{H}, 3-\mathrm{ArH}), 8.14$ (s, 1H, 3-ArH-2), 8.24 (d, $J=9.5 \mathrm{~Hz}, 3 \alpha-\mathrm{NH}), 8.43$ (br 
s, 1H, NH); ${ }^{13} \mathrm{C}$ NMR (100.61 MHz, $\left.\mathrm{CDCl}_{3}\right) \delta 12.39$ (C-18), 14.08 (C-19), 17.59 (C-21), 22.61 (eicosyl $\left.\mathrm{CH}_{3}\right), 22.67\left(\mathrm{CH}_{2}\right), 22.94\left(\mathrm{CH}_{2}\right), 25.77\left(\mathrm{CH}_{2}\right), 25.91\left(\mathrm{CH}_{2}\right), 27.10\left(\mathrm{CH}_{2}\right), 27.24\left(\mathrm{CH}_{2}\right), 28.60\left(\mathrm{CH}_{2}\right), 29.03$ (CH), $29.22\left(\mathrm{CH}_{2}\right), 29.35\left(\mathrm{CH}_{2}\right), 29.49\left(\mathrm{CH}_{2}\right), 29.56\left(\mathrm{CH}_{2}\right), 29.69\left(\mathrm{CH}_{2}\right), 30.78\left(\mathrm{CH}_{2}\right), 31.20\left(\mathrm{CH}_{2}\right), 31.46$ $\left(\mathrm{CH}_{2}\right), 31.92\left(\mathrm{CH}_{2}\right), 34.39,34.72(\mathrm{CH}), 34.84\left(\mathrm{CH}_{2}\right), 35.66\left(\mathrm{CH}_{2}\right), 38.02(\mathrm{CH}), 41.43(\mathrm{CH}), 45.38(\mathrm{CH})$, $46.64(\mathrm{CH}), 47.37(\mathrm{CH}), 51.64(\mathrm{CH}), 64.61$ (eicosyl $\left.\mathrm{OCH}_{2}\right), 72.71(\mathrm{CH}), 118.15(\mathrm{CH}), 119.66(\mathrm{CH}), 125.13$ $(\mathrm{CH}), 125.91(\mathrm{CH}), 126.24(\mathrm{CH}), 126.27(\mathrm{CH}), 129.29(\mathrm{CH}), 129.36,130.63(\mathrm{CH}), 134.37,135.92,141.38$, 143.44, 144.01, 152.62 (carbamate $\mathrm{C}=\mathrm{O}$ ), 152.92 (carbamate $\mathrm{C}=\mathrm{O}$ ), 165.08 (amide $\mathrm{C}=\mathrm{O}$ ), 166.06 (amide $\mathrm{C}=\mathrm{O}), 174.41(\mathrm{C}-24)$; HRMS (FAB) $\mathrm{m} / \mathrm{z}$ calcd for $[\mathrm{M}+\mathrm{Na}]^{+} 1352.7037$, found 1352.7083 . 


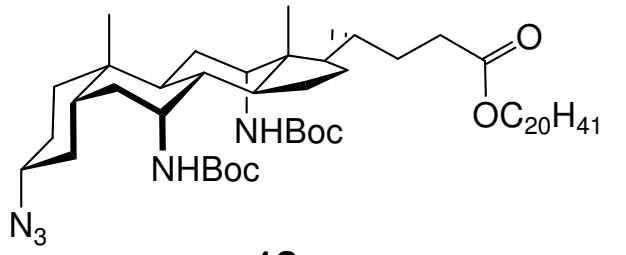

18
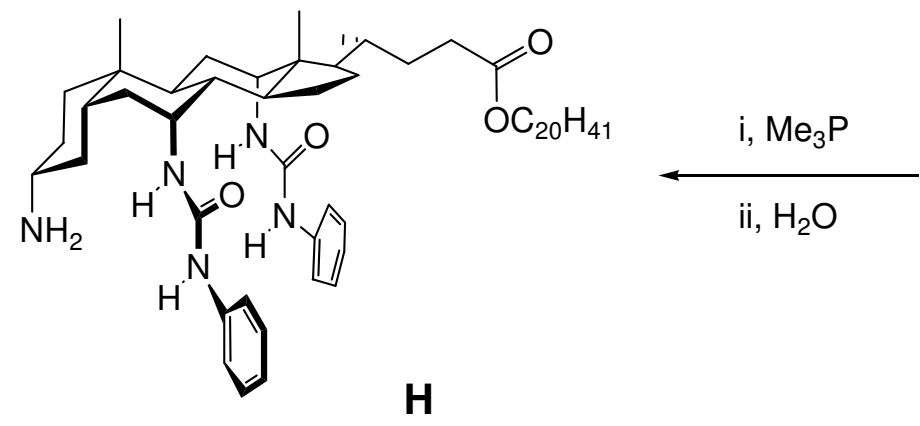

H

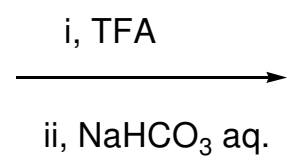

ii, $\mathrm{NaHCO}_{3}$ aq.

ii, $\mathrm{H}_{2} \mathrm{O}$

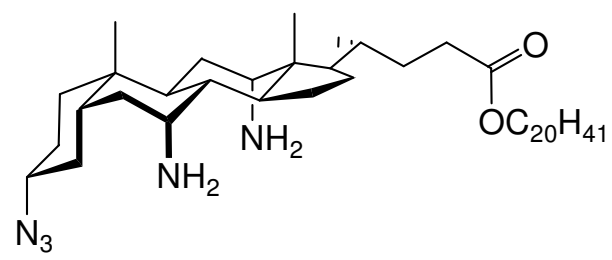

$\mathbf{F}$ PhNCO, $\mathrm{Et}_{3} \mathrm{~N}$

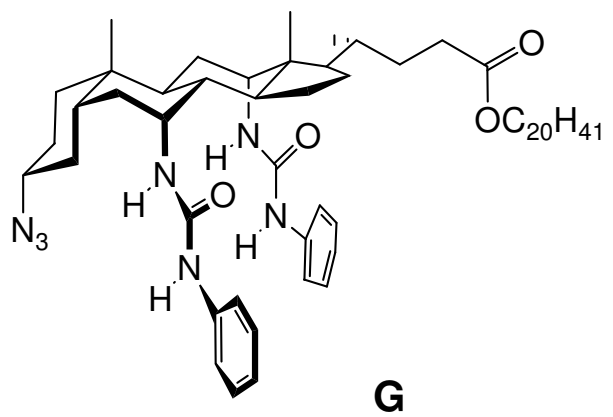
$\mathrm{TsCl}, \mathrm{Et}_{3} \mathrm{~N}$

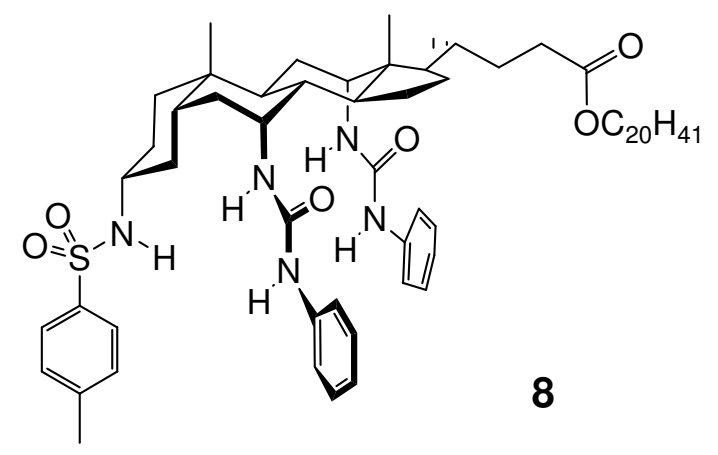

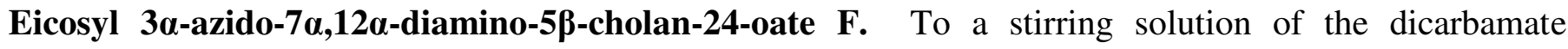
derivative $\mathbf{1 8}^{2}(1.6120 \mathrm{~g}, 1.7768 \mathrm{mmol})$ in dry DCM (40 mL) was added trifluoroacetic acid $(40 \mathrm{~mL}, 59 \mathrm{~g}$, $519 \mathrm{mmol})$. The solution was stirred for $2 \mathrm{~h}$ at $0{ }^{\circ} \mathrm{C}$ and then allowed to reach room temperature and stirred for a further $2.5 \mathrm{~h}$. The solvent was evaporated, and the trifluoroacetic acid was evaporated using dichloromethane. The residue was dissolved in ethyl acetate and washed with $4 \% \mathrm{NaHCO}_{3}$. It was then dried using $\mathrm{MgSO}_{4}$ and the solvent was evaporated under reduced pressure to give the free diamino 
derivative F (1.26 g, quantitative yield) as a white powder: IR (thin film) 3363, 3284, 2927, 2856, 2093, 1734, 1173, $738 \mathrm{~cm}^{-1} ;{ }^{1} \mathrm{H}$ NMR $\left(400 \mathrm{MHz}, \mathrm{CDCl}_{3}\right) \delta 0.73\left(\mathrm{~s}, 3 \mathrm{H}, 18-\mathrm{CH}_{3}\right), 0.87(\mathrm{t}, J=6.8 \mathrm{~Hz}, 3 \mathrm{H}$, 20 '- $\mathrm{CH}_{3}$ ), 0.92 (s, 3H, 19- $\mathrm{CH}_{3}$ ), 0.97 (d, $\left.J=6.5 \mathrm{~Hz}, 3 \mathrm{H}, 21-\mathrm{CH}_{3}\right), 1.25$ (s, 36H, eicosyl $\mathrm{C}_{18} \mathrm{H}_{36}$ ), 3.13 (br s, $1 \mathrm{H}, 7 \beta-H), 3.17(\mathrm{~m}, 1 \mathrm{H}, 3 \beta-H), 3.21($ br s, $1 \mathrm{H}, 12 \beta-H), 4.04\left(\mathrm{t}, J=6.7 \mathrm{~Hz}, 2 \mathrm{H}, 1{ }^{\prime}-\mathrm{CH}_{2}\right) ;{ }^{13} \mathrm{C}$ NMR $\left(100 \mathrm{MHz}, \mathrm{CDCl}_{3}\right) \delta 13.44\left(18-\mathrm{CH}_{3}\right), 14.04\left(20^{\prime}-\mathrm{CH}_{3}\right), 17.14\left(21-\mathrm{CH}_{3}\right), 22.63\left(19^{\prime}-\mathrm{CH}_{2}\right), 22.68\left(19-\mathrm{CH}_{3}\right)$, $23.49\left(\mathrm{CH}_{2}\right), 25.91\left(\mathrm{CH}+18^{\prime}-\mathrm{CH}_{2}\right), 26.80\left(\mathrm{CH}_{2}\right), 27.55\left(\mathrm{CH}_{2}\right), 27.82\left(\mathrm{CH}_{2}\right), 28.63\left(17^{\prime}-\mathrm{CH}_{2}\right), 29.22$ (16'- $\left.\mathrm{CH}_{2}\right), 29.30\left(15^{\prime}-\mathrm{CH}_{2}\right), 29.49\left(14^{\prime}-\mathrm{CH}_{2}\right), 29.54\left(13^{\prime}-\mathrm{CH}_{2}\right), 29.61\left(12^{\prime}-\mathrm{CH}_{2}\right), 29.65\left(\mathrm{CH}_{2}\right), 30.85\left(\mathrm{CH}_{2}\right)$, $31.33\left(\mathrm{CH}_{2}\right), 31.87\left(2^{\prime}-\mathrm{CH}_{2}\right), 34.40\left(\mathrm{CH}_{2}\right), 35.06(\mathrm{CH}), 35.10(10-\mathrm{C}), 35.50\left(\mathrm{CH}_{2}\right), 36.03\left(\mathrm{CH}_{2}\right), 39.39(\mathrm{CH})$, $41.75(\mathrm{CH}), 42.13(\mathrm{CH}), 45.98(13-\mathrm{C}), 47.72(\mathrm{CH}), 47.76(7-\mathrm{CH}), 54.10(12-\mathrm{CH}), 61.47(3-\mathrm{CH}), 64.42(1$ '$\mathrm{CH}_{2}$ ), 174.14 (C-24). Anal. Calcd for $\mathrm{C}_{44} \mathrm{H}_{81} \mathrm{~N}_{5} \mathrm{O}_{2 .}{ }^{1 / 2} \mathrm{H}_{2} \mathrm{O}: \mathrm{C}, 73.28 ; \mathrm{H}, 11.46 ; \mathrm{N}, 9.71$. Found: C, 73.43; H, $11.32 ; \mathrm{N}, 9.51$.

\section{Eicosyl $3 \alpha$-p-toluenesulfonamido-7 $\alpha, 12 \alpha$-bis[(phenylaminocarbonyl)amino]-5 $\beta$-cholan-24-oate 8 .}

The diamine F (508 $\mathrm{mg}, 0.71 \mathrm{mmol})$ was dissolved in dry DCM $(25 \mathrm{~mL})$ with DMAP (93 mg, $0.76 \mathrm{mmol}$, 1.07 equiv), triethylamine ( $220 \mu \mathrm{L}, 160 \mathrm{mg}, 1.56 \mathrm{mmol}, 2.2$ equiv) and phenyl isocyanate ( $220 \mu \mathrm{L}, 241 \mathrm{mg}$, $2 \mathrm{mmol}, 2.82$ equiv). The solution was stirred for 4 days and then the solvent was evaporated. The dry residue was purified by flash chromatography (hexane-EtOAc, 5:1 - 2:1) to give the bisurea $\mathbf{G}$ as a white solid (420 mg, $62 \%$ ): $\mathrm{R}_{f} 0.34$ (hexane-EtOAc, 3:1) 0.34; IR (thin film) 3373, 2924, 2854, 2092, 1664, 1547, 1236, 750, $692 \mathrm{~cm}^{-1} ;{ }^{1} \mathrm{H} \mathrm{NMR}\left(400 \mathrm{MHz}, \mathrm{CDCl}_{3}\right) \delta 0.78\left(\mathrm{~s}, 3 \mathrm{H}, 18-\mathrm{CH}_{3}\right), 0.88\left(\mathrm{~d}, J=5.8 \mathrm{~Hz}, 3 \mathrm{H}, 21-\mathrm{CH}_{3}\right)$, 0.89 (t, $\left.J=6.6 \mathrm{~Hz}, 3 \mathrm{H}, 20^{\prime}-\mathrm{CH}_{3}\right), 0.94\left(\mathrm{~s}, 3 \mathrm{H}, 19-\mathrm{CH}_{3}\right), 1.27\left(\mathrm{~s}, 34 \mathrm{H}\right.$, eicosyl $\left.\mathrm{CH}_{2}\right), 2.00-2.07(\mathrm{~m}, 1 \mathrm{H})$,

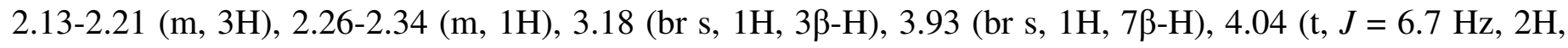
1'- $\mathrm{CH}_{2}$ ), 4.10 (br s, $\left.1 \mathrm{H}, 12 \beta-\mathrm{H}\right), 5.33$ (br s, 1H, NH), 5.61 (br s, $\left.1 \mathrm{H}, \mathrm{NH}\right), 6.83$ (br s, 1H, NH), 7.12 (br s, $1 \mathrm{H}$, $\mathrm{NH})$, 7.03-7.36 (m, 10H); ${ }^{13} \mathrm{C} \mathrm{NMR}\left(100 \mathrm{MHz}, \mathrm{CDCl}_{3}\right) \delta 13.58\left(18-\mathrm{CH}_{3}\right), 14.08\left(20{ }^{\prime}-\mathrm{CH}_{3}\right), 17.30\left(21-\mathrm{CH}_{3}\right)$, $22.66\left(19{ }^{\prime}-\mathrm{CH}_{2}\right), 22.86\left(19-\mathrm{CH}_{3}\right), 23.28\left(\mathrm{CH}_{2}\right), 25.90\left(18^{\prime}-\mathrm{CH}_{2}\right), 26.52\left(\mathrm{CH}_{2}\right), 27.02\left(\mathrm{CH}_{2}\right), 27.19\left(\mathrm{CH}_{2}\right)$, $28.62\left(17^{\prime}-\mathrm{CH}_{2}+\mathrm{CH}\right), 29.26\left(16^{\prime}-\mathrm{CH}_{2}\right), 29.34\left(15^{\prime}-\mathrm{CH}_{2}\right), 29.52\left(14^{\prime}-\mathrm{CH}_{2}\right), 29.59\left(13^{\prime}-\mathrm{CH}_{2}\right), 29.65\left(12^{\prime}-\right.$ 
$\left.\mathrm{CH}_{2}\right), 29.69\left(\mathrm{CH}_{2}\right), 30.82\left(\mathrm{CH}_{2}\right), 31.43\left(\mathrm{CH}_{2}\right), 31.91\left(2^{\prime}-\mathrm{CH}_{2}\right), 32.26\left(\mathrm{CH}_{2}\right), 34.75(10-\mathrm{C}), 34.79(\mathrm{CH}), 35.06$

$\left(\mathrm{CH}_{2}\right), 35.69\left(\mathrm{CH}_{2}\right), 37.21(\mathrm{CH}), 41.51(\mathrm{CH}), 44.65(\mathrm{CH}), 44.76(13-\mathrm{C}), 47.06(\mathrm{CH}), 48.53(7-\mathrm{CH}), 53.01$ (12-CH), 61.67 (3-CH), $64.74\left(1 '-\mathrm{CH}_{2}\right), 119.86(\mathrm{CH}), 120.19(\mathrm{CH}), 121.01(\mathrm{CH}), 129.17(\mathrm{CH}), 129.36(\mathrm{CH})$, $129.45(\mathrm{CH}), 138.62,139.03,155.31$ (urea $\mathrm{C}=\mathrm{O}), 155.71$ (urea $\mathrm{C}=\mathrm{O}), 174.58(\mathrm{C}-24)$.

To a solution of azido compound $\mathbf{G}(0.4 \mathrm{~g}, 0.42 \mathrm{mmol})$ in dry THF ( $4 \mathrm{~mL})$ was added trimethylphosphine ( $0.84 \mathrm{~mL}$ of a $1 \mathrm{M}$ solution in THF, $0.84 \mathrm{mmol}, 2$ equiv). The solution was stirred for $6 \mathrm{~h}$ before water (150 $\mu \mathrm{L}, 0.150 \mathrm{~g}, 8.4 \mathrm{mmol}, 2$ equiv) was added and the solution was stirred for a further $24 \mathrm{~h}$. The solvent was removed under reduced pressure and the residue was partially purified by flash chromatography (DCMmethanolic ammonia, ${ }^{3} 97: 3$ - 9:1) to give free amine $\mathbf{H}$ as a yellow waxy solid containing trimethylphosphine oxide $(0.330 \mathrm{~g}, 85 \%): \mathrm{R}_{f} 0.30$ (DCM-methanolic ammonia, ${ }^{3}$ 9:1); IR (thin film) 3317, 2922, 2852, 1663, 1538, 749, $691 \mathrm{~cm}^{-1} ;{ }^{1} \mathrm{H}$ NMR (400 MHz, $\left.\mathrm{CDCl}_{3}\right) \delta 0.81\left(\mathrm{~s}, 3 \mathrm{H}, 18-\mathrm{CH}_{3}\right), 0.88(\mathrm{t}$, $\left.J=6.8 \mathrm{~Hz}, 3 \mathrm{H}, 20^{\prime}-\mathrm{H}_{3}\right), 0.93\left(\mathrm{~s}, 3 \mathrm{H}, 19-\mathrm{CH}_{3}\right), 0.95\left(\mathrm{~d}, J=6.6 \mathrm{~Hz}, 3 \mathrm{H}, 21-\mathrm{CH}_{3}\right) 1.25\left(\mathrm{~s}, 34 \mathrm{H}\right.$, eicosyl $\left.\mathrm{CH}_{2}\right)$, $1.51\left(\mathrm{~d}, J(\mathrm{H}, \mathrm{P})=12.8 \mathrm{~Hz}, 9 \mathrm{H},\left(\mathrm{CH}_{3}\right)_{3} \mathrm{P}\right), 2.11-2.24(\mathrm{~m}, 1 \mathrm{H}), 2.24-2.38(\mathrm{~m}, 1 \mathrm{H}), 2.63(\mathrm{~m}, 1 \mathrm{H}, 3 \beta-\mathrm{H}), 3.91(\mathrm{~m}$, $1 \mathrm{H}, 7 \beta-\mathrm{H}), 4.01\left(\mathrm{t}, J=6.8 \mathrm{~Hz}, 2 \mathrm{H}, 1^{\prime}-\mathrm{H}_{3}\right), 4.22(\mathrm{~m}, 1 \mathrm{H}, 12 \beta-\mathrm{H}), 6.04(\mathrm{~m}, 2 \mathrm{H}, \mathrm{NH}), 6.88-6.98(\mathrm{~m}, 2 \mathrm{H}$, Ar-CH), 7.17-7.27 (m, 4H, Ar-CH), 7.38-7.54 (m, 4H, Ar-CH), 8.13 (m, 2H, NH).

To a stirred solution of free amine $\mathbf{H}(0.210 \mathrm{~g}, 0.23 \mathrm{mmol})$ and p-toluenesulfonyl chloride $(0.048 \mathrm{~g}$, $0.25 \mathrm{mmol}, 1.1$ equiv) in dry DCM (6 mL) was added triethylamine (35 $\mu \mathrm{L}, 0.025 \mathrm{~g}, 0.25 \mathrm{mmol}, 1.09$ equiv). After $5 \mathrm{~h}$ the solvent was evaporated and the dry residue dissolved in DCM, washed with $1 \mathrm{M} \mathrm{HCl}$ aq. and dried over $\mathrm{MgSO}_{4}$. The solvent was then removed under reduced pressure. Purification of the resultant crude mixture by flash chromatography (DCM-methanolic ammonia, ${ }^{3} 49: 1$ ) gave sulfonamide 8 as a pale yellow waxy solid (0.174 g, $71 \%$ ): $\mathrm{R}_{f} 0.80$ (DCM-methanolic ammonia, ${ }^{3}$ 97:3); IR (thin film) 3420, 2922 , 2852, 1700, 1533, 1377, 1150, 749, $691 \mathrm{~cm}^{-1} ;{ }^{1} \mathrm{H}$ NMR (400 MHz, $\left.\mathrm{CDCl}_{3}\right) \delta 0.78\left(\mathrm{~s}, 3 \mathrm{H}, 18-\mathrm{CH}_{3}\right), 0.82(\mathrm{~s}$, $\left.3 \mathrm{H}, 19-\mathrm{CH}_{3}\right), 0.88\left(\mathrm{t}, J=6.8 \mathrm{~Hz}, 3 \mathrm{H}, 20{ }^{\prime}-\mathrm{CH}_{3}\right), 0.95\left(\mathrm{~d}, J=5.9 \mathrm{~Hz}, 3 \mathrm{H}, 21-\mathrm{CH}_{3}\right), 1.25\left(\mathrm{~s}, 34 \mathrm{H}\right.$, eicosyl $\left.\mathrm{CH}_{2}\right)$, 2.15-2.25 (m, 1H), 2.31 (br s, 3H, Ar-CH $), 2.86(\mathrm{~m}, 1 \mathrm{H}, 3 \beta-\mathrm{H}), 3.78(\mathrm{~m}, 1 \mathrm{H}, 7 \beta-\mathrm{H}), 4.01(\mathrm{t}, J=6.8 \mathrm{~Hz}, 2 \mathrm{H}$, 1 ' $\left.-\mathrm{H}_{2}\right), 4.01(\mathrm{~m}, 1 \mathrm{H}, 12 \beta-\mathrm{H}), 5.24$ (br s, 1H, NH), 5.66 (br s, 1H, NH), 6.65-6.75 (m, 1H), 6.85-6.95 (m, 1H), 
6.95-7.20 (m, 6H), 7.23-7.31 (m, 3H), 7.37-7.50 (m, 3H), 7.90-7.97 (m, 3H); ${ }^{13} \mathrm{C} \mathrm{NMR}\left(100 \mathrm{MHz}, \mathrm{CDCl}_{3}\right) \delta$ $14.0\left(18-\mathrm{CH}_{3}\right), 14.1\left(20^{\prime}-\mathrm{CH}_{2}\right), 17.4\left(21-\mathrm{CH}_{3}\right), 22.7\left(19^{\prime}-\mathrm{CH}_{2}\right), 22.8\left(19-\mathrm{CH}_{3}\right), 22.9,\left(\mathrm{Ar}-\mathrm{CH}_{3}\right), 25.9\left(18^{\prime}-\right.$ $\left.\mathrm{CH}_{2}\right), 27.1,27.5,27.5,28.7$ (17'- $\left.-\mathrm{CH}_{2}\right), 29.3\left(16^{\prime}-\mathrm{CH}_{2}\right), 29.4\left(15^{\prime}-\mathrm{CH}_{2}\right), 29.5\left(14^{\prime}-\mathrm{CH}_{2}\right), 29.6\left(13^{\prime}-\mathrm{CH}_{2}\right), 29.7$ (12'- $\left.\mathrm{CH}_{2}\right), 29.7,30.8,31.4,31.9\left(2^{\prime}-\mathrm{CH}_{2}\right), 34.2,34.9$ (10-C), 34.9, 35.0, 35.0, 36.8, 41.7, 41.7, 41.7, 44.9 (13-C), 45.1, 46.1, 48.5 (7-CH), 52.3 (12-CH), 53.4 (3-CH), 64.5 (1'- $\left.\mathrm{CH}_{2}\right), 117.9$ (Ar-CH), 117.9 (Ar-CH), 117.9 (Ar-CH), 118.0 (Ar-CH), 121.7 ( 2 x Ar-CH), 127.1 ( 2 x Ar-CH), 128.7 (2 x Ar-CH), 128.9 (2 x ArCH), 130.5 (2 x Ar-CH), 138.2 (Ar-C), 139.8 (Ar-C), 139.8 (Ar-C), 144.9 (Ar-C), 155.5 (urea C=O), 155.8 (urea $\mathrm{C}=\mathrm{O}), 174.2(\mathrm{C} 24)$; MS (FAB) $\mathrm{m} / \mathrm{z} 1101(100)[\mathrm{M}+\mathrm{Na}]^{+}$, $1079(11)[\mathrm{M}+\mathrm{H}]^{+}$; Anal. Calcd for $\mathrm{C}_{65} \mathrm{H}_{99} \mathrm{~N}_{5} \mathrm{O}_{6} \mathrm{~S} . \mathrm{H}_{2} \mathrm{O}:$ C, 71.10; H, 9.25; N, 6.49. Found: C, 71.10; H, 8.97; N, 6.24. 

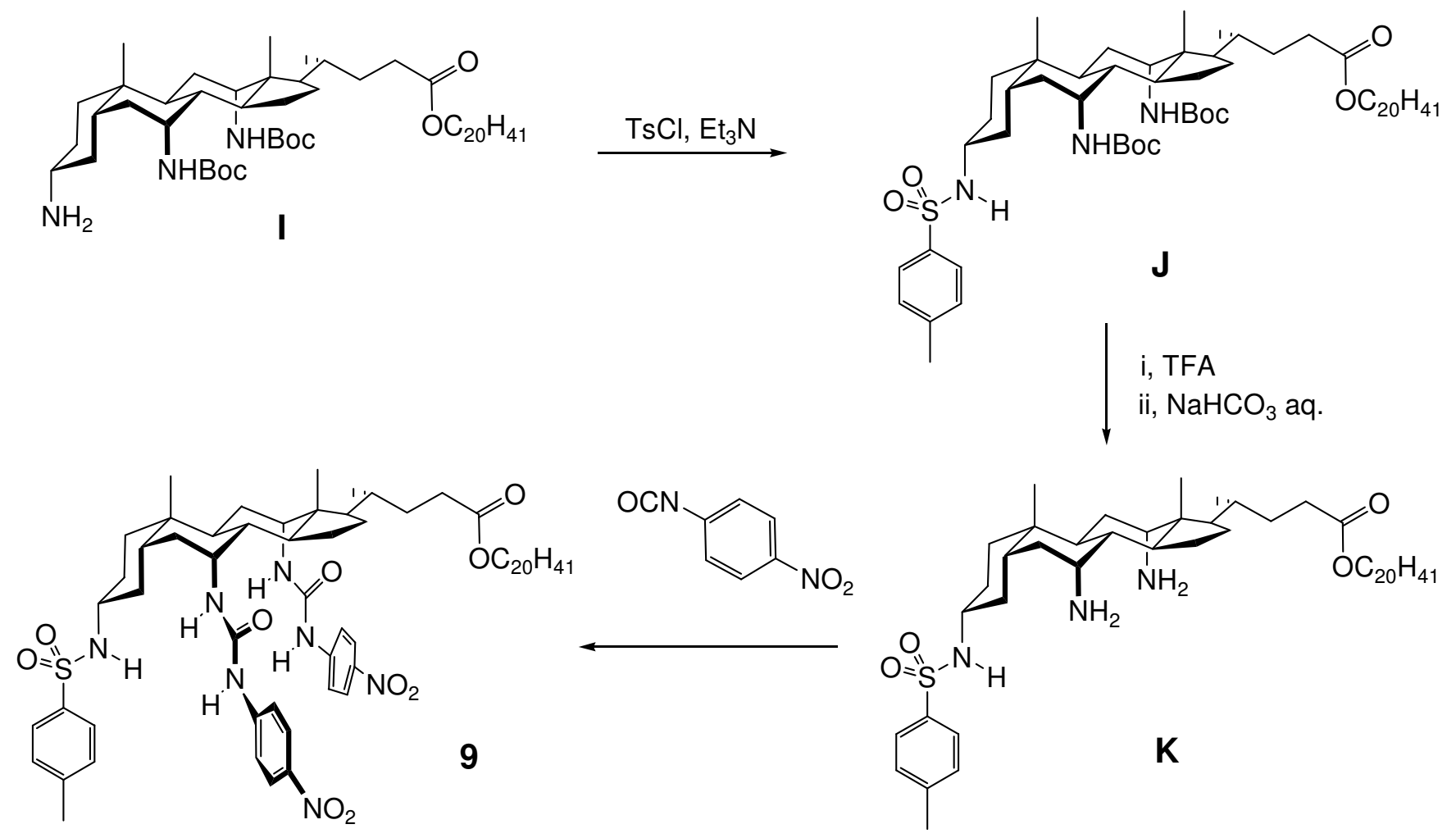

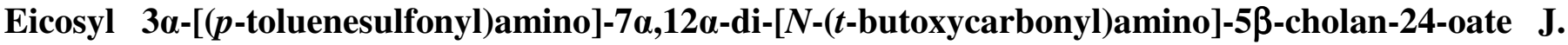

To a stirred solution of amine $\mathbf{I}^{2}(100 \mathrm{mg}, 0.11 \mathrm{mmol})$ in dry DCM was added triethylamine $(27 \mathrm{mg}, 20 \mu \mathrm{L}$, $0.27 \mathrm{mmol}, 2.45$ equiv) followed by $p$-toluenesulfonyl chloride ( $26 \mathrm{mg}, 0.14 \mathrm{mmol}, 1.27$ equiv). The reaction was stirred for $5 \mathrm{~h}$ at room temperature. The reaction mixture was diluted with DCM and washed with $0.2 \mathrm{M} \mathrm{HCl}$. The aqueous phase was extracted 3 times with DCM. The combined organic phases were dried over $\mathrm{MgSO}_{4}$. The solvent was removed under reduced pressure to give a white solid that was purified by flash chromatography (methanol-DCM, $2 \%$ ). The sulfonamide $\mathbf{J}$ was obtained as a white amorphous solid (112 mg, $95 \%$ ): $\mathrm{R}_{f} 0.26$ (methanol-DCM, 2\%); IR (thin film) 3384, 2953, 2853, 1705, 1507, 1364, $1242,1163 \mathrm{~cm}^{-1} ;{ }^{1} \mathrm{H}$ NMR $\left(400 \mathrm{MHz}, \mathrm{CDCl}_{3}\right) \delta 0.75\left(\mathrm{~s}, 3 \mathrm{H}, 18-\mathrm{CH}_{3}\right), 0.85-0.89\left(\mathrm{~m}, 9 \mathrm{H}, 19-\mathrm{CH}_{3}, 21-\mathrm{CH}_{3}\right.$, eicosyl $\left.\mathrm{CH}_{3}\right), 1.25$ (m, 36H, eicosyl $\left.\mathrm{CH}_{2}\right), 1.45$ (br s, 18H, $\left.\mathrm{C}\left(\mathrm{CH}_{3}\right)_{3}\right), 2.13-2.24(\mathrm{~m}, 1 \mathrm{H}), 2.29-2.39(\mathrm{~m}, 1 \mathrm{H})$,

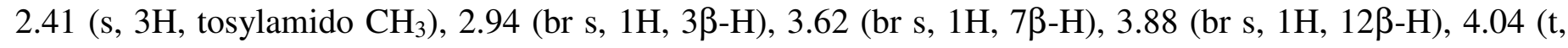


$\left.J=6.6 \mathrm{~Hz}, 2 \mathrm{H}, \mathrm{OCH}_{2}\right), 4.70($ br s, $1 \mathrm{H}, \mathrm{NH}), 4.87($ br s, $1 \mathrm{H}, \mathrm{NH}), 5.07$ (br s, 1H, NH), $7.28($ br d, $J=8.0 \mathrm{~Hz}$, 2H, Ar-H), $7.78\left(\mathrm{~d}, J=8.3 \mathrm{~Hz}, 2 \mathrm{H}\right.$, aryl H); ${ }^{13} \mathrm{C} \mathrm{NMR}\left(100 \mathrm{MHz}, \mathrm{CDCl}_{3}\right) \delta 13.77\left(\mathrm{CH}_{3}\right), 14.10\left(\mathrm{CH}_{3}\right), 17.25$ $\left(\mathrm{CH}_{3}\right), 21.49\left(\mathrm{CH}_{3}\right), 22.67\left(\mathrm{CH}_{2}\right), 22.99\left(\mathrm{CH}_{3}\right), 23.05\left(\mathrm{CH}_{2}\right), 25.93\left(\mathrm{CH}_{2}\right), 27.17\left(\mathrm{CH}_{2}\right), 28.47\left(\mathrm{CH}_{3}\right), 28.63$ $\left(\mathrm{CH}_{2}\right), 29.25\left(\mathrm{CH}_{2}\right), 29.34\left(\mathrm{CH}_{2}\right), 29.58\left(\mathrm{CH}_{2}\right), 29.64\left(\mathrm{CH}_{2}\right), 29.67\left(\mathrm{CH}_{2}\right), 30.81\left(\mathrm{CH}_{2}\right), 31.47\left(\mathrm{CH}_{2}\right), 31.90$ $\left(\mathrm{CH}_{2}\right), 34.49(\mathrm{C}), 34.87(\mathrm{CH}), 35.47\left(\mathrm{CH}_{2}\right), 36.85(\mathrm{CH}), 37.49\left(\mathrm{CH}_{2}\right), 42.06(\mathrm{CH}), 44.78(\mathrm{C}), 47.08(\mathrm{CH})$, $48.44(\mathrm{CH}), 53.17(\mathrm{CH}), 54.36(\mathrm{CH}), 64.52(\mathrm{CH}), 79.20(2 \times \mathrm{C}), 127.00(\mathrm{CH}), 129.61(\mathrm{CH}), 143.28(\mathrm{C})$, $155.43(2 \times \mathrm{C}), 174.30(\mathrm{C})$; MS (FAB) $\mathrm{m} / \mathrm{z} 1062.8[\mathrm{M}+\mathrm{Na}]^{+}$; Anal. Calcd for $\mathrm{C}_{61} \mathrm{H}_{105} \mathrm{~N}_{3} \mathrm{O}_{8} \mathrm{~S} . \mathrm{H}_{2} \mathrm{O}: \mathrm{C}, 69.21$; H, 10.19; N, 3.97. Found: C, 69.20; H, 10.15; N, 3.89.

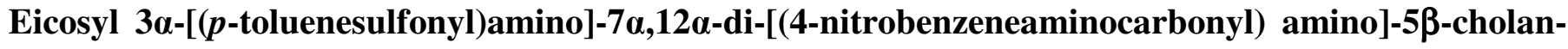
24-oate (9). To a solution of dicarbamate $\mathbf{J}(113 \mathrm{mg}, 0.109 \mathrm{mmol})$ in DCM (4 mL) cooled by an ice bath was added trifluoroacetic acid $(1 \mathrm{~mL})$. The reaction was stirred for $30 \mathrm{~min}$ at $0{ }^{\circ} \mathrm{C}$. The ice bath was removed and the reaction was stirred for $1 \mathrm{~h}$ at room temperature. The solvent was removed under reduced pressure. The residue was dissolved in DCM and washed with a saturated solution of $\mathrm{NaHCO}_{3}$. The aqueous phase was extracted with aliquots of DCM and the combined organic phases were dried over $\mathrm{MgSO}_{4}$ and the solvent removed under reduced pressure to give diamine $\mathbf{K}(86 \mathrm{mg}, 95 \%)$ as a white solid: IR (thin film) 3300, 2921, 2852, 1734, 1599, 1464, 1377, 1326, $12531155,1093,920,814,720.5 \mathrm{~cm}^{-1} ;{ }^{1} \mathrm{H} \mathrm{NMR}$ $\left(400 \mathrm{MHz}, \mathrm{CDCl}_{3}\right) \delta 0.69\left(\mathrm{~s}, 3 \mathrm{H}, 18-\mathrm{CH}_{3}\right), 0.85\left(\mathrm{~s}, 3 \mathrm{H}, 19-\mathrm{CH}_{3}\right), 0.88\left(\mathrm{t}, J=6.6 \mathrm{~Hz}, 3 \mathrm{H}\right.$, eicosyl $\left.\mathrm{CH}_{3}\right), 0.96$ $\left(\mathrm{d}, J=6.4 \mathrm{~Hz}, 3 \mathrm{H}, 19-\mathrm{CH}_{3}\right), 1.25\left(\mathrm{~m}, 36 \mathrm{H}\right.$, eicosyl $\left.\mathrm{CH}_{2}\right), 2.42\left(\mathrm{~s}, 3 \mathrm{H}\right.$, tosylamido $\left.\mathrm{CH}_{3}\right), 2.99(\mathrm{~m}, 1 \mathrm{H}, 3 \beta-\mathrm{H})$, $3.09(\mathrm{~m}, 1 \mathrm{H}), 3.17(\mathrm{~m}, 1 \mathrm{H}), 4.05\left(\mathrm{t}, J=6.8 \mathrm{~Hz}, 2 \mathrm{H}, \mathrm{OCH}_{2}\right), 5.90($ br s, $1 \mathrm{H}, \mathrm{NH}), 7.27(\mathrm{~d}, J=8.1 \mathrm{~Hz}, 2 \mathrm{H}, \mathrm{Ar}-$ $\mathrm{H}), 7.75(\mathrm{~d}, J=6.6 \mathrm{~Hz}, 2 \mathrm{H}, \mathrm{Ar}-\mathrm{H}) ;{ }^{13} \mathrm{C} \mathrm{NMR}\left(100 \mathrm{MHz}, \mathrm{CDCl}_{3}\right) \delta 13.41\left(\mathrm{CH}_{3}\right), 14.09\left(\mathrm{CH}_{3}\right), 17.22\left(\mathrm{CH}_{3}\right)$, $21.45\left(\mathrm{CH}_{3}\right), 22.52\left(\mathrm{CH}_{3}\right), 22.65\left(\mathrm{CH}_{2}\right), 23.57\left(\mathrm{CH}_{2}\right), 25.71(\mathrm{CH}), 25.91\left(\mathrm{CH}_{2}\right), 27.52\left(\mathrm{CH}_{2}\right), 27.82\left(\mathrm{CH}_{2}\right)$, $28.63\left(\mathrm{CH}_{2}\right), 28.69\left(\mathrm{CH}_{2}\right), 29.23\left(\mathrm{CH}_{2}\right), 29.32\left(\mathrm{CH}_{2}\right), 29.51\left(\mathrm{CH}_{2}\right), 29.56\left(\mathrm{CH}_{2}\right), 29.62\left(\mathrm{CH}_{2}\right), 29.67\left(\mathrm{CH}_{2}\right)$, $30.94\left(\mathrm{CH}_{2}\right), 31.44\left(\mathrm{CH}_{2}\right), 31.89\left(\mathrm{CH}_{2}\right), 34.58\left(\mathrm{CH}_{2}\right), 34.71(\mathrm{C}), 35.07(\mathrm{CH}), 35.99\left(\mathrm{CH}_{2}\right), 38.31\left(\mathrm{CH}_{2}\right)$, 
$39.43(\mathrm{CH}), 41.55(\mathrm{CH}), 42.38(\mathrm{CH}), 46.01(\mathrm{C}), 47.54(\mathrm{CH}), 47.94(\mathrm{CH}), 53.81(\mathrm{CH}), 54.02(\mathrm{CH}), 64.43$ $\left(\mathrm{CH}_{2}\right), 126.79(\mathrm{CH}), 129.45(\mathrm{CH}), 139.28(\mathrm{C}), 142.63(\mathrm{C}), 174.15(\mathrm{C})$.

To a stirred solution of diamine $\mathbf{K}(86 \mathrm{mg}, 0.102 \mathrm{mmol})$ in dry tetrahydrofuran $(2 \mathrm{~mL})$ was added 4nitrophenyl isocyanate $(42 \mathrm{mg}, 0.26 \mathrm{mmol}, 2.55$ equiv). The reaction was stirred overnight at room temperature. The solvent was removed under reduced pressure and the crude mixture was purified by flash chromatography (DCM-EtOAc, 1:0 - 5:1) using a shallow depth of silica. The solvent was removed under reduced pressure and the residue dissolved in DCM. A yellow impurity was removed by two filtrations. The solvent was evaporated under reduced pressure, giving the desired compound 9 as a yellow amorphous solid (101 mg, $80 \%$ ): R 0.30 (DCM-methanol, 94:6); IR (thin film) 3407, 2923, 2852, 1704, 1597, 1501, 1467, 1325, 1300, 1248, 1203, 1175, 1110, 1064, 1035, $850 \mathrm{~cm}^{-1} ;{ }^{1} \mathrm{H}$ NMR $\left(400 \mathrm{MHz}, \mathrm{CO}\left(\mathrm{CD}_{3}\right)_{2}\right) \delta 0.75-0.92(\mathrm{~m}$, 9H), $0.94(\mathrm{~s}, 3 \mathrm{H}), 1.27\left(\mathrm{~m}, 36 \mathrm{H}\right.$, eicosyl $\left.\mathrm{CH}_{2}\right), 2.36\left(\mathrm{~s}, 3 \mathrm{H}\right.$, tosylamido $\left.\mathrm{CH}_{3}\right), 2.79$ (br s, 1H, 3ß-H), $3.97(\mathrm{t}$, $\left.J=6.8 \mathrm{~Hz}, 2 \mathrm{H}, \mathrm{OCH}_{2}\right), 4.00(\mathrm{~m}, 1 \mathrm{H}, 7 \beta-\mathrm{H}), 4.17(\mathrm{~m}, 1 \mathrm{H}, 12 \beta-\mathrm{H}), 5.92(\mathrm{br} \mathrm{d}, J=8.3 \mathrm{~Hz}, 1 \mathrm{H}, \mathrm{NH}), 6.08(\mathrm{br}$ $\mathrm{d}, J=7.3 \mathrm{~Hz}, 1 \mathrm{H}, \mathrm{NH}), 7.35(\mathrm{~d}, J=7.3 \mathrm{~Hz}, 2 \mathrm{H}, \mathrm{Ar}-\mathrm{H}), 7.62-7.74(\mathrm{~m}, 4 \mathrm{H}, \mathrm{Ar}-\mathrm{H}), 7.77(\mathrm{~d}, J=8.3 \mathrm{~Hz}, 2 \mathrm{H}$, Ar-H), 8.10-8.19 (m, 4H, Ar-H), 8.45 (br s, $1 \mathrm{H}, \mathrm{NH}), 8.59$ (br s, $1 \mathrm{H}, \mathrm{NH}) ;{ }^{13} \mathrm{C}$ NMR $\left(100 \mathrm{MHz}, \mathrm{CDCl}_{3}\right) \delta$ $14.01\left(\mathrm{CH}_{3}\right), 14.10\left(\mathrm{CH}_{3}\right), 17.34\left(\mathrm{CH}_{3}\right), 21.75\left(\mathrm{CH}_{3}\right), 22.66\left(\mathrm{CH}_{2}\right), 22.82\left(\mathrm{CH}_{2}\right) 23.08\left(\mathrm{CH}_{3}\right), 25.85\left(\mathrm{CH}_{2}\right)$, $27.14\left(\mathrm{CH}_{2}\right), 28.57\left(\mathrm{CH}_{2}\right), 29.21\left(\mathrm{CH}_{2}\right), 29.33\left(\mathrm{CH}_{2}\right), 29.48\left(\mathrm{CH}_{2}\right), 29.66\left(\mathrm{CH}_{2}\right), 29.93(\mathrm{CH}), 30.70\left(\mathrm{CH}_{2}\right)$, $31.35\left(\mathrm{CH}_{2}\right), 31.90\left(\mathrm{CH}_{2}\right), 34.05(\mathrm{C}), 34.61\left(\mathrm{CH}_{2}\right), 34.92(\mathrm{CH}), 35.41(\mathrm{CH}), 36.50(\mathrm{CH}), 41.93(\mathrm{CH}), 45.04$ (C), $46.17(\mathrm{CH}), 48.67(\mathrm{CH}), 55.17(\mathrm{CH}), 64.54\left(\mathrm{CH}_{2}\right), 116.35(\mathrm{CH}), 117.20(\mathrm{CH}), 124.84(\mathrm{CH}), 125.27$ $(\mathrm{CH}), 126.90(\mathrm{CH}), 130.79(\mathrm{CH}), 134.87(\mathrm{CH}), 140.52(\mathrm{C}), 141.90(\mathrm{C}), 146.04(\mathrm{C}), 146.52(\mathrm{C}), 153.29(\mathrm{C})$, $153.68(\mathrm{C}), 174.28(\mathrm{C}) ; \mathrm{MS}\left(\mathrm{ES}^{+}\right) \mathrm{m} / \mathrm{z} 1190.8[\mathrm{M}+\mathrm{Na}]^{+} . \mathrm{MS}(\mathrm{MALDI}) \mathrm{m} / \mathrm{z} 1174.8[\mathrm{M}+\mathrm{Li}]^{+}, 1190.7$ $[\mathrm{M}+\mathrm{Na}]^{+}$. Anal. Calcd for $\mathrm{C}_{65} \mathrm{H}_{97} \mathrm{~N}_{7} \mathrm{O}_{10} \mathrm{~S}: \mathrm{C}, 66.81 ; \mathrm{H}, 8.37 ; \mathrm{N}, 8.39$. Found: C, 66.95; H, 8.67; N, 8.22. 


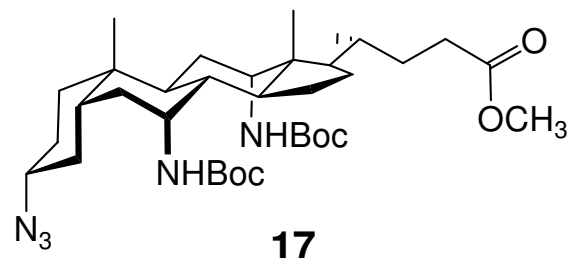

17
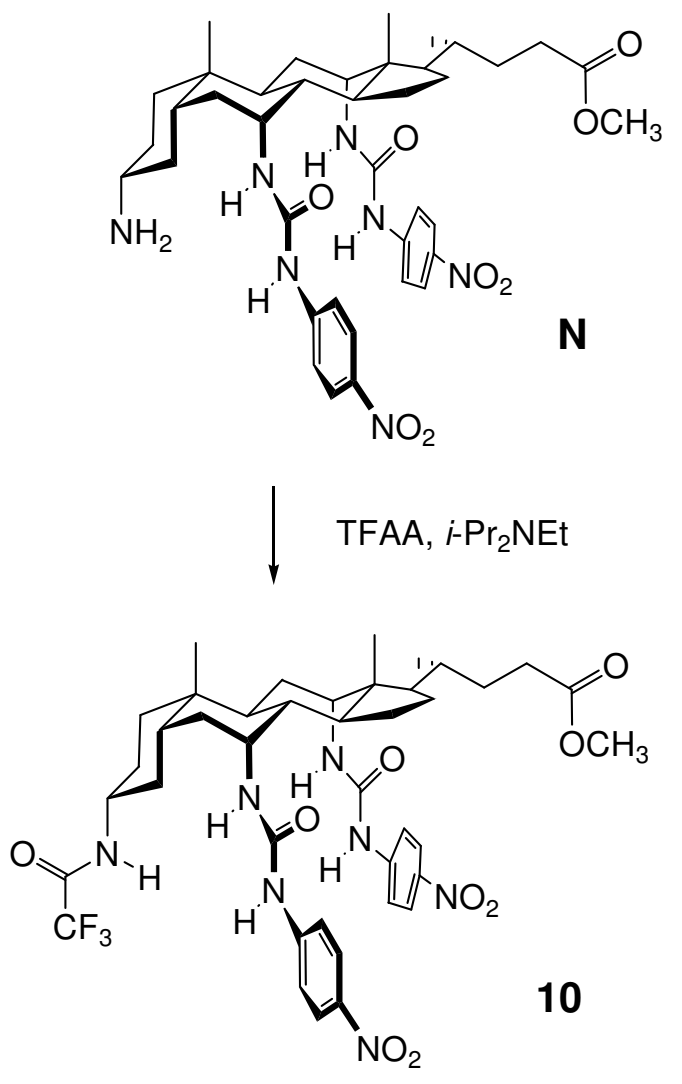
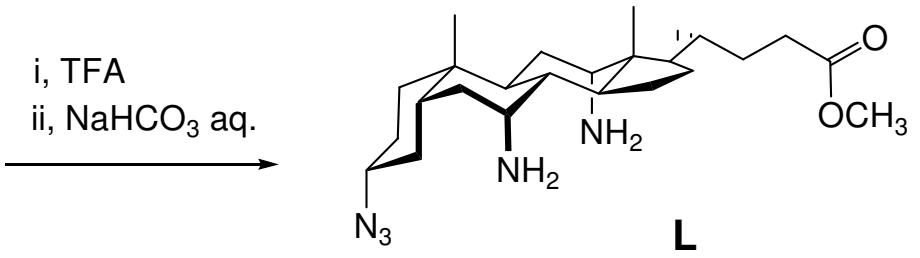<smiles>O=[N+]([O-])c1ccc([N+](=O)[O-])cc1</smiles>
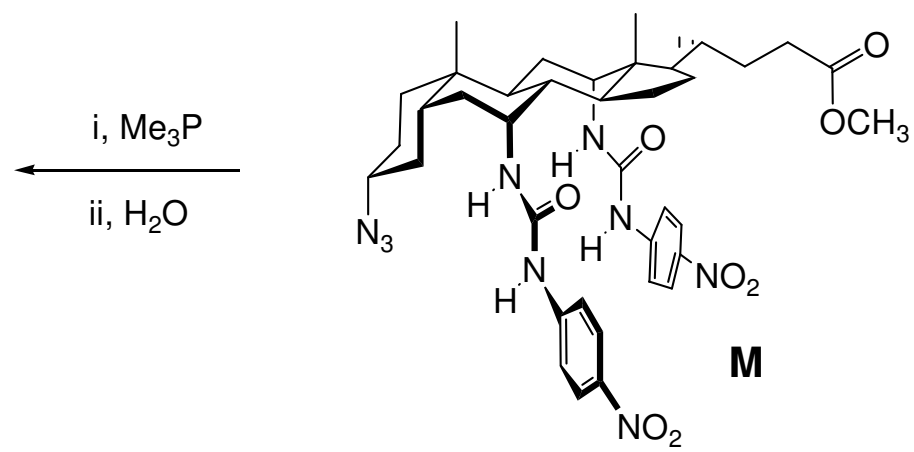

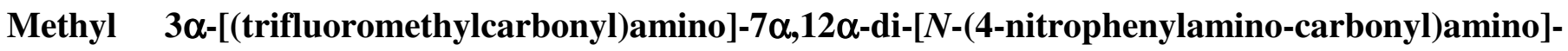

5ß-cholan-24-oate 10. Diaminoazide $\mathbf{L}$ was prepared from biscarbamate $\mathbf{1 7}$ as described previously. ${ }^{4}{ }^{4}$ nitrophenyl isocyanate ( $165 \mathrm{mg}, 1 \mathrm{mmol}, 2.5$ equiv) was added to a stirred solution of $\mathbf{L}$ ( $259 \mathrm{mg}, 0.4 \mathrm{mmol}$ ) in dry DCM. The reaction was stirred overnight and the solvent was removed under reduced pressure. The crude mixture was purified by flash chromatography (DCM-EtOAc, 1:0 - 95:5). The desired bisurea $\mathbf{M}$ was obtained as a yellow solid (285 mg, 92\%). Crystallization (DCM-hexane) gave small yellow crystals (257 mg, $83 \%$ ): $\mathrm{R}_{f} 0.29$ (DCM-methanol, 97:3); m.p. 212-214 ${ }^{\circ} \mathrm{C}$ (DCM-hexane); IR (thin film) 3359, 2946, 
2868, 2091, 1708, 1596, 1495, 1413, 1381, 1299, 1316, 1248, 1201, 1174, 1108, 848, $750 \mathrm{~cm}^{-1} ;{ }^{1} \mathrm{H}$ NMR $\left(400 \mathrm{MHz}, \mathrm{CDCl}_{3}\right) \delta 0.87\left(\mathrm{~d}, J=6.6 \mathrm{~Hz}, 3 \mathrm{H}, 21-\mathrm{CH}_{3}\right), 0.94\left(\mathrm{~s}, 3 \mathrm{H}, 18-\mathrm{CH}_{3}\right), 1.14\left(\mathrm{~s}, 3 \mathrm{H}, 19-\mathrm{CH}_{3}\right), 3.15(\mathrm{~m}$,

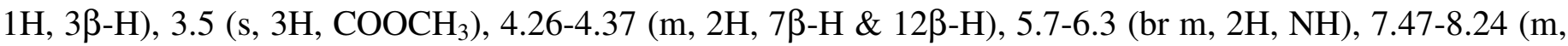
$10 \mathrm{H}, \mathrm{Ar}-\mathrm{H} \& 2 \mathrm{x} \mathrm{NH}) ;{ }^{1} \mathrm{H} \mathrm{NMR}\left(400 \mathrm{MHz},\left(\mathrm{CD}_{3}\right)_{2} \mathrm{CO}\right) \delta 0.87\left(\mathrm{~d}, J=6.6 \mathrm{~Hz}, 3 \mathrm{H}, 21-\mathrm{CH}_{3}\right), 0.92(\mathrm{~s}, 3 \mathrm{H}, 18-$ $\left.\mathrm{CH}_{3}\right), 1.08\left(\mathrm{~s}, 3 \mathrm{H}, 19-\mathrm{CH}_{3}\right), 3.42(\mathrm{~m}, 1 \mathrm{H}, 3 \beta-\mathrm{H}), 3.55\left(\mathrm{~s}, 3 \mathrm{H}, \mathrm{COOCH}_{3}\right), 4.10(\mathrm{~m}, 1 \mathrm{H}, 7 \beta-\mathrm{H}), 4.18(\mathrm{~m}, 1 \mathrm{H}$, $12 \beta-\mathrm{H}), 6.08$ (br d, $J=9.8 \mathrm{~Hz}, 1 \mathrm{H}, \mathrm{NH}), 6.13$ (br s, 1H, NH), 7.73 (d, J=9.3 Hz, 4H, Ar-H), 8.16 (d, $J=9.3 \mathrm{~Hz}, 2 \mathrm{H}, \mathrm{Ar}-\mathrm{H}), 8.17(\mathrm{~d}, J=9.3 \mathrm{~Hz}, 2 \mathrm{H}, \mathrm{Ar}-\mathrm{H}), 8.63$ (br s, $1 \mathrm{H}, \mathrm{NH}), 8.75$ (br s, $1 \mathrm{H}, \mathrm{NH}) ;{ }^{13} \mathrm{C} \mathrm{NMR}$ $\left(100 \mathrm{MHz}, \mathrm{CDCl}_{3}\right) \delta 13.33\left(\mathrm{CH}_{3}\right), 17.28\left(\mathrm{CH}_{3}\right), 22.82\left(\mathrm{CH}_{3}\right), 24.34\left(\mathrm{CH}_{2}\right), 26.36\left(\mathrm{CH}_{2}\right), 26.88\left(\mathrm{CH}_{2}\right), 27.47$ $\left(\mathrm{CH}_{2}\right), 28.23(\mathrm{CH}), 30.74\left(\mathrm{CH}_{2}\right), 30.89\left(\mathrm{CH}_{2}\right), 32.95\left(\mathrm{CH}_{2}\right), 34.76(\mathrm{CH}), 35.50\left(\mathrm{CH}_{2}\right), 35.69(\mathrm{C}), 37.78(\mathrm{CH})$, $41.48(\mathrm{CH}), 43.65(\mathrm{CH}), 44.70(\mathrm{C}), 46.93(\mathrm{CH}), 48.54(\mathrm{CH}), 51.41\left(\mathrm{CH}_{3}\right), 52.96(\mathrm{CH}), 60.86(\mathrm{CH}), 117.05$ $(\mathrm{CH}), 117.21(\mathrm{CH}), 125.33(\mathrm{CH}), 125.73(\mathrm{CH}), 139.54(2 \times \mathrm{C}), 148.37(\mathrm{C}), 148.50(\mathrm{C}), 153.06(2 \times \mathrm{C})$, $174.31(\mathrm{C}) ; \mathrm{MS}\left(\mathrm{ES}^{+}\right) \mathrm{m} / \mathrm{z} 774.4[\mathrm{M}+\mathrm{H}]^{+}, 796.6[\mathrm{M}+\mathrm{Na}]^{+}$.

A 1 M solution of trimethylphosphine in THF $(312 \mu \mathrm{L}, 0.312 \mathrm{mmol}, 3$ equiv) was added to a suspension of azide $\mathbf{M}(80 \mathrm{mg}, 0.104 \mathrm{mmol})$ in dry THF $(1 \mathrm{~mL})$. The color of the reaction mixture changed from yellow to orange. After $45 \mathrm{~min}$, water $(36 \mu \mathrm{L}, 2 \mathrm{mmol})$ was added. The solution became clear and the color changed slowly to pale yellow. The reaction was left stirring overnight. The solvent was removed under reduced pressure. The crude mixture was dissolved in EtOAc and washed 3 times with a large amount of water. The organic phase was dried over $\mathrm{Na}_{2} \mathrm{SO}_{4}$. Removal of the solvent under reduced pressure gave the amine $\mathbf{N}$ as a yellow solid (76 mg, 97 \%): $\mathrm{R}_{f} 0.29$ (DCM-methanol, 88:12); IR (thin film) 3286, 2936, 2870, 1692, 1597, 1537, 1497, 1323, 1300,1204, 1175, 1108, 850, $750 \mathrm{~cm}^{-1} ;{ }^{1} \mathrm{H}$ NMR (400 MHz, CD $\left.3 \mathrm{OD}\right) \delta 0.92(\mathrm{~s}, 3 \mathrm{H}, 18-$ $\left.\mathrm{CH}_{3}\right), 0.93\left(\mathrm{~d}, J=4.9 \mathrm{~Hz}, 3 \mathrm{H}, 21-\mathrm{CH}_{3}\right), 1.07\left(\mathrm{~s}, 3 \mathrm{H}, 19 \mathrm{CH}_{3}\right), 2.82(\mathrm{~m}, 1 \mathrm{H}, 3 \beta-\mathrm{H}), 3.51\left(\mathrm{~s}, 3 \mathrm{H}, \mathrm{COOCH}_{3}\right)$, 3.96 (br s, 1H), 4.29 (br s, 1H), 7.38-8.2 (m, $10 \mathrm{Ar}-\mathrm{H} \& 2$ x NH); $\left.{ }^{13} \mathrm{C} \mathrm{NMR} \mathrm{(100} \mathrm{MHz,} \mathrm{CD}{ }_{3} \mathrm{OD}\right) \delta 13.97$ $\left(\mathrm{CH}_{3}\right), 18.08\left(\mathrm{CH}_{3}\right), 23.20\left(\mathrm{CH}_{3}\right), 24.39\left(\mathrm{CH}_{2}\right), 25.22(\mathrm{CH}), 28.07\left(\mathrm{CH}_{2}\right), 28.34\left(\mathrm{CH}_{2}\right), 31.78\left(\mathrm{CH}_{2}\right), 31.93$ $\left(\mathrm{CH}_{2}\right), 33.11\left(\mathrm{CH}_{2}\right), 35.81(\mathrm{C}), 36.11(\mathrm{CH}), 36.30\left(\mathrm{CH}_{2}\right), 36.90\left(\mathrm{CH}_{2}\right), 38.34(\mathrm{CH}), 42.93(\mathrm{CH}), 45.78(\mathrm{CH})$, $46.11(\mathrm{C}), 47.87(\mathrm{CH}), 49.80(\mathrm{CH}), 51.98\left(\mathrm{CH}_{3}\right), 52.41(\mathrm{CH}), 53.87(\mathrm{CH}), 118.07(\mathrm{CH}), 118.26(\mathrm{CH}), 125.85$ 
(CH), $125.95(\mathrm{CH}), 142.63(\mathrm{C}), 142.69(\mathrm{C}), 147.96(\mathrm{C}), 148.01(\mathrm{C}), 156.31(\mathrm{C}), 156.36(\mathrm{C}), 176.30(\mathrm{C}) ; \mathrm{MS}$ (FAB) $m / z 748.5[\mathrm{M}+\mathrm{H}]^{+}, 770.5[\mathrm{M}+\mathrm{Na}]^{+}$.

To a solution of amine $\mathbf{N}(62 \mathrm{mg}, 0.083 \mathrm{mmol})$ in dry DCM (1 mL) was added diisopropylethylamine (32 mg, $44 \mu \mathrm{L}, 0.25 \mathrm{mmol}, 3.01$ equiv), followed by drop-wise addition of freshly distilled trifluoroacetic anhydride ( $21 \mathrm{mg}, 14 \mu \mathrm{L}, 0.1 \mathrm{mmol}, 1.20$ equiv). The reaction was stirred for $1 \mathrm{~h}$ at room temperature and washed with a saturated solution of $\mathrm{NaHCO}_{3}$. The aqueous phase was extracted with DCM and the combined organic layers were dried over $\mathrm{Na}_{2} \mathrm{SO}_{4}$. The crude mixture was purified by flash chromatography (DCM-methanol, 88:12) and two close running spots were collected together. Several crystallizations from EtOAc at $4{ }^{\circ} \mathrm{C}$ gave the desired compound 10 (31 mg, $\left.44 \%\right): \mathrm{R}_{f}=0.19$ (DCM-methanol, 88:12); m.p. $258^{\circ} \mathrm{C}$ (EtOAc); IR (thin film) 3350, 2946, 2872, 1709, 1597, 1494, 1324, 1300, 1203, 1175, 1109, 1033, 1005, 849, $751 \mathrm{~cm}^{-1} ;{ }^{1} \mathrm{H} \mathrm{NMR}\left(400 \mathrm{MHz},\left(\mathrm{CD}_{3}\right)_{2} \mathrm{CO}\right) \delta 0.85\left(\mathrm{~d}, J=6.6 \mathrm{~Hz}, 3 \mathrm{H}, 21-\mathrm{CH}_{3}\right), 0.91\left(\mathrm{~s}, 3 \mathrm{H}, 18-\mathrm{CH}_{3}\right), 1.09(\mathrm{~s}$, $\left.3 \mathrm{H}, 19-\mathrm{CH}_{3}\right), 3.47(\mathrm{~m}, 1 \mathrm{H}, 3 \beta-\mathrm{H}), 3.54\left(\mathrm{~s}, 3 \mathrm{H}, \mathrm{COOCH}_{3}\right), 4.07(\mathrm{~m}, 1 \mathrm{H}, 7 \beta-\mathrm{H}), 4.17$ (m, 1H, $\left.12 \beta-\mathrm{H}\right), 6.06$ (br s, $1 \mathrm{H}, \mathrm{NH}), 6.12$ (br s, 1H, NH), 7.68 (d, $J=9.2 \mathrm{~Hz}, 2 \mathrm{H}, \mathrm{Ar}-\mathrm{H}), 7.72(\mathrm{~d}, J=9.3 \mathrm{~Hz}, 2 \mathrm{H}, \operatorname{Ar}-\mathrm{H}), 7.83$ (br s, 1H, NH), 8.15 (d, J=9.1 Hz, 4H, Ar-H), 8.40 (br s, $1 \mathrm{H}, \mathrm{NH}), 8.70$ (br s, $1 \mathrm{H}, \mathrm{NH}) ;{ }^{13} \mathrm{C} \mathrm{NMR}(100 \mathrm{MHz}$, $\left.\left(\mathrm{CD}_{3}\right)_{2} \mathrm{CO}\right) \delta 13.88\left(\mathrm{CH}_{3}\right), 17.87\left(\mathrm{CH}_{3}\right), 23.17\left(\mathrm{CH}_{3}\right), 24.03\left(\mathrm{CH}_{2}\right), 27.27\left(\mathrm{CH}_{2}\right), 27.45\left(\mathrm{CH}_{2}\right), 27.99\left(\mathrm{CH}_{2}\right)$, $31.37\left(\mathrm{CH}_{2}\right), 31.58\left(\mathrm{CH}_{2}\right), 32.99(\mathrm{C}), 35.51\left(\mathrm{CH}_{2}\right), 35.65(\mathrm{CH}), 35.74(\mathrm{CH}), 36.31\left(\mathrm{CH}_{2}\right), 38.03(\mathrm{CH}), 42.67$ $(\mathrm{CH}), 45.37(\mathrm{CH}), 45.67(\mathrm{C}), 47.34(\mathrm{CH}), 48.10\left(\mathrm{CH}_{2}\right), 49.14(\mathrm{CH}), 51.47\left(\mathrm{CH}_{3}\right), 51.70(\mathrm{CH}), 53.43(\mathrm{CH})$, $117.62(\mathrm{CH}), 125.81(\mathrm{CH}), 142.01(\mathrm{C}), 148.26(\mathrm{C}), 148.37(\mathrm{C}), 154.55(\mathrm{C}), 154.60(\mathrm{C}), 154.80(\mathrm{C}), 174.45$ (C); MS $\left(\mathrm{ES}^{+}\right) \mathrm{m} / \mathrm{z} 844.7[\mathrm{M}+\mathrm{H}]^{+}, 866.5[\mathrm{M}+\mathrm{Na}]^{+}$; Anal. Calcd for $\mathrm{C}_{41} \mathrm{H}_{52} \mathrm{~F}_{3} \mathrm{~N}_{7} \mathrm{O}_{9} .2 \mathrm{H}_{2} \mathrm{O}: \mathrm{C}, 55.96 ; \mathrm{H}$, 6.41; N, 11.14. Found: C, 55.77; H, 6.15; N, 10.91. 

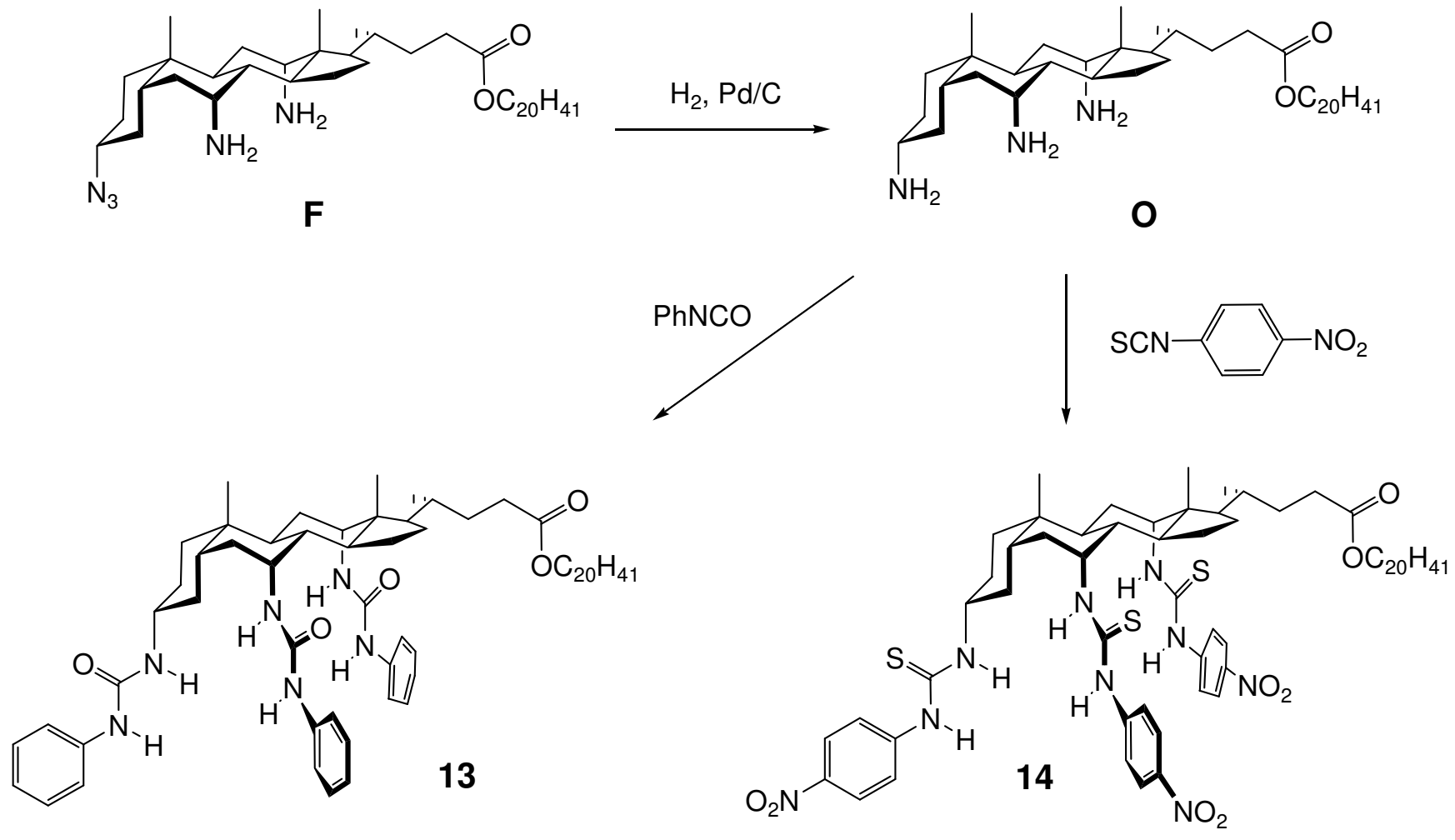

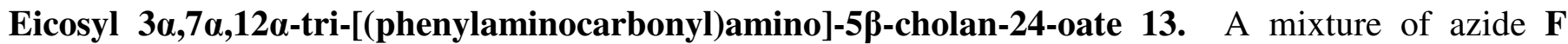
(124 mg, $0.174 \mathrm{mmol}), \mathrm{Pd} / \mathrm{C}(10 \%$ on weight, $50 \%$ water) $(20 \mathrm{mg})$ in methanol was stirred at room temperature for $24 \mathrm{~h}$ under hydrogen $(1 \mathrm{~atm})$. The catalyst was filtered over celite and the solvent was removed under reduced pressure to yield triamine $\mathbf{O}$ (119 mg, $100 \%$ ): IR (thin film) 3275, 2917, 2850, 1737 , 1579, 1446, 1375, $1170 \mathrm{~cm}^{-1} ;{ }^{1} \mathrm{H}$ NMR $\left(400 \mathrm{MHz},\left(\mathrm{CD}_{3}\right)_{2} \mathrm{CO}\right) \delta 0.72\left(\mathrm{~s}, 3 \mathrm{H}, 18-\mathrm{CH}_{3}\right), 0.88(\mathrm{t}, J=5.4 \mathrm{~Hz}$, 3H, eicosyl $\left.\mathrm{CH}_{3}\right), 0.91\left(\mathrm{~s}, 3 \mathrm{H}, 19-\mathrm{CH}_{3}\right), 0.97\left(\mathrm{~d}, J=5.4 \mathrm{~Hz}, 3 \mathrm{H}, 21-\mathrm{CH}_{3}\right), 1.26\left(\mathrm{~m}, 36 \mathrm{H}\right.$, eicosyl $\left.\mathrm{CH}_{2}\right), 2.52$ (m, 1H, 3ß-H), $3.06(\mathrm{~m}, 1 \mathrm{H}), 3.17(\mathrm{~m}, 1 \mathrm{H}), 4.05\left(\mathrm{t}, J=6.4 \mathrm{~Hz}, 2 \mathrm{H}, \mathrm{OCH}_{2}\right)$; MS (FAB) $\mathrm{m} / \mathrm{z} 686.8[\mathrm{M}+\mathrm{H}]^{+}$.

To a stirred solution of triamine $\mathbf{O}(58 \mathrm{mg}, 0.084 \mathrm{mmol})$ in dry THF $(2 \mathrm{~mL})$ was added freshly distilled phenyl isocyanate ( $45 \mathrm{mg}, 42 \mu \mathrm{L}, 0.38 \mathrm{mmol}, 4.5$ equiv). The reaction was stirred overnight. The solvent was removed under reduced pressure and the crude residue was purified by flash chromatography (DCMEtOAc, 49:1 - 4:1). This gave 13 as an amorphous colorless glass (66 mg, $75 \%$ ): $\mathrm{R}_{f} 0.30$ (DCM-methanol, 9:1); IR (thin film) 3333, 2922, 2853, 1735, 1666, 1597, 1543, 1498, 1440, 1309, 1258, 1234, 1175, 1093, 1017, 798, 749, $692 \mathrm{~cm}^{-1} ;{ }^{1} \mathrm{H}$ NMR (400 MHz, $\left.\mathrm{CO}\left(\mathrm{CD}_{3}\right)_{2}\right) \delta 0.85-0.91(\mathrm{~m}, 9 \mathrm{H}), 1.01(\mathrm{~s}, 3 \mathrm{H}), 1.29(\mathrm{~m}, 36 \mathrm{H}$, 
eicosyl $\left.\mathrm{CH}_{2}\right), 3.23(\mathrm{~m}, 1 \mathrm{H}, 3 \beta-\mathrm{H}), 3.99\left(\mathrm{t}, J=6.6 \mathrm{~Hz}, 2 \mathrm{H}, \mathrm{OCH}_{2}\right), 4.03(\mathrm{~m}, 1 \mathrm{H}, 7 \beta-\mathrm{H}), 4.15(\mathrm{~m}, 1 \mathrm{H}, 12 \beta-\mathrm{H})$, $5.49($ br d, $J=5.4 \mathrm{~Hz}, 1 \mathrm{H}, \mathrm{NH}), 5.81(\mathrm{br} \mathrm{s}, 1 \mathrm{H}, \mathrm{NH}), 5.87$ (br d, $J=7.8 \mathrm{~Hz}, 1 \mathrm{H}, \mathrm{NH}), 6.85(\mathrm{t}, J=7.3 \mathrm{~Hz}, 1 \mathrm{H}$, Ar-H), $6.90(\mathrm{t}, J=7.3 \mathrm{~Hz}, 2 \mathrm{H}, \mathrm{Ar}-\mathrm{H}), 7.14-7.25(\mathrm{~m}, 6 \mathrm{H}, \mathrm{Ar}-\mathrm{H}), 7.38(\mathrm{~d}, J=7.6 \mathrm{~Hz}, 2 \mathrm{H}, \mathrm{Ar}-\mathrm{H}), 7.46$ (d, $J=7.8 \mathrm{~Hz}, 2 \mathrm{H}, \mathrm{Ar}-\mathrm{H}), 7.50(\mathrm{~d}, J=7.8 \mathrm{~Hz}, 2 \mathrm{H}, \mathrm{Ar}-\mathrm{H}), 7.79$ (br s, 1H, NH), $7.91(\mathrm{~s}, 1 \mathrm{H}, \mathrm{NH}), 8.05(\mathrm{~s}, 1 \mathrm{H}$, $\mathrm{NH}) ;{ }^{13} \mathrm{C}$ NMR $\left(100 \mathrm{MHz}, \mathrm{CO}\left(\mathrm{CD}_{3}\right)_{2}\right) \delta 14.12\left(\mathrm{CH}_{3}\right), 14.38\left(\mathrm{CH}_{3}\right), 17.56\left(\mathrm{CH}_{3}\right), 23.32\left(\mathrm{CH}_{2}\right), 23.60\left(\mathrm{CH}_{3}\right)$, $24.10\left(\mathrm{CH}_{2}\right), 26.65\left(\mathrm{CH}_{2}\right), 27.57\left(\mathrm{CH}_{2}\right), 27.98\left(\mathrm{CH}_{2}\right), 28.51\left(\mathrm{CH}_{2}\right), 29.43\left(\mathrm{CH}_{2}\right), 29.64(\mathrm{CH}), 29.96\left(\mathrm{CH}_{2}\right)$, $30.07\left(\mathrm{CH}_{2}\right), 30.26\left(\mathrm{CH}_{2}\right), 30.30\left(\mathrm{CH}_{2}\right), 30.36\left(\mathrm{CH}_{2}\right), 30.40\left(\mathrm{CH}_{2}\right), 31.60\left(\mathrm{CH}_{2}\right), 31.70\left(\mathrm{CH}_{2}\right), 32.62\left(\mathrm{CH}_{2}\right)$, $33.68\left(\mathrm{CH}_{2}\right), 35.55(\mathrm{CH}), 35.81(\mathrm{C}), 36.68\left(\mathrm{CH}_{2}\right), 37.32\left(\mathrm{CH}_{2}\right), 37.36\left(\mathrm{CH}_{2}\right), 38.27(\mathrm{CH}), 42.90(\mathrm{CH}), 45.44$ $(\mathrm{CH}), 45.59(\mathrm{C}), 47.03(\mathrm{CH}), 49.09(\mathrm{CH}), 52.32(\mathrm{CH}), 53.58(\mathrm{CH}), 64.60\left(\mathrm{CH}_{2}\right), 118.65(\mathrm{CH}), 118.91(\mathrm{CH})$, $119.15(\mathrm{CH}), 122.09(\mathrm{CH}), 122.21(\mathrm{CH}), 122.37(\mathrm{CH}), 129.44(\mathrm{CH}), 129.47(\mathrm{CH}), 129.50(\mathrm{CH}), 141.24(\mathrm{C})$, 141.58 (C), 141.72 (C), 155.63 (C), 155.50 (C), 155.95 (C), 173.99 (C); MS (FAB) m/z 1066 [M + Na] Anal. Calcd for $\mathrm{C}_{65} \mathrm{H}_{98} \mathrm{~N}_{6} \mathrm{O}_{5}:$ C, 74.81; H, 9.47; N, 8.05. Found: C, 74.72; H, 9.80; N, 8.06.

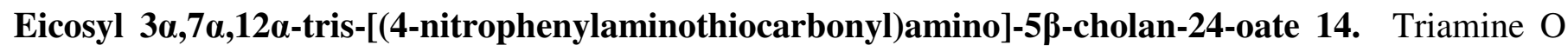
was obtained as described above. To a solution of $\mathbf{O}(106 \mathrm{mg}, 0.155 \mathrm{mmol})$ in dry THF ( $3.5 \mathrm{~mL})$ was added 4-nitrophenyl isothiocyanate $(111 \mathrm{mg}, 0.618 \mathrm{mmol}, 4$ equiv). The reaction was stirred for $20 \mathrm{~h}$ at room temperature. The solvent was removed under reduced pressure and the residue was purified by flash chromatography (DCM-EtOAc, 1:0 - 9:1). This gave the desired compound 14 as a dark yellow solid (128 mg, $67 \%$ ): $\mathrm{R}_{f} 0.23$ (DCM-methanol, 9:1); IR (thin film) 3367, 3329, 2921, 2852, 1735, 1595, 1494, 1321, 1295, 1242, 1203, 1174, 1109, $847 \mathrm{~cm}^{-1} ;{ }^{1} \mathrm{H}$ NMR (400 MHz, $\left.\left(\mathrm{CD}_{3}\right)_{2} \mathrm{CO}\right) \delta 0.85-0.96(\mathrm{~m}, 12 \mathrm{H}, 18-$ $\mathrm{CH}_{3}, 19-\mathrm{CH}_{3}, 21-\mathrm{CH}_{3}$, eicosyl $\left.\mathrm{CH}_{3}\right), 1.28\left(\mathrm{~m}, 36 \mathrm{H}\right.$, eicosyl $\left.\mathrm{CH}_{2}\right), 4.00$ (br s, $\left.1 \mathrm{H}, 3 \beta-\mathrm{H}\right), 4.00$ (t, $J=6.6 \mathrm{~Hz}$,

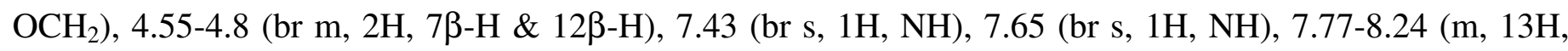
Ar-H \& NH), 9.16 (br s, 1H, NH), 9.30 (br s, $1 \mathrm{H}, \mathrm{NH}), 9.60$ (br s, $1 \mathrm{H}, \mathrm{NH}) ;{ }^{1} \mathrm{H}$ NMR $\left(400 \mathrm{MHz},\left(\mathrm{CD}_{3}\right)_{2} \mathrm{CO}\right)$ \& excess $\left.\mathrm{Et}_{4} \mathrm{~N}^{+} \mathrm{Cl}\right) \delta 0.87\left(\mathrm{t}, J=6.8 \mathrm{~Hz}, 3 \mathrm{H}\right.$, eicosyl $\left.\mathrm{CH}_{3}\right), 0.91\left(\mathrm{~s}, 3 \mathrm{H}, 18-\mathrm{CH}_{3}\right), 1.03(\mathrm{~d}, J=6.6 \mathrm{~Hz}, 3 \mathrm{H}, 21-$ $\left.\mathrm{CH}_{3}\right), 1.07\left(\mathrm{~s}, 3 \mathrm{H}, 19-\mathrm{CH}_{3}\right), 1.28\left(\mathrm{~m}, 36 \mathrm{H}\right.$, eicosyl $\left.\mathrm{CH}_{2}\right), 1.34\left(\mathrm{tt}, J=7.1 \mathrm{~Hz}, J=1.9 \mathrm{~Hz}, \mathrm{Et}_{4} \mathrm{~N}^{+}-\mathrm{CH}_{3}\right), 3.47(\mathrm{q}$, 
$\left.J=7.1 \mathrm{~Hz}, \mathrm{Et}_{4} \mathrm{~N}^{+}-\mathrm{CH}_{2}\right), 4.02\left(\mathrm{t}, J=6.6 \mathrm{~Hz}, \mathrm{OCH}_{2}\right), 4.02(\mathrm{~m}, 1 \mathrm{H}, 3 \beta-\mathrm{H}), 4.46(\mathrm{~m}, 1 \mathrm{H}), 4.92(\mathrm{~m}, 1 \mathrm{H}), 8.09(\mathrm{~d}$, $J=8.6 \mathrm{~Hz}, 2 \mathrm{H}, \mathrm{Ar}-\mathrm{H}), 8.13(\mathrm{~d}, J=9.3 \mathrm{~Hz}, 2 \mathrm{H}, \mathrm{Ar}-\mathrm{H}), 8.21(\mathrm{~d}, J=9.0 \mathrm{~Hz}, 2 \mathrm{H}, \mathrm{Ar}-\mathrm{H}), 8.30-8.39(\mathrm{~m}, 6 \mathrm{H}, \mathrm{Ar}-$ H), 8.94 (br s, 1H, NH), 9.04 (br s, 1H, NH), 9.15 (br s, 1H, NH), 10.84 (br s, 1H, NH), 11.15 (br s, 1H, NH), $12.28($ br s, $1 \mathrm{H}, \mathrm{NH}) ;{ }^{1} \mathrm{H}$ NMR $\left(400 \mathrm{MHz}, \mathrm{CDCl}_{3} \&\right.$ excess $\left.\mathrm{Et}_{4} \mathrm{~N}^{+} \mathrm{Cl}\right) \delta 0.85$ (s, 3H, 18- $\left.\mathrm{CH}_{3}\right), 0.87(\mathrm{t}$, $J=6.6 \mathrm{~Hz}, 3 \mathrm{H}$, eicosyl $\left.\mathrm{CH}_{3}\right), 0.99\left(\mathrm{~s}, 3 \mathrm{H}, 19-\mathrm{CH}_{3}\right), 1.00\left(\mathrm{~d}, J=6.1 \mathrm{~Hz}, 3 \mathrm{H}, 21-\mathrm{CH}_{3}\right), 1.24(\mathrm{~m}, 36 \mathrm{H}$, eicosyl $\left.\mathrm{CH}_{2}\right), 1.28\left(\mathrm{t}, J=7.3 \mathrm{~Hz}, \mathrm{Et}_{4} \mathrm{~N}^{+}-\mathrm{CH}_{3}\right), 3.27$ (q, $\left.J=7.3 \mathrm{~Hz}, \mathrm{Et}_{4} \mathrm{~N}^{+}-\mathrm{CH}_{2}\right), 4.00$ (t, $\left.J=6.6 \mathrm{~Hz}, 2 \mathrm{H}, \mathrm{OCH}_{2}\right), 4.11$ (m, 1H, 3ß-H), $4.42(\mathrm{~m}, 1 \mathrm{H}), 4.90(\mathrm{~m}, 1 \mathrm{H}), 7.95-8.30(\mathrm{~m}, 13 \mathrm{H}$, Ar-H \& NH), 8.43 (br d, $J=9.8 \mathrm{~Hz}, 1 \mathrm{H}$, $\mathrm{NH}), 8.86$ (br d, $J=7.6 \mathrm{~Hz}, 1 \mathrm{H}, \mathrm{NH}), 10.51$ (br s, 2H, 2 x NH), 10.67 (br s, $1 \mathrm{H}, \mathrm{NH}) ;{ }^{13} \mathrm{C} \mathrm{NMR}(100 \mathrm{MHz}$, $\left.\mathrm{CO}\left(\mathrm{CD}_{3}\right)_{2}\right) \delta 13.97\left(\mathrm{CH}_{3}\right), 14.37\left(\mathrm{CH}_{3}\right), 17.92\left(\mathrm{CH}_{3}\right), 23.32\left(\mathrm{CH}_{2}\right), 23.39\left(\mathrm{CH}_{3}\right), 24.16\left(\mathrm{CH}_{2}\right), 25.75\left(\mathrm{CH}_{2}\right)$, $26.67\left(\mathrm{CH}_{2}\right), 27.88\left(\mathrm{CH}_{2}\right), 29.44\left(\mathrm{CH}_{2}\right), 29.92\left(\mathrm{CH}_{2}\right), 30.06\left(\mathrm{CH}_{2}\right), 30.39\left(\mathrm{CH}_{2}\right), 30.45\left(\mathrm{CH}_{2}\right), 31.61\left(\mathrm{CH}_{2}\right)$, $31.67\left(\mathrm{CH}_{2}\right), 32.63\left(\mathrm{CH}_{2}\right), 35.37(\mathrm{CH}), 36.23(\mathrm{C}), 36.34(\mathrm{CH}), 37.88(\mathrm{CH}), 42.48(\mathrm{CH}), 42.59(\mathrm{CH}), 45.77$ (C), $49.40(\mathrm{CH}), 51.35(\mathrm{CH}), 55.61(\mathrm{CH}), 57.67(\mathrm{CH}), 64.68\left(\mathrm{CH}_{2}\right), 120.99(\mathrm{CH}), 121.09(\mathrm{CH}), 121.82(\mathrm{CH})$, $125.63(\mathrm{CH}), 143.39$ (C), 143.73 (C), 147.00 (C), 147.61 (C), 174.04 (C), 180.33 (C x 2), 180.49 (C); MS $\left(\mathrm{ES}^{+}\right) \mathrm{m} / \mathrm{z} 1248.9[\mathrm{M}+\mathrm{Na}]^{+}$; Anal. Calcd for $\mathrm{C}_{65} \mathrm{H}_{95} \mathrm{~N}_{9} \mathrm{O}_{8} \mathrm{~S}_{3}: \mathrm{C}, 63.64 ; \mathrm{H}, 7.81$. Found: C, 63.30; H, 8.05. 


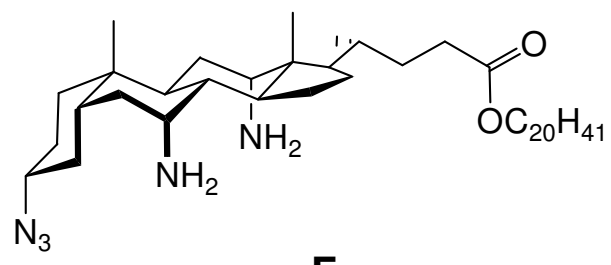

$\mathbf{F}$

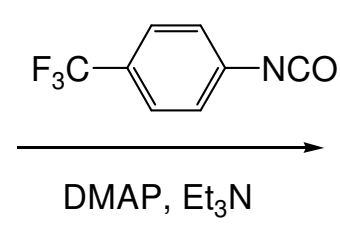

i, $\mathrm{Me}_{3} \mathrm{P}$
ii, $\mathrm{H}_{2} \mathrm{O}$
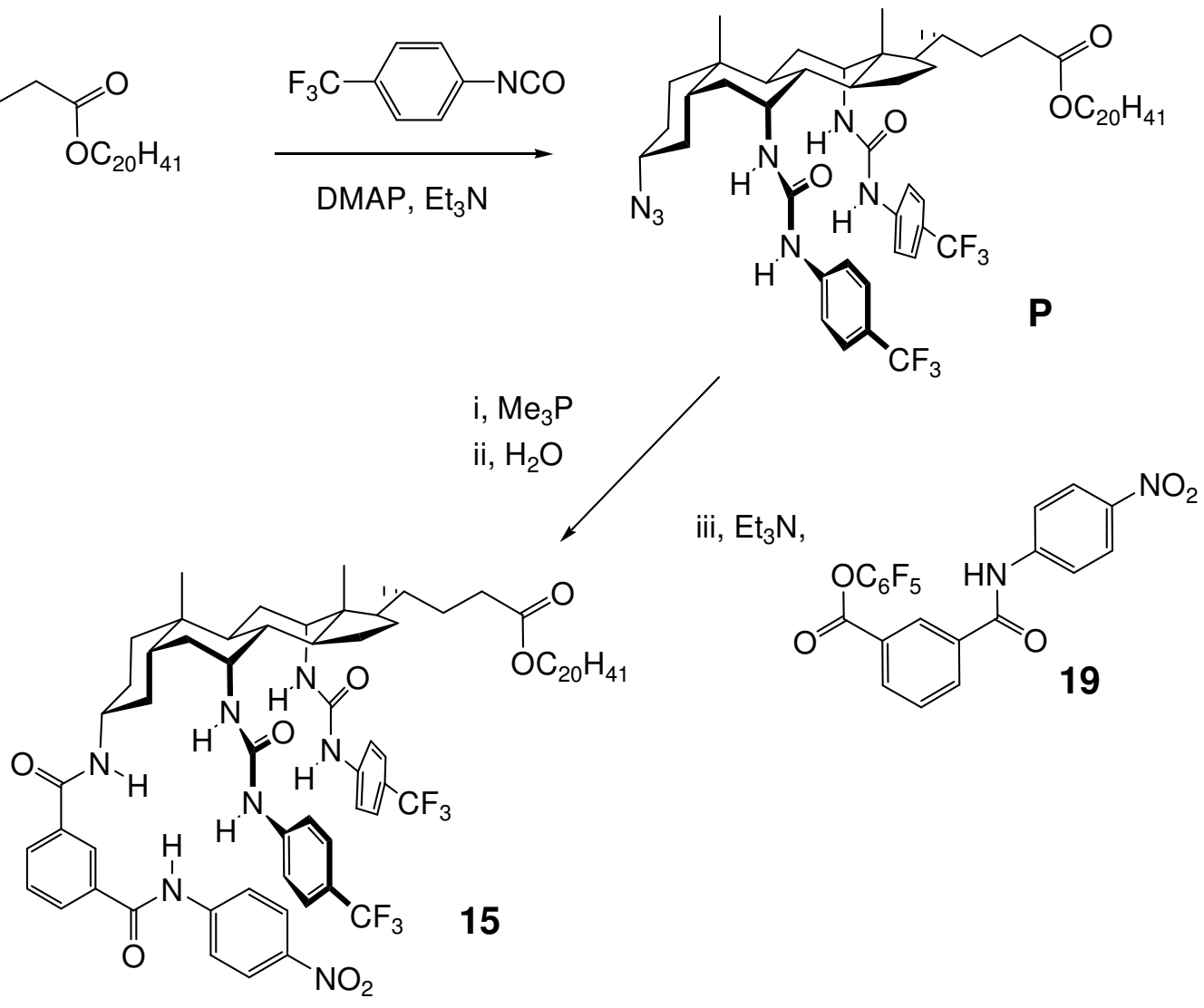

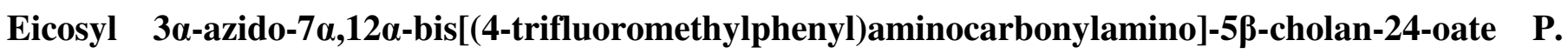

To a solution of diamine $\mathbf{F}(700 \mathrm{mg}, 0.99 \mathrm{mmol})$ in dry DCM $(35 \mathrm{~mL})$ was added DMAP $(70 \mathrm{mg}$, $0.57 \mathrm{mmol}, 0.58$ equiv), triethylamine ( $290 \mu \mathrm{L}, 208 \mathrm{mg}, 2.05 \mathrm{mmol}, 2.07$ equiv) and 4-trifluoromethylphenyl isocyanate ( $290 \mu \mathrm{L}, 380 \mathrm{mg}, 2.05 \mathrm{mmol}, 2.07$ equiv) and the solution was stirred for 5 days. The reaction solution was washed with $5 \%$ aq. $\mathrm{NaHCO}_{3}$, dried over $\mathrm{MgSO}_{4}$ and the solvent was evaporated under reduced pressure. Purification of the dry residue by flash chromatography (hexane-EtOAc, 9:1 - 1:1) gave bisurea $\mathbf{P}$ as a white solid (0.89 g, $83 \%$ ): $\mathbf{R}_{f} 0.30$ (hexane-EtOAc, 4:1); IR (thin film) 3389, 2925, 2096, $1680,1656,1544,1164,1117,740 \mathrm{~cm}^{-1} ;{ }^{1} \mathrm{H}$ NMR $\left(400 \mathrm{MHz}, \mathrm{CDCl}_{3}\right) \delta 0.80\left(\mathrm{~s}, 3 \mathrm{H}, 18-\mathrm{CH}_{3}\right), 0.89(\mathrm{t}, 3 \mathrm{H}$, $\left.J=6.6 \mathrm{~Hz}, 20^{\prime}-\mathrm{CH}_{3}\right), 0.90\left(\mathrm{~d}, 3 \mathrm{H}, J=6.0 \mathrm{~Hz}, 21-\mathrm{CH}_{3}\right), 0.97\left(\mathrm{~s}, 3 \mathrm{H}, 19-\mathrm{CH}_{3}\right), 1.27(\mathrm{~s}, 34 \mathrm{H}), 2.08(\mathrm{~m}, 1 \mathrm{H})$,

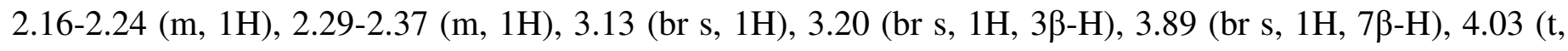
$2 \mathrm{H}, J$ 6.8, 1'- $\mathrm{CH}_{2}$ ), 4.08 (br s, 1H, 12ß-H), 5.48 (br s, 1H, NH), 5.63 (br s, 1H, NH), 7.16 (br s, 1H, NH), $7.27($ br s, $1 \mathrm{H}, \mathrm{NH}), 7.45-7.51\left(\mathrm{~m}, 8 \mathrm{H}, \mathrm{C}_{6} \mathrm{H}_{5}\right) ;{ }^{13} \mathrm{C} \mathrm{NMR}\left(100 \mathrm{MHz}, \mathrm{CDCl}_{3}\right) \delta 13.55\left(18-\mathrm{CH}_{3}\right), 14.07$ 
(20’- $\left.\mathrm{CH}_{3}\right), 17.33\left(21-\mathrm{CH}_{3}\right), 22.66\left(19^{\prime}-\mathrm{CH}_{2}\right), 22.78\left(19-\mathrm{CH}_{3}\right), 23.30\left(\mathrm{CH}_{2}\right), 25.87\left(18^{\prime}-\mathrm{CH}_{2}\right), 26.42\left(\mathrm{CH}_{2}\right)$, $26.92\left(\mathrm{CH}_{2}\right), 27.10\left(\mathrm{CH}_{2}\right), 28.54\left(17^{\prime}-\mathrm{CH}_{2}\right), 28.66(\mathrm{CH}), 29.23\left(16^{\prime}-\mathrm{CH}_{2}\right), 29.34\left(15^{\prime}-\mathrm{CH}_{2}\right), 29.49\left(14^{\prime}-\mathrm{CH}_{2}\right)$, 29.57 (13'- $\left.-\mathrm{CH}_{2}\right), 29.64\left(12^{\prime}-\mathrm{CH}_{2}\right), 29.69\left(\mathrm{CH}_{2}\right), 30.75\left(\mathrm{CH}_{2}\right), 31.45\left(\mathrm{CH}_{2}\right), 31.91\left(2^{\prime}-\mathrm{CH}_{2}\right), 32.12\left(\mathrm{CH}_{2}\right)$, $34.71(\mathrm{CH}), 34.84(10-\mathrm{C}), 34.98\left(\mathrm{CH}_{2}\right), 35.72\left(\mathrm{CH}_{2}\right), 37.26(\mathrm{CH}), 41.35(\mathrm{CH}), 44.44(\mathrm{CH}), 44.98(13-\mathrm{C})$, $47.65(\mathrm{CH}), 48.59$ (7-CH), $53.41(12-\mathrm{CH}), 61.29$ (3-CH), $65.03\left(1\right.$ '- $\left.\mathrm{CH}_{2}\right), 118.32$ (Ar-CH), $118.86(\mathrm{Ar}-\mathrm{CH})$, $122.22\left(\mathrm{CF}_{3}\right), 125.50$ (Ar-C), 126.25 (Ar-CH), $126.50($ Ar-CH), 142.18 (Ar-C), 154.62 (urea C=O), 156.61 (urea $\mathrm{C}=\mathrm{O}$ ), 174.97 (C); Anal. Calcd for $\mathrm{C}_{60} \mathrm{H}_{89} \mathrm{~F}_{6} \mathrm{~N}_{7} \mathrm{O}_{4} \cdot \mathrm{H}_{2} \mathrm{O}: \mathrm{C}, 65.25 ; \mathrm{H}, 8.31 ; \mathrm{N}, 8.88$. Found: C, 65.65; H, $8.22 ; \mathrm{N}, 8.84$.

\section{Eicosyl}

\section{3 $\alpha$-[3(4-nitrophenylcarbamoyl)benzamido]-7 $\alpha, 12 \alpha$-bis[(4-trifluoro-}

methylphenyl)carbamoylamino]-5 $\beta$-cholan-24-oate (15). To a solution of azide bisurea $\mathbf{P}$ (120 mg, $0.115 \mathrm{mmol})$ in dry THF $(2.0 \mathrm{~mL})$ was added trimethylphosphine $(1.0 \mathrm{M}$ solution in THF, $0.14 \mathrm{~mL}$, $0.14 \mathrm{mmol}, 1.2$ equiv) under nitrogen at room temperature. The solution was stirred for $2 \mathrm{~h}$ after which water (41 $\mu \mathrm{L}, 20$ equiv) was added. The solution was stirred at room temperature for a further $4 \mathrm{~h}$ after which the solvent was removed under reduced pressure. The free amine was evaporated from toluene $(2 \times 2 \mathrm{~mL})$, followed by DCM (3 x $2 \mathrm{~mL})$. It was then dissolved in dry THF (2.0 mL) and pentafluorophenyl ester 19 (78 mg, $0.17 \mathrm{mmol}, 1.5$ equiv) and triethylamine (64 $\mu \mathrm{L} 0.46 \mathrm{mmol}, 4$ equiv) were added. The solution was stirred overnight at room temperature under nitrogen. The solvent was removed under reduced pressure. Flash chromatography (DCM-methanol, 99:1 - 20:1) gave the receptor 15 as a pale yellow solid (111 mg, $0.084 \mathrm{mmol}, 73 \%): R_{\mathrm{f}} 0.2$ (DCM-methanol, 9:1); IR (thin film) $1684(\mathrm{C}=\mathrm{O}), 1533\left(\mathrm{NO}_{2}\right), 1324\left(\mathrm{NO}_{2}\right) \mathrm{cm}^{-1}$; ${ }^{1} \mathrm{H}$ NMR $\left(400.18 \mathrm{MHz}, \mathrm{CDCl}_{3} \& 1.3\right.$ equiv $\left.\mathrm{Et}_{4} \mathrm{~N}^{+} \mathrm{Cl}\right) \delta 0.85\left(\mathrm{~s}, 3 \mathrm{H}, 18-\mathrm{CH}_{3}\right), 0.86(\mathrm{t}, J=6.5 \mathrm{~Hz}, 3 \mathrm{H}$, eicosyl $\left.\mathrm{CH}_{3}\right), 0.99\left(\mathrm{~s}, 3 \mathrm{H}, 19-\mathrm{CH}_{3}\right), 1.06\left(\mathrm{~d}, J=6.5 \mathrm{~Hz}, 3 \mathrm{H}, 21-\mathrm{CH}_{3}\right), 1.24\left(\mathrm{~m}, \sim 36 \mathrm{H}\right.$, eicosyl $\left.\mathrm{C}_{18} \mathrm{H}_{36}\right), 1.35(\mathrm{~m}$; $\left.\mathrm{Et}_{4} \mathrm{~N}^{+} \mathrm{CH}_{3}\right), 2.22(\mathrm{~m}, 2 \mathrm{H}), 2.35(\mathrm{~m}, 1 \mathrm{H}), 2.57(\mathrm{~m}, 1 \mathrm{H}), 3.41\left(\mathrm{q}, J=7.0 \mathrm{~Hz}, \mathrm{Et}_{4} \mathrm{~N}^{+} \mathrm{CH}_{2}\right), 3.98(\mathrm{~m}, 2 \mathrm{H}, 3 \beta-\mathrm{H} \&$ $7 \beta-\mathrm{H}), 4.02\left(\mathrm{t}, J=7.0 \mathrm{~Hz}, 2 \mathrm{H}\right.$, eicosyl $\left.\mathrm{OCH}_{2}\right), 4.35(\mathrm{~d}, J=10.5 \mathrm{~Hz}, 1 \mathrm{H}, 12 \beta-\mathrm{H}), 6.24(\mathrm{~d}, J=10.5 \mathrm{~Hz}, 1 \mathrm{H}$, $12 \alpha-\mathrm{NH}), 6.93(\mathrm{~d}, J=8.5 \mathrm{~Hz}, 1 \mathrm{H}, 7 \alpha-\mathrm{NH}), 7.15(\mathrm{~d}, J=8.5 \mathrm{~Hz}, 2 \mathrm{H}, 2$ x Ar-H), $7.21(\mathrm{~d}, J=9.0 \mathrm{~Hz}, 2 \mathrm{H}, 2 \mathrm{x}$ 
Ar-H), $7.46(\mathrm{~d}, J=8.0 \mathrm{~Hz}, 2 \mathrm{H}, 2$ x Ar-H), $7.47(\mathrm{~d}, J=8.0 \mathrm{~Hz}, 2 \mathrm{H}, 2$ x Ar-H), 7.63 (t, $J=7.5 \mathrm{~Hz}, 1 \mathrm{H}, \mathrm{Ar}-\mathrm{H})$, $7.75(\mathrm{~d}, J=9.0 \mathrm{~Hz}, 1 \mathrm{H}, 3 \alpha-\mathrm{NH}), 8.25(\mathrm{~m}, 3 \mathrm{H}, 3 \mathrm{x} \mathrm{Ar}-\mathrm{H}), 8.37(\mathrm{~d}, J=7.5 \mathrm{~Hz}, 1 \mathrm{H}, \mathrm{Ar}-\mathrm{H}), 8.53(\mathrm{~m}, 2 \mathrm{H}, 2 \mathrm{x}$ Ar-H), 8.68 (s, 1H, urea NH), 8.96 (s, 1H, Ar-H), 9.09 (s, 1H, urea NH), 10.54 (3-anilide NH); ${ }^{13} \mathrm{C}$ NMR $\left(100.635 \mathrm{MHz}, \mathrm{CDCl}_{3}\right) \delta 7.55\left(\mathrm{Et}_{4} \mathrm{~N}^{+} \mathrm{CH}_{3}\right), 13.64(\mathrm{C}-18), 14.12\left(\right.$ eicosyl $\left.\mathrm{CH}_{3}\right), 17.77(\mathrm{C}-21), 22.20(\mathrm{C}-19)$, $22.69\left(\mathrm{CH}_{2}\right), 23.50\left(\mathrm{CH}_{2}\right), 25.94\left(\mathrm{CH}_{2}\right), 26.40\left(\mathrm{CH}_{2}\right), 26.92\left(\mathrm{CH}_{2}\right), 27.61\left(\mathrm{CH}_{2}\right), 28.59(\mathrm{CH}), 28.64\left(\mathrm{CH}_{2}\right)$, $29.27\left(\mathrm{CH}_{2}\right), 29.36\left(\mathrm{CH}_{2}\right), 29.54\left(\mathrm{CH}_{2}\right), 29.61\left(\mathrm{CH}_{2}\right), 29.66\left(\mathrm{CH}_{2}\right), 29.70\left(\mathrm{CH}_{2}\right), 30.92\left(\mathrm{CH}_{2}\right), 30.99\left(\mathrm{CH}_{2}\right)$, $31.68\left(\mathrm{CH}_{2}\right), 31.82\left(\mathrm{CH}_{2}\right), 31.92\left(\mathrm{CH}_{2}\right), 34.29,34.51\left(\mathrm{CH}_{2}\right), 35.35(\mathrm{CH}), 35.58\left(\mathrm{CH}_{2}\right), 37.07(\mathrm{CH}), 41.20$ $(\mathrm{CH}), 44.69,44.71(\mathrm{CH}), 46.44(\mathrm{CH}), 48.12(\mathrm{CH}), 48.32(\mathrm{CH}), 52.24(\mathrm{C}-12), 52.67\left(\mathrm{t}, J_{\mathrm{C}, \mathrm{N}}=3.0 \mathrm{~Hz}, \mathrm{Et}_{4} \mathrm{~N}^{+}\right.$ $\mathrm{CH}_{2}$ ), 64.45 (eicosyl $\mathrm{OCH}_{2}$ ), 117.18 (urea ArC-2), 117.47 (urea ArC-2), 120.92 (3-N-ArC-3), 129.41 (d, $J_{\mathrm{C}, \mathrm{F}}=36 \mathrm{~Hz}$, urea ArC-4), $123.00\left(\mathrm{~d}, J_{\mathrm{C}, \mathrm{F}}=25 \mathrm{~Hz}\right.$, urea ArC-4), 123.87 (3-ArC-2), $124.80(3-N-\operatorname{ArC}-2)$, $125.57\left(\mathrm{~d}, J_{\mathrm{C}, \mathrm{F}}=4.0 \mathrm{~Hz}\right.$, urea ArC-3), $125.70\left(\mathrm{~d}, J_{\mathrm{C}, \mathrm{F}}=4.0 \mathrm{~Hz}\right.$, urea ArC-3), 129.40 (3-ArC-5), 132.12 (3ArC-6), 132.52 (3-ArC-4), 133.32 (3-ArC), 135.03 (3-ArC), 143.35 (3-N-ArC-4), 143.92 (2C; 2 x urea ArC1), $145.24(3-N-A r C-1), 154.65(\mathrm{C}=\mathrm{O}), 155.23(\mathrm{C}=\mathrm{O}), 164.61(\mathrm{C}=\mathrm{O}), 165.57$ (3-anilide $\mathrm{C}=\mathrm{O}), 174.49(\mathrm{C}-$ 24); MS (FAB) found for $[\mathrm{M}+\mathrm{Na}]^{+}$1349; HRMS (FAB) calcd for $[\mathrm{M}+\mathrm{Na}]^{+} 1350.7357$, found 1350.7385 . $^{2}$ 
Measurements of distribution constants $K_{d}$ for the partitioning of tetraethylammonium salts between chloroform and water (Table 1)

\section{Direct method ("Method A"), typical example ( $\left.\mathbf{E t}_{4} \mathbf{N}^{+} \mathbf{I}\right)$. An aqueous solution of $\mathrm{Et}_{4} \mathrm{~N}^{+} \mathrm{I}^{-}(0.5 \mathrm{M}, 50 \mathrm{~mL})$} was added to chloroform $(500 \mathrm{~mL}$, presaturated with water) in a round bottom flask $(1 \mathrm{~L})$. The flask was immersed in a water bath at $303 \mathrm{~K}$, stoppered and the mixture was stirred vigorously for $15 \mathrm{~min}$. The mixture was then poured into a separating funnel and allowed to separate. The organic phase was filtered through Whatman 1PS hydrophobic filter paper to remove any excess undissolved aqueous phase, and the solvent was evaporated under reduced pressure. The resulting solid was dried for 4 hours under high vacuum and then weighed. $K_{\mathrm{d}}$ was calculated according to Eq. 4.

For certain salts where the amount extracted could not be determined accurately by weighing (see Table 1), the solid was dissolved in deuterated chloroform, and a solution of 1,1,2,2-tetrachloroethane in deuterated chloroform $(0.095 \mathrm{M}, 300 \mu \mathrm{L})$ was added. The ${ }^{1} \mathrm{H}$ NMR spectrum was then collected. The singlet peak of the standard and the methylene signal of $\mathrm{Et}_{4} \mathrm{~N}^{+}$were integrated to calculate the concentration of $\mathrm{Et}_{4} \mathrm{~N}^{+}$in the sample, and this was used to determine the value of $K_{\mathrm{d}}$.

\section{Indirect method (“Method B”). (a) Measurement of binding constants to receptor 3 by ${ }^{1} \mathrm{H}$ NMR}

titration. The following procedure is typical. A solution of eicosyl $3 \alpha-$-(chloroacetylamino)-7 $\alpha, 12 \alpha-$ bis(chloroacetylaminocarbonyloxy)-5 $\beta$-cholan-24oate $3(1 \mathrm{mM})$ in water-saturated deuterated chloroform was prepared and a known volume $(600 \mu \mathrm{L})$ was added to a standard NMR tube. The ${ }^{1} \mathrm{H}$ NMR spectrum was then collected for this sample at $303 \mathrm{~K}$. Aliquots of a solution of $\mathrm{Et}_{4} \mathrm{~N}^{+} \mathrm{Cl}^{-}(21 \mathrm{mM})$ in water-saturated deuterated chloroform were then added to the NMR tube. After each addition, the contents of the tube were mixed well and a spectrum collected at $303 \mathrm{~K}$. Fourteen additions were made of the following volumes: $5 \mu \mathrm{L}, 5 \mu \mathrm{L}, 5 \mu \mathrm{L}, 5 \mu \mathrm{L}, 5 \mu \mathrm{L}, 5 \mu \mathrm{L}, 5 \mu \mathrm{L}, 5 \mu \mathrm{L}, 5 \mu \mathrm{L}, 5 \mu \mathrm{L}, 10 \mu \mathrm{L}, 10 \mu \mathrm{L}, 15 \mu \mathrm{L}$ and $30 \mu \mathrm{L}$. The downfield movements of carbamoyl NH signals were analyzed by a non-linear curve fitting program implemented in 
Excel, to give $K_{\mathrm{a}}$ and the limiting chemical shift. Sample binding curves for this and other experiments are shown below.

\section{${ }^{1} \mathrm{H}$ NMR Titration of $\mathrm{Et}_{4} \mathrm{~N}^{+} \mathrm{Cl}^{-}$with receptor 3 .}

The chemical shift of a carbamate $\mathrm{NH}$ proton was followed throughout this titration.

Solution concentrations: Host $=1 \mathrm{mM}$ Guest $=21 \mathrm{~mm}$.

Initial volume of host $=600 \mu \mathrm{L}$. Initial shift $(\delta)$ of proton $=8.616 \mathrm{ppm}$.

Limiting shift $(\delta): 10.957 \mathrm{ppm}$.

\begin{tabular}{|ccccc|}
\hline $\begin{array}{c}\mu \mathrm{L} \text { of guest } \\
\text { added }\end{array}$ & $\begin{array}{c}\text { [Guest] added } \\
(\mathrm{M})\end{array}$ & $\begin{array}{c}\text { Observed shift } \\
(\mathrm{ppm})\end{array}$ & $\begin{array}{c}\text { Change in shift relative } \\
\text { to } \delta(\mathrm{ppm})\end{array}$ & $\begin{array}{c}\text { Computer calculated change in } \\
\text { shift }(\mathrm{ppm})\end{array}$ \\
0 & 0.0000000 & 8.6161 & 0.0000 & 0.0000 \\
5 & 0.0001736 & 9.0102 & 0.3941 & 0.3814 \\
10 & 0.0003443 & 9.3897 & 0.7736 & 0.7503 \\
15 & 0.0005122 & 9.7462 & 1.1302 & 1.0986 \\
20 & 0.0006774 & 10.0472 & 1.4312 & 1.4125 \\
25 & 0.0008400 & 10.3000 & 1.6839 & 1.6730 \\
30 & 0.0010000 & 10.4752 & 1.8592 & 1.8655 \\
35 & 0.0011575 & 10.5949 & 1.9789 & 1.9936 \\
40 & 0.0013125 & 10.6791 & 2.0631 & 2.0758 \\
45 & 0.0014651 & 10.7329 & 2.1168 & 2.1294 \\
55 & 0.0017634 & 10.7982 & 2.1822 & 2.1920 \\
65 & 0.0020526 & 10.8404 & 2.2243 & 2.2262 \\
75 & 0.0023333 & 10.8623 & 2.2463 & 2.2474 \\
90 & 0.0027391 & 10.8868 & 2.2707 & 2.2672 \\
120 & 0.0035000 & 10.9099 & 2.2939 & 2.2883 \\
\hline
\end{tabular}

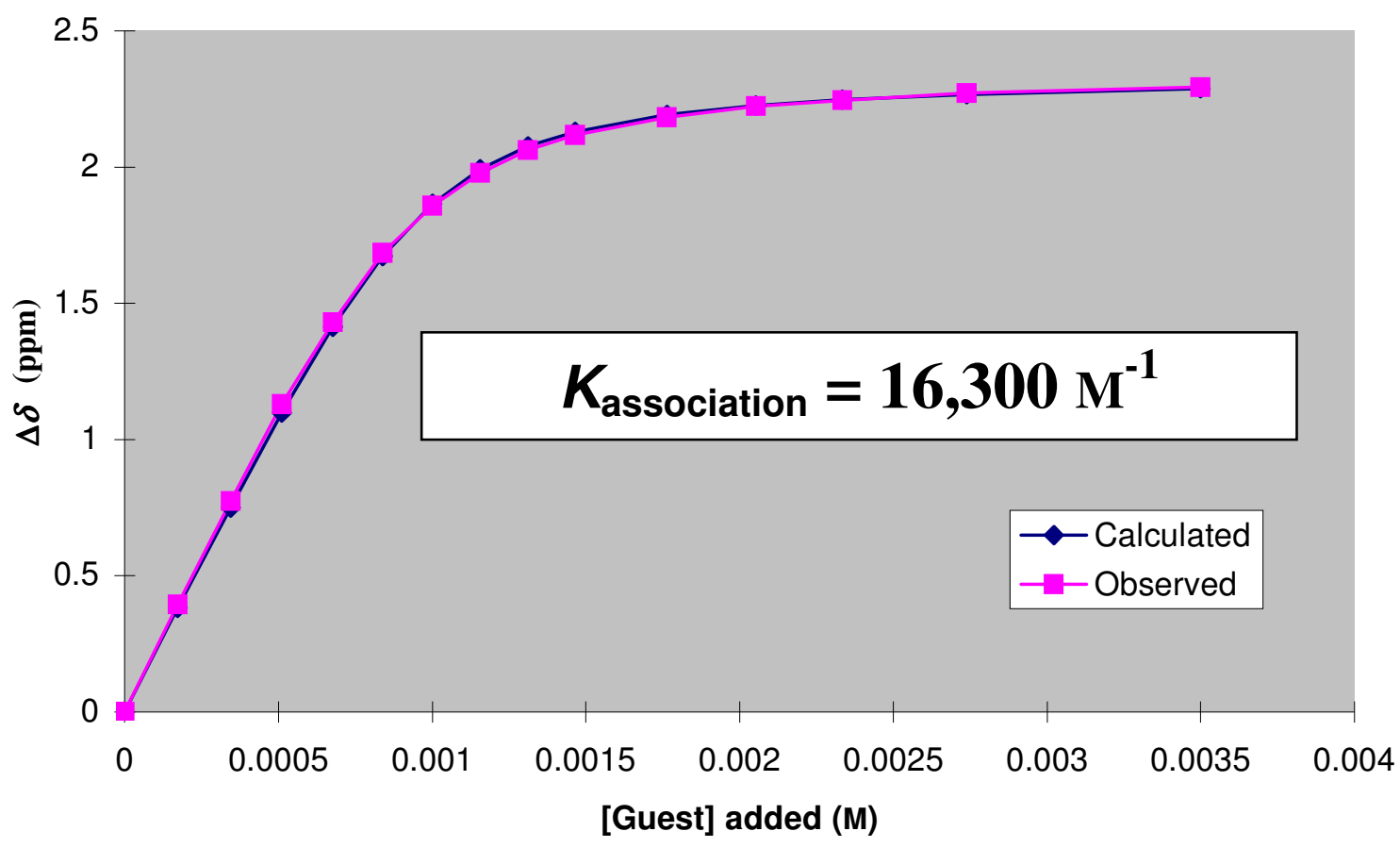




\section{${ }^{1} \mathrm{H}$ NMR Titration of $\mathrm{Et}_{4} \mathrm{~N}^{+} \mathrm{Br}^{-}$with receptor 3 .}

The chemical shift of $3 \alpha \mathrm{NH}$ proton was followed throughout this titration.

Solution concentrations: Host $=2 \mathrm{mM}$ Guest $=50 \mathrm{mM}$.

Initial volume of host $=500 \mu \mathrm{L}$. Initial shift $(\delta)$ of the $3 \alpha \mathrm{NH}$ proton $=6.467 \mathrm{ppm}$.

Limiting shift $(\delta): 7.890$ ppm.

\begin{tabular}{|ccccc|}
\hline$\mu$ of guest added & $\begin{array}{c}\text { [Guest] added } \\
(\mathrm{M})\end{array}$ & $\begin{array}{c}\text { Observed shift } \\
(\mathrm{ppm})\end{array}$ & $\begin{array}{c}\text { Change in shift relative } \\
\text { to } \delta(\mathrm{ppm})\end{array}$ & $\begin{array}{c}\text { Computer calculated } \\
\text { change in shift }(\mathrm{ppm})\end{array}$ \\
0 & 0.0000000 & 6.4663 & 0.0000 & 0.0000 \\
4 & 0.0003968 & 6.7447 & 0.2784 & 0.2666 \\
8 & 0.0007874 & 6.9962 & 0.5300 & 0.5235 \\
15 & 0.0014563 & 7.4041 & 0.9378 & 1.0528 \\
18 & 0.0017375 & 7.5274 & 1.0612 & 1.1518 \\
21 & 0.0020154 & 7.6160 & 1.1497 & 1.2201 \\
24 & 0.0022901 & 7.6801 & 1.2138 & 1.29663 \\
27 & 0.0025617 & 7.7243 & 1.2581 & 1.3177 \\
30 & 0.0028302 & 7.7549 & 1.2886 & 1.3412 \\
33 & 0.0030957 & 7.7781 & 1.3118 & 1.3563 \\
38 & 0.0035316 & 7.8040 & 1.3377 & 1.3667 \\
43 & 0.0039595 & 7.8217 & 1.3554 & 1.3799 \\
48 & 0.0043796 & 7.8345 & 1.3683 & 1.3879 \\
58 & 0.0051971 & 7.8507 & 1.3845 & \\
68 & 0.0059859 & 7.8568 & 1.3906 & \\
\hline
\end{tabular}

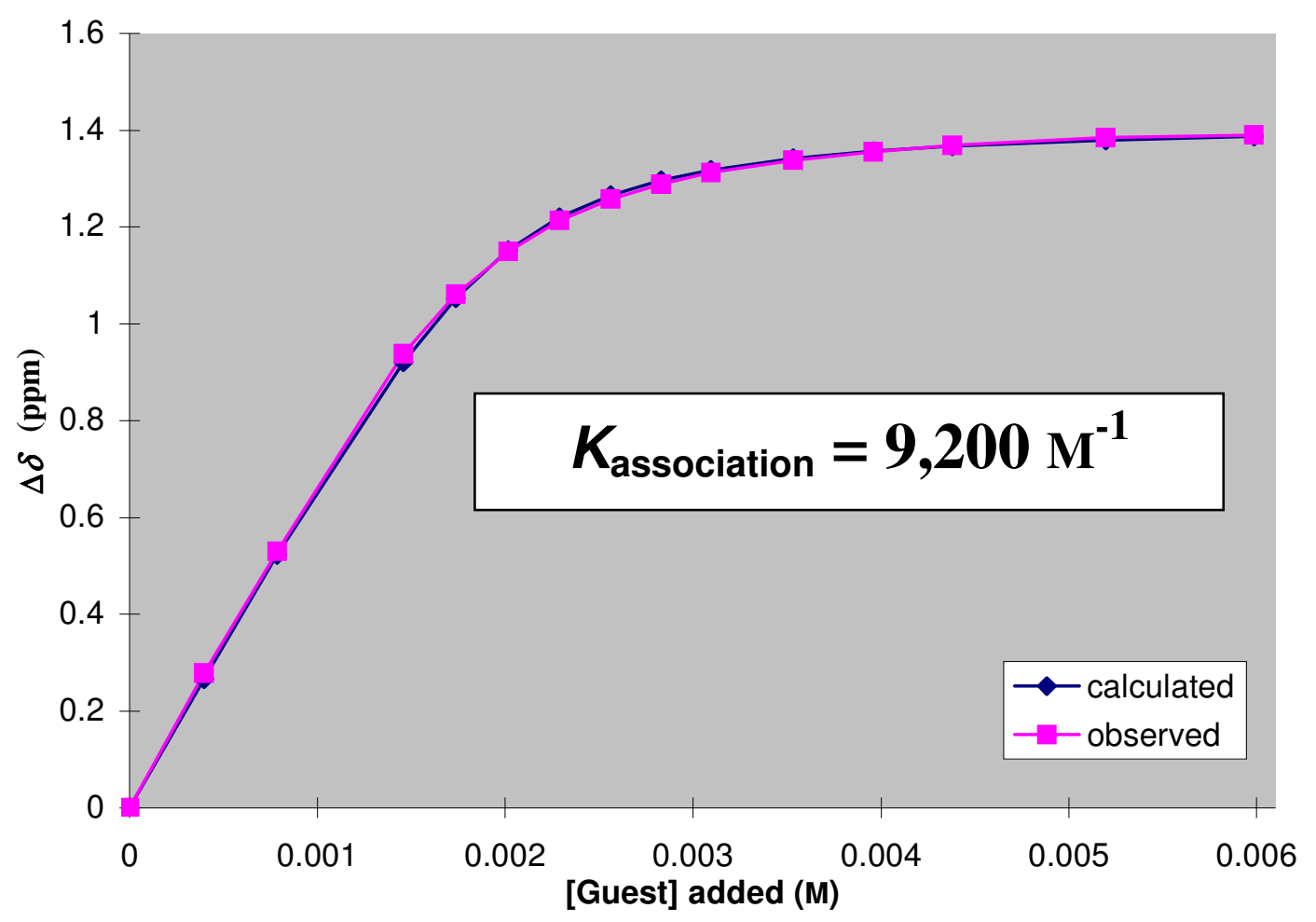




\section{${ }^{1} \mathrm{H}$ NMR Titration of $\mathrm{Et}_{4} \mathrm{~N}^{+} \mathrm{NO}_{3}^{-}$with receptor 3 .}

The chemical shift of the $3 \alpha \mathrm{NH}$ proton was followed throughout this titration.

Solution concentrations: Host $=1.38 \mathrm{mM}$ Guest $=15 \mathrm{mM}$.

Initial volume of host $=600 \mu \mathrm{L}$. Initial shift $(\delta)$ of the $3 \alpha \mathrm{NH}$ proton $=6.3825 \mathrm{ppm}$.

Limiting shift $(\delta)$ : 7.9384 ppm.

\begin{tabular}{|ccccc|}
\hline $\begin{array}{c}\mu \text { of guest } \\
\text { added }\end{array}$ & $\begin{array}{c}\text { Guest] added } \\
(\mathrm{M})\end{array}$ & $\begin{array}{c}\text { Observed shift } \\
(\mathrm{ppm})\end{array}$ & $\begin{array}{c}\text { Change in shift } \\
\text { relative to } \delta(\mathrm{ppm})\end{array}$ & $\begin{array}{c}\text { Computer calculated change } \\
\text { in shift }(\mathrm{ppm})\end{array}$ \\
0 & 0.000000 & 6.3825 & 0.0000 & 0.0000 \\
10 & 0.000246 & 6.6494 & 0.2790 & 0.2668 \\
15 & 0.000366 & 6.7877 & 0.4175 & 0.4051 \\
20 & 0.000484 & 6.9300 & 0.5549 & 0.5474 \\
25 & 0.000600 & 7.0676 & 0.6910 & 0.6850 \\
40 & 0.000938 & 7.4437 & 1.0801 & 1.0611 \\
43 & 0.001003 & 7.5176 & 1.1508 & 1.1350 \\
49 & 0.001133 & 7.6562 & 1.2768 & 1.2736 \\
52 & 0.001196 & 7.7084 & 1.3291 & 1.3258 \\
55 & 0.001260 & 7.7564 & 1.3725 & 1.3738 \\
58 & 0.001322 & 7.7930 & 1.4069 & 1.4104 \\
61 & 0.001384 & 7.8211 & 1.4335 & 1.4385 \\
64 & 0.001446 & 7.8434 & 1.4536 & 1.4608 \\
69 & 0.001547 & 7.8678 & 1.4771 & 1.4852 \\
75 & 0.001667 & 7.8849 & 1.4949 & 1.5023 \\
81 & 0.001784 & 7.8953 & 1.5065 & 1.5127 \\
101 & 0.002161 & 7.9111 & 1.5258 & 1.5285 \\
120 & 0.002500 & 7.9184 & 1.5339 & 1.5359 \\
\hline
\end{tabular}

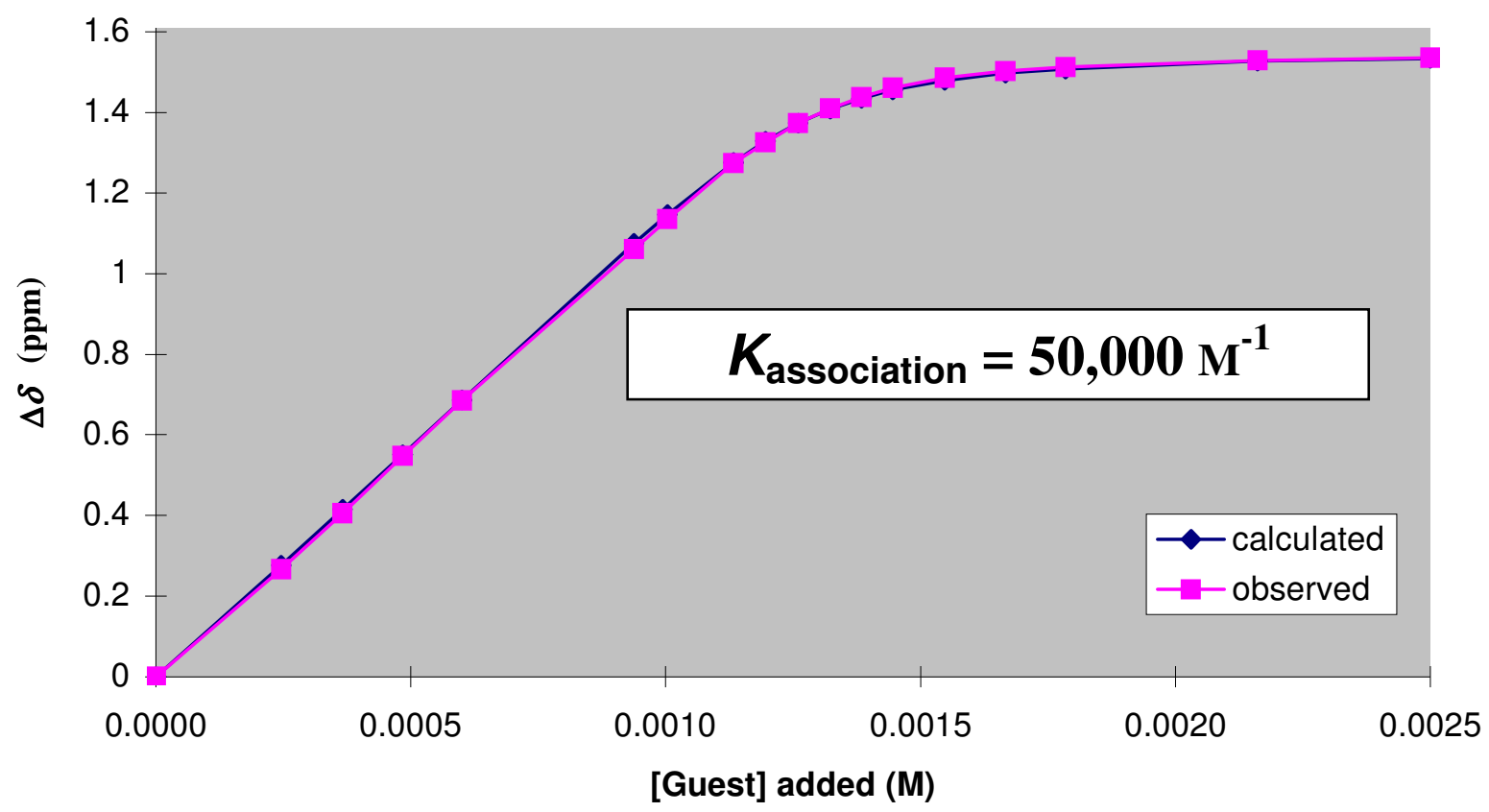




\section{${ }^{1} \mathrm{H}$ NMR Titration of $\mathrm{Et}_{4} \mathrm{~N}^{+} \mathrm{EtSO}_{3}{ }^{-}$with receptor 3 .}

The chemical shift of the $3 \alpha \mathrm{NH}$ proton was followed throughout this titration.

Solution concentrations: Host $=1.38 \mathrm{mM}$ Guest $=26 \mathrm{mM}$.

Initial volume of host $=600 \mu \mathrm{L}$. Initial shift $(\delta)$ of the $3 \alpha \mathrm{NH}$ proton $=6.407 \mathrm{ppm}$.

Limiting shift $(\delta): 8.205$ ppm.

\begin{tabular}{|ccccc|}
\hline $\begin{array}{c}\mu \mathrm{L} \text { of guest } \\
\text { added }\end{array}$ & $\begin{array}{c}\text { Guest] added } \\
(\mathrm{M})\end{array}$ & $\begin{array}{c}\text { Observed shift } \\
(\mathrm{ppm})\end{array}$ & $\begin{array}{c}\text { Change in shift relative to } \delta \\
(\mathrm{ppm})\end{array}$ & $\begin{array}{c}\text { Computer calculated change in shift } \\
(\mathrm{ppm})\end{array}$ \\
0 & 0.000000 & 6.4073 & 0.0000 & 0.0000 \\
4 & 0.000172 & 6.6024 & 0.1951 & 0.2014 \\
8 & 0.000342 & 6.7972 & 0.3898 & 0.3965 \\
11 & 0.000468 & 6.9370 & 0.5296 & 0.5375 \\
13 & 0.000551 & 7.0365 & 0.6292 & 0.6284 \\
15 & 0.000634 & 7.1208 & 0.7134 & 0.7164 \\
21 & 0.000879 & 7.3546 & 0.9473 & 0.9586 \\
23 & 0.000960 & 7.4444 & 1.0370 & 1.0307 \\
25 & 0.001040 & 7.5182 & 1.1109 & 1.0979 \\
28 & 0.001159 & 7.5945 & 1.1872 & 1.2914 \\
32 & 0.001316 & 7.7023 & 1.2950 & 1.3737 \\
36 & 0.001472 & 7.7838 & 1.3765 & 1.4892 \\
44 & 0.001776 & 7.8983 & 1.4910 & 1.6065 \\
60 & 0.002364 & 8.0006 & 1.5933 & 1.6691 \\
80 & 0.003059 & 8.0790 & 1.6717 & 1.6999 \\
\hline
\end{tabular}

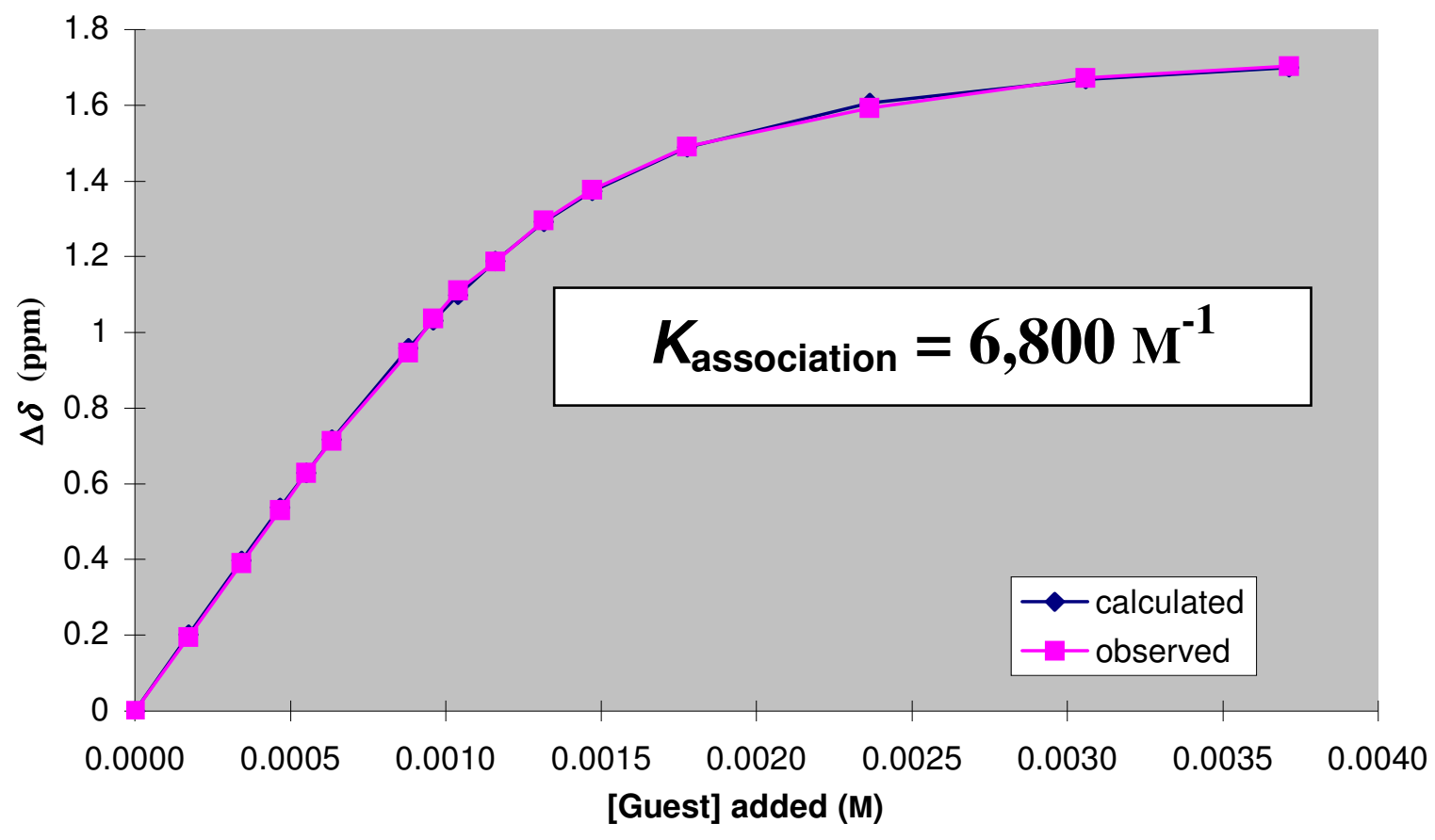




\section{${ }^{1} \mathrm{H}$ NMR Titration of $\mathrm{Et}_{4} \mathrm{~N}^{+} \mathrm{AcO}^{-}$with receptor 3 .}

The chemical shift of the $3 \alpha \mathrm{NH}$ proton was followed throughout this titration.

Solution concentrations: Host $=1 \mathrm{mM} \mathrm{Guest}=21 \mathrm{mM}$.

Initial volume of host $=500 \mu \mathrm{L}$.

Initial shift $(\delta)$ of the $3 \alpha \mathrm{NH}$ proton $=6.470 \mathrm{ppm}$.

Limiting shift $(\delta): 8.723$ ppm.

\begin{tabular}{|ccccc|}
\hline $\begin{array}{r}\mu \mathrm{L} \text { of } \\
\text { guest added }\end{array}$ & $\begin{array}{c}\text { [Guest] added } \\
(\mathrm{M})\end{array}$ & $\begin{array}{c}\text { Observed } \\
\text { shift }(\mathrm{ppm})\end{array}$ & $\begin{array}{c}\text { Change in shift } \\
\text { relative to } \delta(\mathrm{ppm})\end{array}$ & $\begin{array}{c}\text { Computer calculated } \\
\text { change in shift }(\mathrm{ppm})\end{array}$ \\
0 & 0.0000000 & 6.4696 & 0.0000 & 0.0000 \\
3 & 0.0007336 & 6.6222 & 0.1526 & 0.1643 \\
28 & 0.0006522 & 7.9750 & 1.5054 & 1.4985 \\
35 & 0.0008047 & 8.3074 & 1.8378 & 1.8240 \\
40 & 0.0009111 & 8.4817 & 2.0121 & 1.9997 \\
45 & 0.0010156 & 8.5611 & 2.0915 & 2.1035 \\
50 & 0.0011182 & 8.6148 & 2.1452 & 2.1551 \\
55 & 0.0012789 & 8.6429 & 2.1733 & 2.1820 \\
60 & 0.0013178 & 8.6606 & 2.1910 & 2.1977 \\
65 & 0.0014150 & 8.6734 & 2.2038 & 2.2077 \\
75 & 0.0016043 & 8.6872 & 2.2176 & 2.2198 \\
85 & 0.0017872 & 8.7000 & 2.2304 & 2.2267 \\
120 & 0.0023806 & 8.7189 & 2.2493 & 2.2374 \\
\hline
\end{tabular}

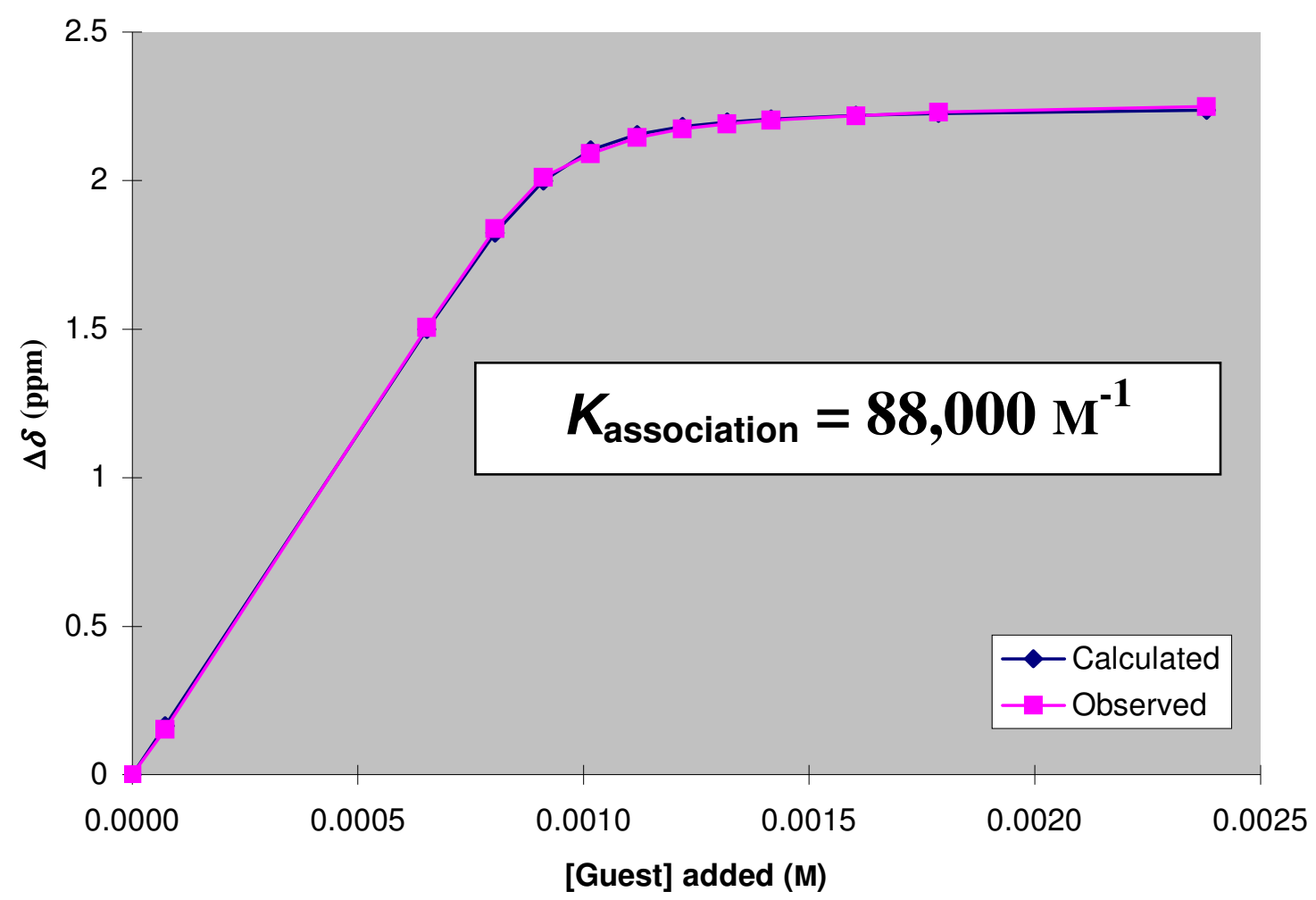




\section{Indirect method ("Method B"). (b) Extraction of $\mathbf{E t}_{4} \mathbf{N}^{+}$salt from water into chloroform in the}

presence of receptor 3. A solution of eicosyl $3 \alpha$-(chloroacetylamido)-7 $\alpha, 12 \alpha$-bis(chloroacetylaminocarbonyloxy)-5 $\beta$-cholan-24-oate 3 in water-saturated chloroform $(0.6 \mathrm{~mm}, 5 \mathrm{~mL})$ was placed in a sample tube $(30 \mathrm{~mL})$. Aqueous $\mathrm{Et}_{4} \mathrm{~N}^{+} \mathrm{Cl}^{-}(0.5 \mathrm{M}, 1 \mathrm{~mL})$ was added. A small magnetic stirring bar was then added to the tube and the lower half of the tube was immersed in a water bath at $303 \mathrm{~K}$. The tube was stoppered and the contents were stirred vigorously. After 15 minutes, stirring was stopped and the two phases were allowed to separate. The majority of the aqueous phase was then removed using a pipette and the remaining mixture was filtered through Whatman 1PS hydrophobic filter paper to remove any excess undissolved aqueous phase. Solvent was then evaporated from the filtrate under reduced pressure. The resulting solid was dissolved in $\mathrm{CDCl}_{3}$. A solution of $\mathrm{Ph}_{4} \mathrm{P}^{+} \mathrm{Br}^{-}$in $\mathrm{CDCl}_{3}(45 \mu \mathrm{L}, 0.1 \mathrm{M})$ was added, and the sample analyzed by ${ }^{1} \mathrm{H}$ NMR. Integration of the $\mathrm{Et}_{4} \mathrm{~N}^{+}$vs. receptor protons was used to calculate $K_{\mathrm{d}}$ as described elsewhere. ${ }^{1}$

\section{Measurements of binding constants $K_{a}$ using Cram's extraction method (Table 2)}

Extraction experiments employing receptors 4-15 were performed essentially as described above for 3 . The concentration of the receptor was constant at $0.6 \mathrm{~mm}$. The volume of the organic phase was varied between 1 and $4 \mathrm{~mL}$ (typically $2 \mathrm{~mL}$ ). The concentration of guest and volume of aqueous phase were adjusted so that (a) $R$ (see Eq. A) was in the range $0.15-0.7$, avoiding saturation of the receptor and allowing accurate integration, and (b) the guest was always in fairly large excess. For the strongest receptors such as 11, guest aqueous concentrations of $\leq 1 \mathrm{mM}$ were needed for some anions. The integration data was analyzed as discussed previously to obtain $K_{\mathrm{a}}$ values. $^{2}$ 
Determination of relative binding constants using NMR competition titrations

For the equilibrium shown in Eq. 5, the equilibrium constant, and thus the ratio of the binding constants for formation of $\mathrm{AB}$ and $\mathrm{AC}$, is given by Eq. 6.

$$
\begin{aligned}
\mathrm{AB}+\mathrm{C} \stackrel{K_{\text {exch }}}{\rightleftharpoons} \mathrm{AC}+\mathrm{B} \\
K_{\text {exch }}=\frac{[\mathrm{AC}][\mathrm{B}]}{[\mathrm{AB}][\mathrm{C}]}=\frac{K_{A C}}{K_{A B}}
\end{aligned}
$$

Let $\left[\mathrm{A}_{\mathrm{i}}\right],\left[\mathrm{B}_{\mathrm{i}}\right]$ and $\left[\mathrm{C}_{\mathrm{i}}\right]$ be the initial concentrations of each species before any complexation takes place (the total amounts added by the experimenter, divided by the total volume). These quantities are known. As $\mathrm{C}$ is titrated into the mixture of $\mathrm{A}+\mathrm{B}$, we need to determine how $[\mathrm{AC}]$ is related to $K_{\text {exch }}$.

From mass balance,

$$
\left[\mathrm{A}_{\mathrm{i}}\right]=[\mathrm{A}]+[\mathrm{AC}]+[\mathrm{AB}]
$$

However, if complexes $\mathrm{AB}$ and $\mathrm{AC}$ are both tightly bound, and if $\mathrm{B}$ and/or $\mathrm{C}$ are always present in large excess, then $[\mathrm{A}] \approx 0$. Eq. S1 then simplifies to

$$
\left[\mathrm{A}_{\mathrm{i}}\right]=[\mathrm{AC}]+[\mathrm{AB}]
$$

Rearranging Eq. S2

$$
[\mathrm{AB}]=\left[\mathrm{A}_{\mathrm{i}}\right]-[\mathrm{AC}]
$$

Also from mass balance

$$
[\mathrm{B}]=\left[\mathrm{B}_{\mathrm{i}}\right]-[\mathrm{AB}]
$$

Substituting Eq. S3 into Eq. S4 


$$
[\mathrm{B}]=\left[\mathrm{B}_{\mathrm{i}}\right]+[\mathrm{AC}]-\left[\mathrm{A}_{\mathrm{i}}\right]
$$

Finally from mass balance

$$
[\mathrm{C}]=\left[\mathrm{C}_{\mathrm{i}}\right]-[\mathrm{AC}]
$$

Substituting equations S3, S5 and S6 into equation 6:

$$
K_{\text {exch }}=\frac{[\mathrm{AC}]\left[\left[\mathrm{B}_{\mathrm{i}}\right]+[\mathrm{AC}]-\left[\mathrm{A}_{\mathrm{i}}\right]\right\}}{\left(\left[\mathrm{A}_{\mathrm{i}}\right]-[\mathrm{AC}]\right)\left(\left[\mathrm{C}_{\mathrm{i}}\right]-[\mathrm{AC}]\right)}
$$

During the titration, the chemical shift of a proton, $\delta_{\mathrm{obs}}$ moves from the value for complex $\mathrm{AB}\left(\delta_{\mathrm{AB}}\right)$ towards that for $\mathrm{AC}\left(\delta_{\mathrm{AC}}\right)$. If complexes $\mathrm{AB}$ and $\mathrm{AC}$ are both tightly bound, $\delta_{\mathrm{AB}}$ and $\delta_{\mathrm{AC}}$ should be directly measurable. The proportion of A existing as AC is then given by Eq. S8:

$$
\frac{[\mathrm{AC}]}{\left[\mathrm{A}_{\mathrm{i}}\right]}=\frac{\left(\delta_{\mathrm{obs}}-\delta_{\mathrm{AB}}\right)}{\left(\delta_{\mathrm{AC}}-\delta_{\mathrm{AB}}\right)}
$$

[AC] can thus be determined and $K_{\text {exch }}$ estimated from each point in the titration, and then averaged. However, in practice it is convenient to expand and rearrange Eq. S7 to give Eq. S9:

$$
\left.\left.[\mathrm{AC}]^{2}\left\{K_{\text {exch }}-1\right\}+[\mathrm{AC}]\right\}\left[\mathrm{A}_{\mathrm{i}}\right]-\left[\mathrm{A}_{\mathrm{i}}\right] K_{\text {exch }}-\left[\mathrm{C}_{\mathrm{i}}\right] K_{\text {exch }}-\left[\mathrm{B}_{\mathrm{i}}\right]\right\}+\left[\mathrm{A}_{\mathrm{i}}\right]\left[\mathrm{C}_{\mathrm{i}}\right] K_{\text {exch }}=0
$$

Equation $\mathrm{S} 9$ is a quadratic in $[\mathrm{AC}]$. Using the standard formula:

$$
x=\frac{-b \pm \sqrt{b^{2}-4 a c}}{2 a}
$$

it can be solved to give [AC] in terms of $K_{\text {exch. }}$. In this form it can be used to modify a standard curve fitting program originally written for 1:1 binding. The program gives a weighted average value for $K_{\text {exch }}$ and allows assessment of the binding model by visual inspection. Binding curves for the titrations performed on $\mathbf{8}, \mathbf{1 1}$ and $\mathbf{1 2}$ are shown below. 


\section{${ }^{1} \mathrm{H}$ NMR Competition Titration of $\mathrm{Et}_{4} \mathrm{~N}^{+} \mathrm{Cl}^{-}$with receptor 8, pre-complexed with $\mathrm{Et}_{4} \mathrm{~N}^{+} \mathrm{EtSO}_{3}{ }^{-}$.}

Solvent: Water-saturated $\mathrm{CDCl}_{3}$. Temperature: $303 \mathrm{~K}$

Concentrations in NMR tube prior to addition of $\mathrm{Et}_{4} \mathrm{~N}^{+} \mathrm{Cl}^{-}$: [8] $=1 \mathrm{mM},\left[\mathrm{Et}_{4} \mathrm{~N}^{+} \mathrm{EtSO}_{3}^{-}\right]=1.9 \mathrm{mM}(1.9 \mathrm{molar}$ equivalents).

Initial Volume in Tube: $600 \mu \mathrm{L}$. Concentration of $\mathrm{Et}_{4} \mathrm{~N}^{+} \mathrm{Cl}^{-}$in added solution $=50 \mathrm{mM}$.

The chemical shift of the $3 \alpha \mathrm{NH}$ proton was followed. The limiting chemical shift (from spreadsheet) is: $6.235 \mathrm{ppm}$.

\begin{tabular}{|c|c|c|c|c|}
\hline $\mathrm{Et}_{4} \mathrm{~N}^{+} \mathrm{Cl}^{-}$added $(\mu \mathrm{L})$ & $\begin{array}{l}{\left[\mathrm{Et}_{4} \mathrm{~N}^{+} \mathrm{Cl}^{-}\right] \text {added }} \\
(\mathrm{M})\end{array}$ & $\begin{array}{l}\text { Observed } \\
(\mathrm{ppm})\end{array}$ & $\begin{array}{l}\text { Change in shift } \\
\text { relative to } \delta(\mathrm{ppm})\end{array}$ & $\begin{array}{l}\text { Computer calculated } \\
\text { change in shift (ppm) }\end{array}$ \\
\hline $\begin{array}{c}0 \\
3 \\
6 \\
9 \\
12 \\
15 \\
18 \\
24 \\
36 \\
54 \\
72 \\
108 \\
144 \\
180 \\
216 \\
252 \\
288\end{array}$ & $\begin{array}{l}0.00000 \\
0.00025 \\
0.00049 \\
0.00074 \\
0.00098 \\
0.00121 \\
0.00145 \\
0.00192 \\
0.00282 \\
0.00411 \\
0.00534 \\
0.00760 \\
0.00965 \\
0.01150 \\
0.01319 \\
0.01475 \\
0.01617\end{array}$ & $\begin{array}{l}6.8776 \\
6.8025 \\
6.7293 \\
6.6798 \\
6.6297 \\
6.5901 \\
6.5559 \\
6.5076 \\
6.4435 \\
6.3947 \\
6.3605 \\
6.3293 \\
6.3043 \\
6.2890 \\
6.2805 \\
6.2744 \\
6.2701\end{array}$ & $\begin{array}{c}0.0000 \\
-0.0751 \\
-0.1483 \\
-0.1978 \\
-0.2479 \\
-0.2875 \\
-0.3217 \\
-0.3700 \\
-0.4341 \\
-0.4829 \\
-0.5171 \\
-0.5483 \\
-0.5733 \\
-0.5886 \\
-0.5971 \\
-0.6032 \\
-0.6075\end{array}$ & $\begin{array}{c}0.0000 \\
-0.0847 \\
-0.1518 \\
-0.2057 \\
-0.2497 \\
-0.2861 \\
-0.3167 \\
-0.3649 \\
-0.4290 \\
-0.4845 \\
-0.5174 \\
-0.5543 \\
-0.5745 \\
-0.5872 \\
-0.5959 \\
-0.6023 \\
-0.6072\end{array}$ \\
\hline
\end{tabular}

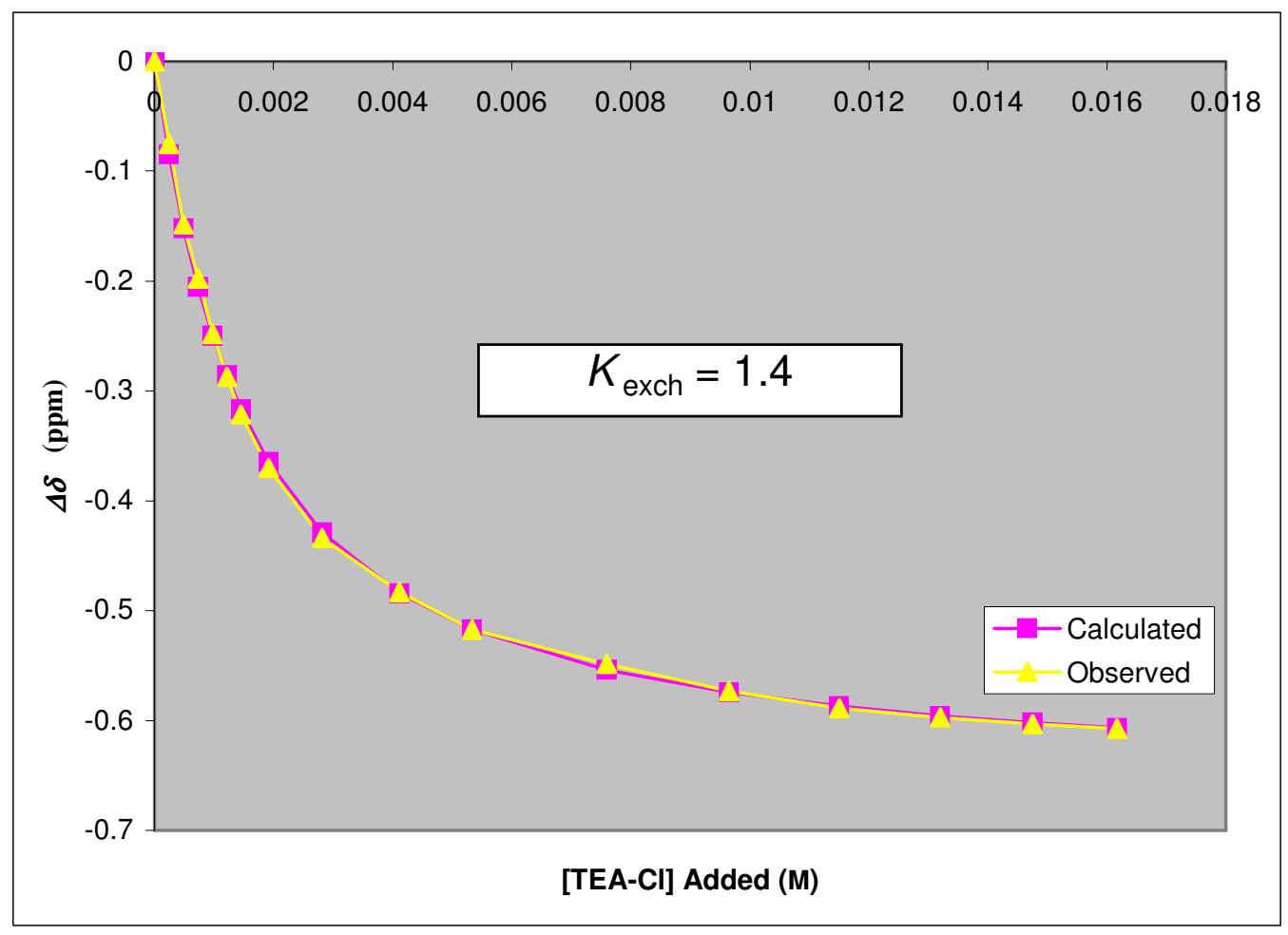




\section{${ }^{1} \mathrm{H}$ NMR Competition Titration of $\mathrm{Et}_{4} \mathrm{~N}^{+} \mathrm{Cl}^{-}$with receptor 11, pre-complexed with $\mathrm{Et}_{4} \mathrm{~N}^{+} \mathrm{EtSO}_{3}{ }^{-}$.}

Solvent: Water-saturated $\mathrm{CDCl}_{3}$. Temperature: $303 \mathrm{~K}$

Concentrations in NMR tube prior to addition of $\mathrm{Et}_{4} \mathrm{~N}^{+} \mathrm{Cl}^{-}:[11]=1 \mathrm{mM},\left[\mathrm{Et}_{4} \mathrm{~N}^{+} \mathrm{EtSO}_{3}{ }^{-}\right]=2.3 \mathrm{mM}(2.3 \mathrm{molar}$ equivalents)

Initial Volume in Tube: $600 \mu \mathrm{L}$. Concentration of $\mathrm{Et}_{4} \mathrm{~N}^{+} \mathrm{Cl}^{-}$in added solution $=50 \mathrm{mM}$.

The chemical shift of the $3 \alpha \mathrm{NH}$ proton was followed. The limiting chemical shift (from spreadsheet) is: $6.572 \mathrm{ppm}$.

\begin{tabular}{|c|c|c|c|c|}
\hline $\mathrm{Et}_{4} \mathrm{~N}^{+} \mathrm{Cl}^{-}$added $(\mu \mathrm{L})$ & $\begin{array}{l}{\left[\mathrm{Et}_{4} \mathrm{~N}^{+} \mathrm{Cl}^{-}\right] \text {added }} \\
(\mathrm{M})\end{array}$ & $\begin{array}{l}\text { Observed } \\
(\mathrm{ppm})\end{array}$ & $\begin{array}{l}\text { Change in shift } \\
\text { relative to } \delta(\mathrm{ppm})\end{array}$ & $\begin{array}{l}\text { Computer calculated } \\
\text { change in shift (ppm) }\end{array}$ \\
\hline 0 & 0.00000 & 7.0700 & 0.0000 & 0.0000 \\
\hline 4 & 0.00033 & 6.9595 & -0.1105 & -0.1025 \\
\hline 8 & 0.00065 & 6.8850 & -0.1850 & -0.1798 \\
\hline 12 & 0.00098 & 6.8312 & -0.2388 & -0.2370 \\
\hline 16 & 0.00129 & 6.7922 & -0.2778 & -0.2794 \\
\hline 20 & 0.00161 & 6.7610 & -0.3090 & -0.3114 \\
\hline 26 & 0.00207 & 6.7256 & -0.3444 & -0.3461 \\
\hline 32 & 0.00252 & 6.7000 & -0.3700 & -0.3706 \\
\hline 44 & 0.00340 & 6.6713 & -0.3987 & -0.4022 \\
\hline 56 & 0.00425 & 6.6470 & -0.4230 & -0.4215 \\
\hline 80 & 0.00586 & 6.6291 & -0.4409 & -0.4437 \\
\hline 116 & 0.00807 & 6.6090 & -0.4610 & -0.4603 \\
\hline 152 & 0.01007 & 6.6010 & -0.4690 & -0.4692 \\
\hline 188 & 0.01188 & 6.5919 & -0.4781 & -0.4747 \\
\hline
\end{tabular}

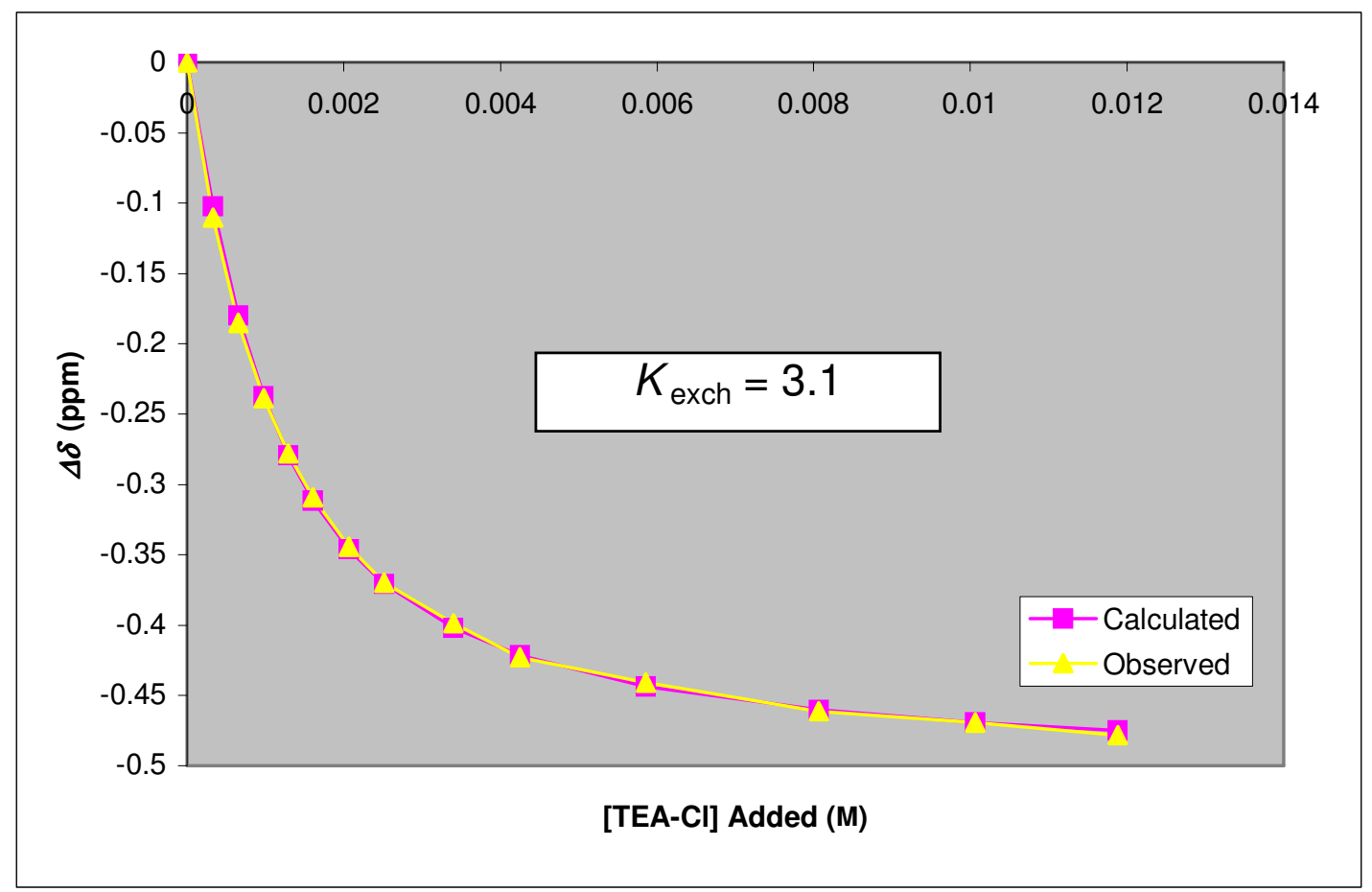




\section{${ }^{1} \mathrm{H}$ NMR Competition Titration of $\mathrm{Et}_{4} \mathrm{~N}^{+} \mathrm{Cl}^{-}$with receptor 12, pre-complexed with $\mathrm{Et}_{4} \mathrm{~N}^{+} \mathrm{EtSO}_{3}$.}

Solvent: Water-saturated $\mathrm{CDCl}_{3}$. Temperature: $303 \mathrm{~K}$

Concentrations in NMR tube prior to addition of $\mathrm{Et}_{4} \mathrm{~N}^{+} \mathrm{Cl}^{-}:[12]=1 \mathrm{mM},\left[\mathrm{Et}_{4} \mathrm{~N}^{+} \mathrm{EtSO}_{3}{ }^{-}\right]=3.1 \mathrm{mM}(3.1 \mathrm{molar}$ equivalents)

Initial Volume in Tube: $600 \mu \mathrm{L}$. Concentration of $\mathrm{Et}_{4} \mathrm{~N}^{+} \mathrm{Cl}^{-}$in added solution $=50 \mathrm{mM}$.

The chemical shift of the $3 \alpha \mathrm{NH}$ proton was followed. The limiting chemical shift (from spreadsheet) is: $6.456 \mathrm{ppm}$.

\begin{tabular}{|c|c|c|c|c|}
\hline $\mathrm{Et}_{4} \mathrm{~N}^{+} \mathrm{Cl}^{-}$added $(\mu \mathrm{L})$ & $\begin{array}{l}{\left[\mathrm{Et}_{4} \mathrm{~N}^{+} \mathrm{Cl}^{-}\right] \text {added }} \\
(\mathrm{M})\end{array}$ & $\begin{array}{l}\text { Observed } \\
(\mathrm{ppm})\end{array}$ & $\begin{array}{l}\text { Change in shift } \\
\text { relative to } \delta(\mathrm{ppm})\end{array}$ & $\begin{array}{l}\text { Computer calculatec } \\
\text { change in shift (ppm) }\end{array}$ \\
\hline 0 & 0.00000 & 7.0205 & 0.0000 & 0.0000 \\
\hline 3 & 0.00025 & 6.8840 & -0.1365 & -0.1188 \\
\hline 6 & 0.00049 & 6.7818 & -0.2387 & -0.2234 \\
\hline 9 & 0.00074 & 6.7057 & -0.3148 & -0.3088 \\
\hline 12 & 0.00098 & 6.6506 & -0.3699 & -0.3727 \\
\hline 15 & 0.00122 & 6.6078 & -0.4127 & -0.4176 \\
\hline 21 & 0.00169 & 6.5577 & -0.4628 & -0.4697 \\
\hline 27 & 0.00215 & 6.5278 & -0.4927 & -0.4963 \\
\hline 33 & 0.00260 & 6.5101 & -0.5104 & -0.5117 \\
\hline 42 & 0.00326 & 6.4930 & -0.5275 & -0.5253 \\
\hline 60 & 0.00453 & 6.4826 & -0.5379 & -0.5386 \\
\hline 72 & 0.00534 & 6.4771 & -0.5434 & -0.5434 \\
\hline 108 & 0.00761 & 6.4740 & -0.5465 & -0.5509 \\
\hline 144 & 0.00965 & 6.4704 & -0.5501 & -0.5544 \\
\hline 180 & 0.01151 & 6.4667 & -0.5538 & -0.5565 \\
\hline 216 & 0.01320 & 6.4631 & -0.5574 & -0.5578 \\
\hline 252 & 0.01475 & 6.4582 & -0.5623 & -0.5587 \\
\hline 302 & 0.01670 & 6.4515 & -0.5690 & -0.5597 \\
\hline
\end{tabular}

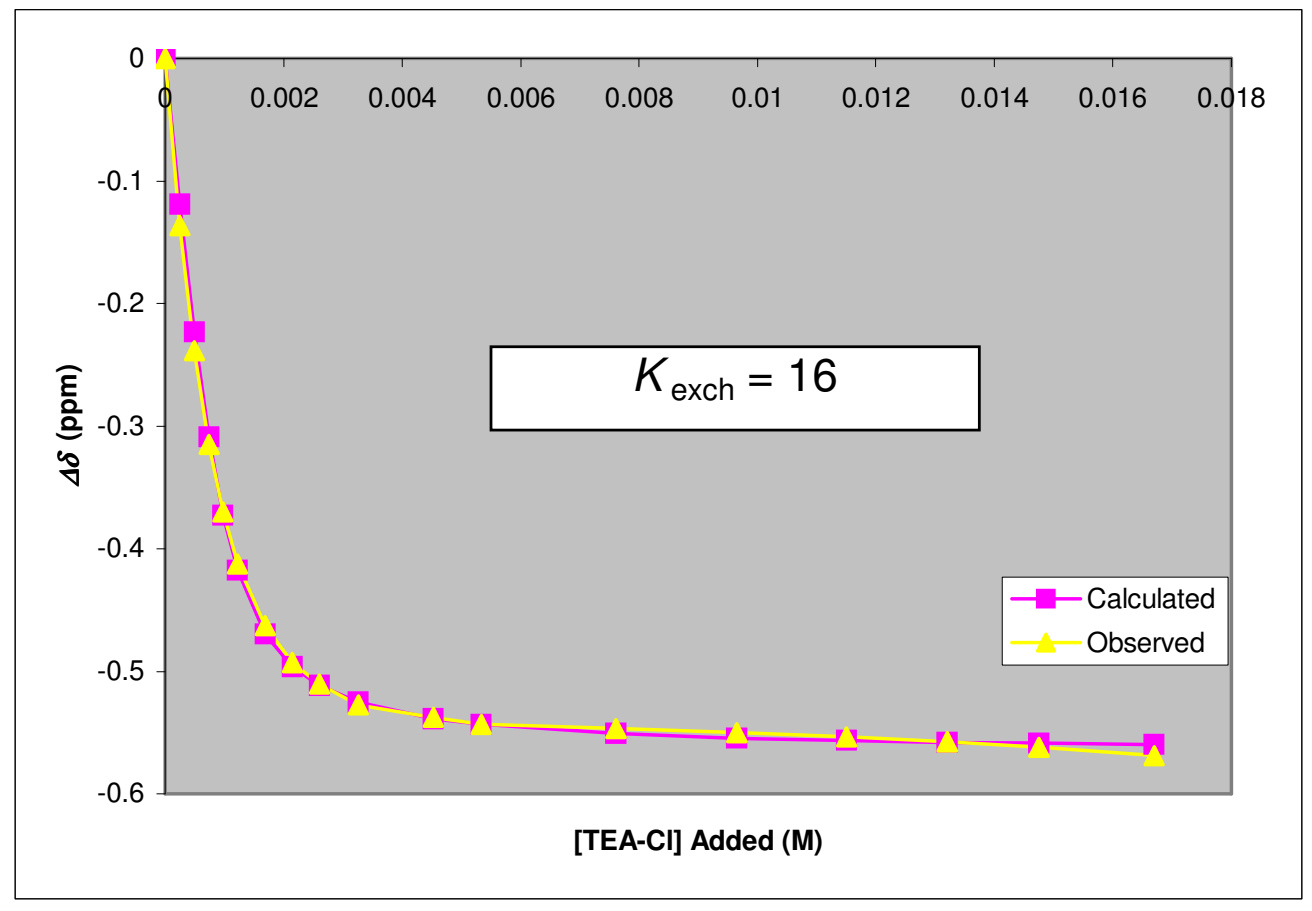




\section{References and Notes}

1. Ayling, A. J.; Broderick, S.; Clare, J. P.; Davis, A. P.; Pérez-Payán, M. N.; Lahtinen, M.; Nissinen, M. J.; Rissanen, K. Chem. Eur. J. 2002, 8, 2197.

2. Ayling, A. J.; Pérez-Payán, M. N.; Davis, A. P. J. Am. Chem. Soc. 2001, 123, 12716.

3. Methanolic ammonia was produced by bubbling ammonia gas through methanol at room temperature, until a saturated solution had been formed.

4. Boon, J. M.; Lambert, T. N.; Sisson, A. L.; Davis, A. P.; Smith, B. D. J. Am. Chem. Soc. 2003, 125, 8195. 